\title{
ADAPTING TO CONSTRAINTS - A STUDY OF GREEN STAR NEW ZEALAND'S EFFECTS ON DECISION MAKING USING CLASSIC GROUNDED THEORY
}

BY

HENDRIK PRINS

A thesis submitted to the Victoria University of Wellington

in fulfilment of the requirements for the degree of

Master of Building Science

Victoria University of Wellington 



\section{Preface}

This thesis was submitted in fulfilment of the requirements of the degree of Master of Building Science to the School of Architecture, Victoria University of Wellington.

\section{Author}

Hendrik Prins

School of Architecture

Victoria University of Wellington

Email: hendrikprinsii@gmail.com

\section{Supervisor}

Dr. George Baird

Professor of Building Science

School of Architecture

Victoria University of Wellington

Email: george.baird@vuw.ac.nz 


\begin{abstract}
Over the last 25 years building rating systems have been developed to quantify and promote sustainable development in the construction industry. Many countries have now developed their own rating system and some systems have been adapted for international use. The different outcomes and results from their use have been under much scrutiny from developers, clients, industry, and academics. Concerns such as increased cost, points buying, and discrepancies between the rated design and completed projects have been identified.
\end{abstract}

In order to better understand why these concerns occur, the Green Star New Zealand rating system - adapted from Green Star Australia - was studied to quantify its effects on rated projects. The overall aim of this thesis was to investigate the effects of Green Star New Zealand on the decision making process. Specifically, the way in which this system affects the decision making processes during the design of a rated building was investigated to provide insight into reasons why these different outcomes may occur.

This was undertaken through a classic grounded theory study during which professionals experienced in the use of Green Star were interviewed, and the data collected from the interviews was inductively analysed to generate conceptual theory and concepts. The interview data and discussion with the participants identified that decision making is affected largely through the different constraints and conditions encountered when using Green Star and how they are adapted to. These are applied to decision making through a number of different ways, being directly or indirectly related to Green Star, something decided on with or without prior experience, or internal or external to the design team.

The analysis identified several categories which explained processes and behaviours resulting from the use of Green Star. These are 'managing Green Star requirements', 'credit targeting', 'working with unknowns', 'disconnection of knowledge', and 'balancing project requirements'. It is these categories that caused adaptation to emerge as the primary process of resolving constraints, with 'adapting to constraints' emerging as the core variable. 


\section{Confidentiality Statement}

The author has agreed with the participants that all identifiable information is kept confidential. This includes the names of participants and other people, buildings, projects, and any other identifiable information.

To maintain confidentiality, all identifiable information is replaced with pseudonyms when quoted or referred to directly, such as 'participant', 'project', or 'building'.

See Section 3.4 for additional information regarding confidentiality and ethical considerations. 


\section{Acknowledgements}

I would like to thank the following people for their contribution to this research, without which this thesis would not have been possible:

George Baird, my supervisor, for his insight and advice into the research, his timely feedback, and support throughout the entire process. The guidance and encouragement you gave me allowed me to further my work and enthusiasm, for which I am extremely grateful.

Patrick Arnold, Alec Couchman, Phil Smith, Scott Smith, Scott Waller, Tony Sullivan, Michael Warwick, and all the other participants who wished to remain anonymous for giving their time and enthusiasm in participating in the interviews, for which I owe a debt of gratitude.

Staff and colleagues at Victoria University for their assistance at various stages of the research. In particular Michael Dudding (VUW School of Architecture) for his advice on the interview and analysis methods and Hans Lehmann (VUW School of Information Management) for his advice on applying and using grounded theory.

Clare Gallagher of the New Zealand Green Building Council for her interest and assistance in this research.

Finally, my friends and family for their support and encouragement over the last year. In particular I would like to thank those who were willing to proof read my work and put up with my research induced rambling. 


\section{List of Acronyms and Abbreviations}

The following are the acronyms and abbreviations used within this thesis.

\section{General}

BSRT Building Sustainability Rating Tools

CGT Classic Grounded Theory

ESD Environmentally Sustainable Design

GBC Green Building Council

'Green Star' Green Star New Zealand (when not discussing Green Star Australia)

GSAP Green Star Accredited Professional

GT Grounded Theory

\section{Building Sustainability Rating Tools}

BDM Bâtiments Durables Méditerranéens (Sustainable Buildings Mediterranean)

BEAM Plus Building Environmental Assessment Method Plus

BERDE Building for Ecologically Responsive Design Excellence

BREEAM Building Research Establishment Environmental Assessment Method

CASBEE Comprehensive Assessment System for Building Environmental Efficiency

DGNB System Deutsche Gesellschaft für Nachhaltiges Bauen (German Sustainable Building Council) Certification System

G-SEED Green Standard for Energy and Environmental Design

HK-BEAM Hong Kong Building Environmental Assessment Method

HQE Haute Qualité Environnementale (High Quality Environmental standard)

LEED Leadership in Energy and Environmental Design

LiderA Liderar pelo Ambiente para a construção sustentável (Lead for the environment in search of sustainability construction)

SB-Tool Sustainable Building Tool

TQB Total Quality Building

TREES Thai's Rating of Energy and Environmental Sustainability 


\section{Organisations}

BOMA Building Owners and Manufacturers Association of Canada

BRE

Building Research Establishment

DGNB Deutsche Gesellschaft für Nachhaltiges Bauen (German Sustainable Building Council)

GBCA Green Building Council Australia

GBI Green Building Initiative

HKGBC Hong Kong Green Building Council

iiSBE International Initiative for a Sustainable Built Environment

JSBC Japanese Sustainable Building Consortium

NZGBC New Zealand Green Building Council

USGBC United States Green Building Council 


\section{Table of Contents}

Preface

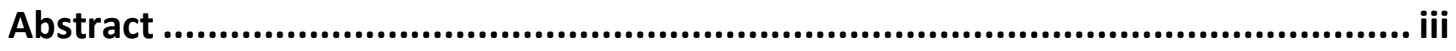

Confidentiality Statement ................................................................................ v

Acknowledgements ............................................................................................ vii

List of Acronyms and Abbreviations ............................................................... viii

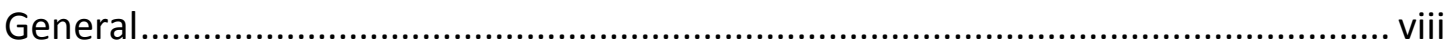

Building Sustainability Rating Tools .................................................................. viii

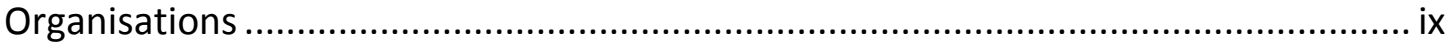

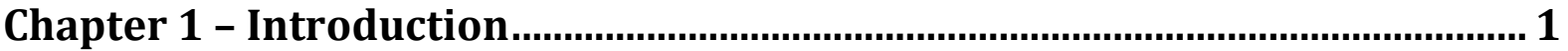

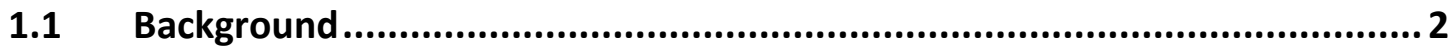

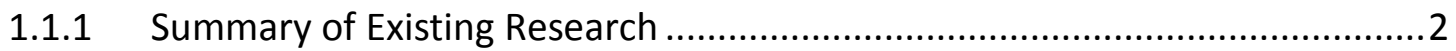

1.1.2 Defining Building Sustainability Rating Tools .............................................

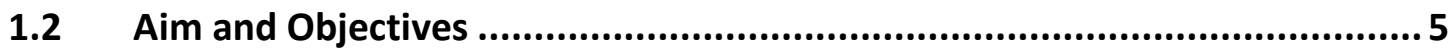

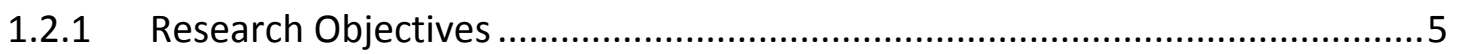

1.3 Methodology Summary ................................................................. 5

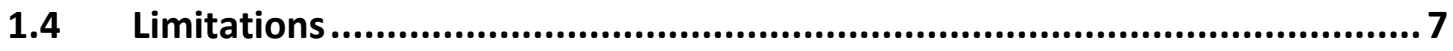

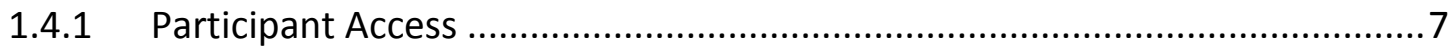

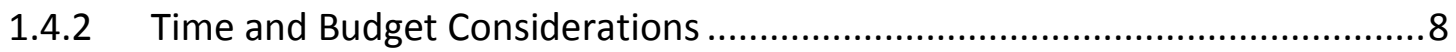

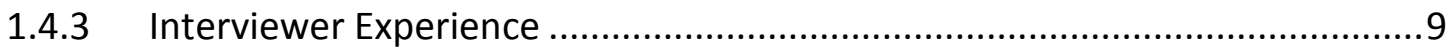

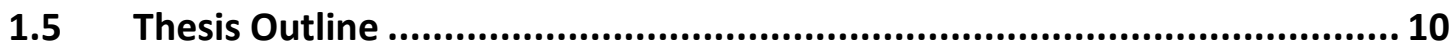

Chapter 2 - Literature Review .......................................................................13

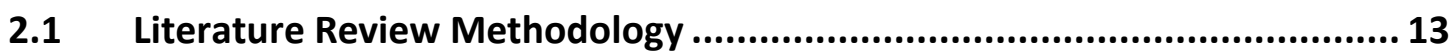

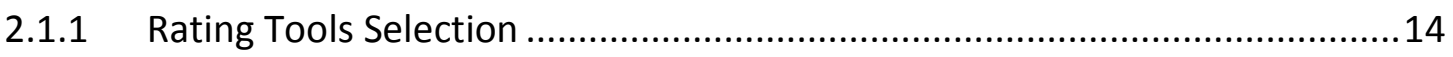

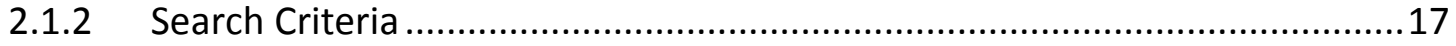

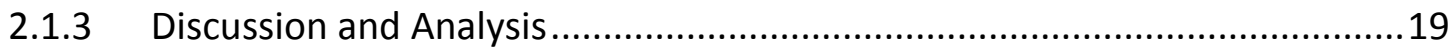

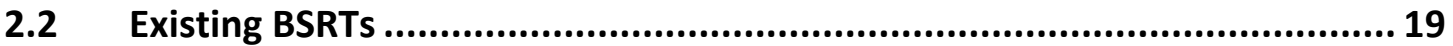

2.2.1 Building Research Establishment Environmental Assessment Method

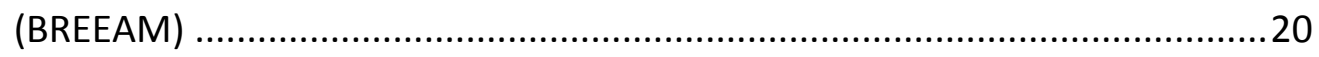

2.2.2 Leadership in Energy and Environmental Design (LEED) ............................20 
2.2.3 Comprehensive Assessment System for Building Environmental Efficiency (CASBEE)

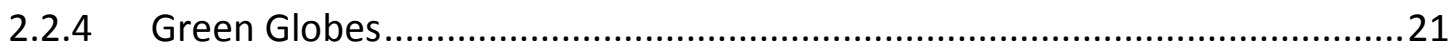

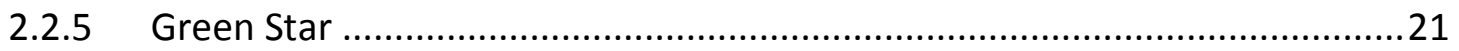

2.2.6 Building Environmental Assessment Method Plus (BEAM Plus)....................22

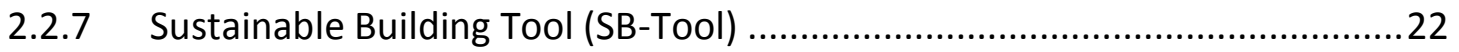

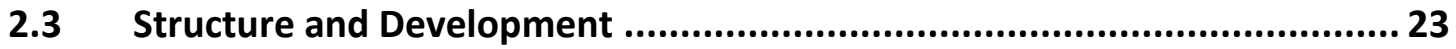

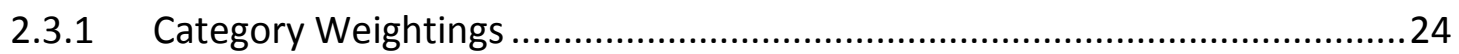

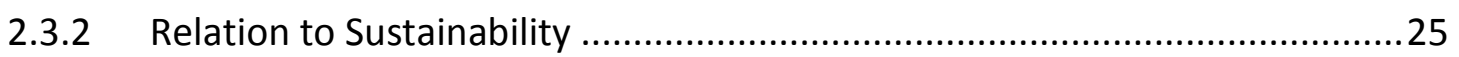

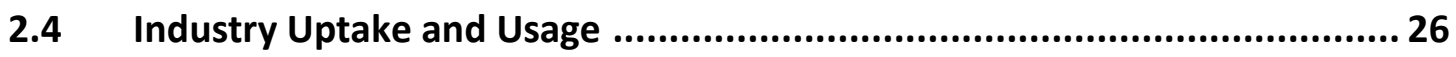

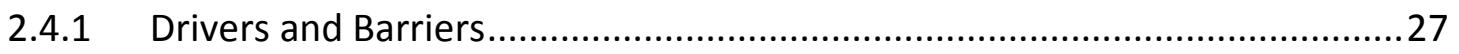

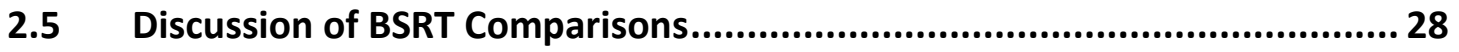

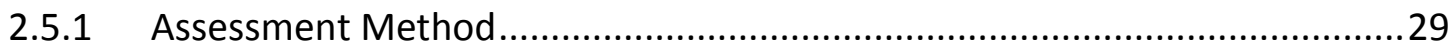

2.5.2 Relevance and reliability of comparisons ..................................................30

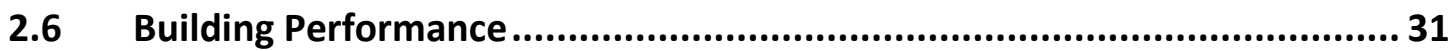

2.7 Effects of BSRTs on Decision Making ........................................................ 32

2.8 Summary of the Literature Review ........................................................ 33

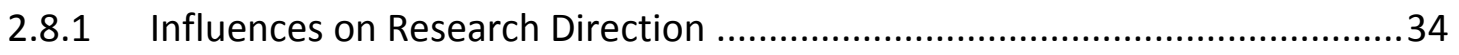

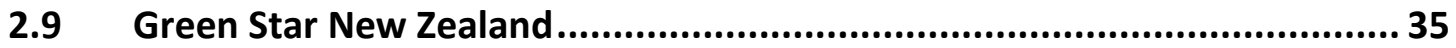

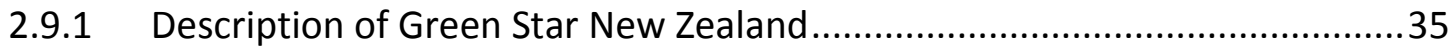

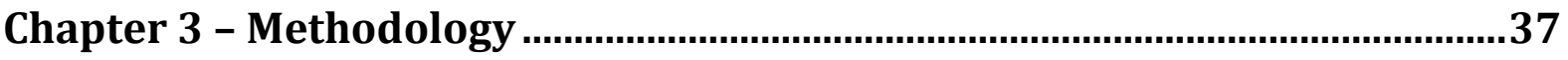

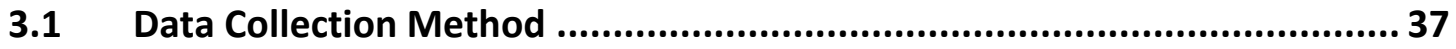

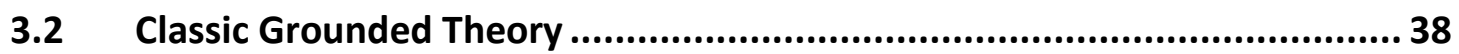

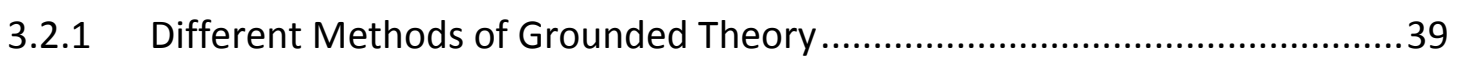

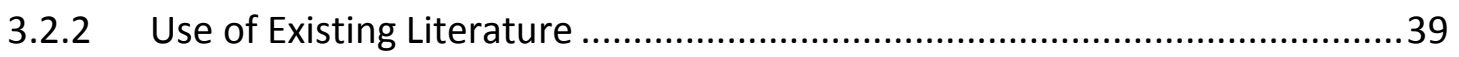

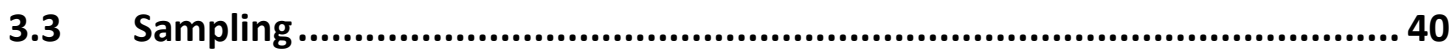

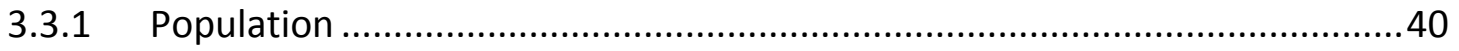

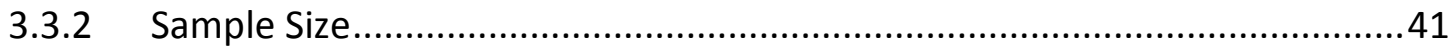

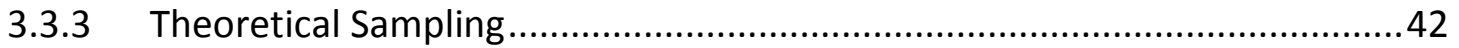

3.4 Human Ethics Considerations .............................................................. 43

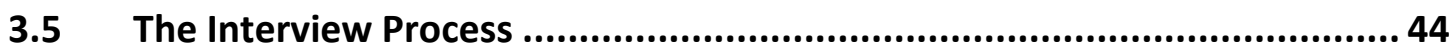

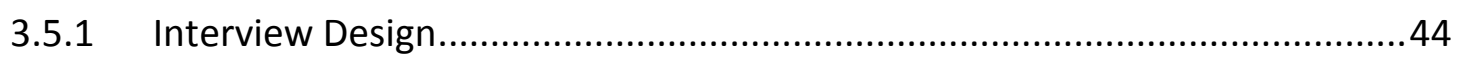

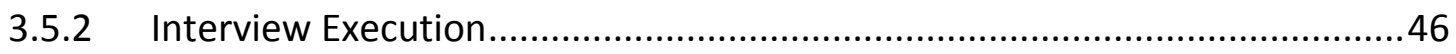




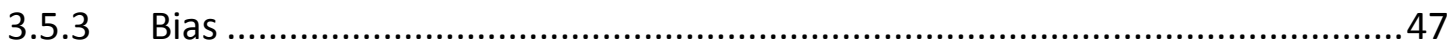

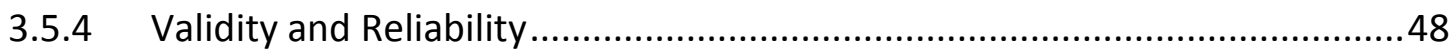

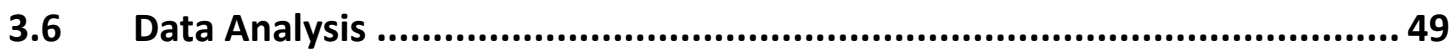

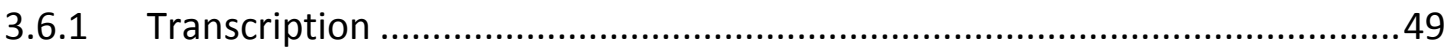

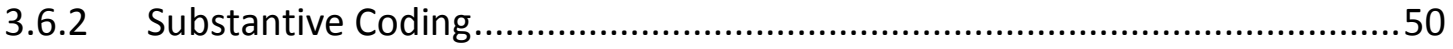

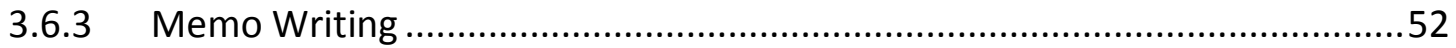

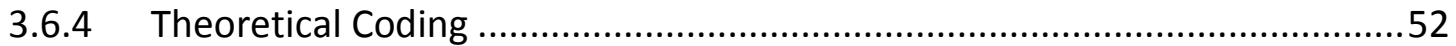

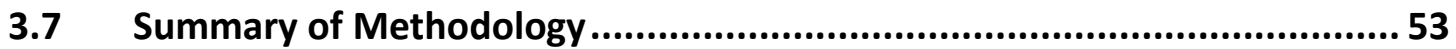

Chapter 4 - Theory Development .......................................................................55

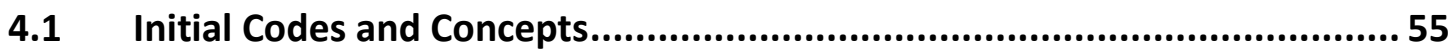

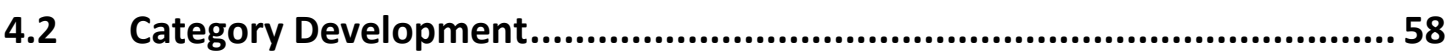

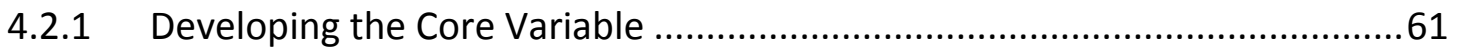

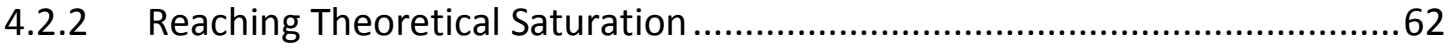

4.3 Developing the Theoretical Code ........................................................62

Chapter 5 - Findings ..................................................................................65

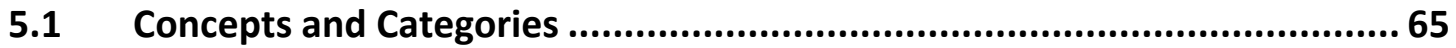

5.2 Managing Green Star Requirements ..................................................66

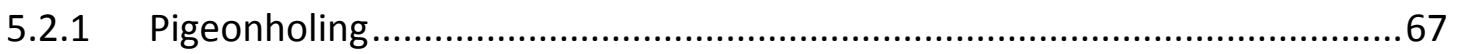

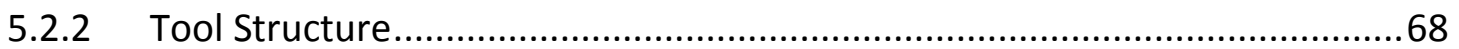

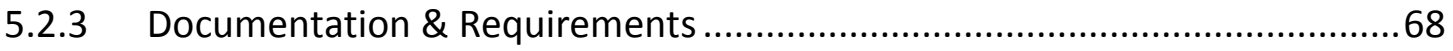

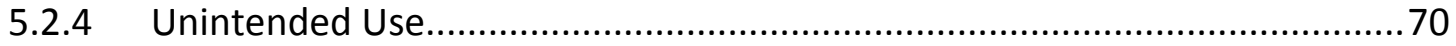

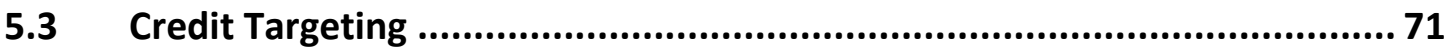

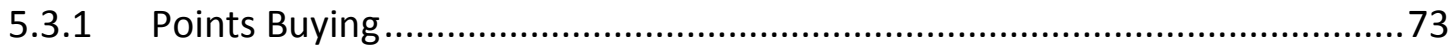

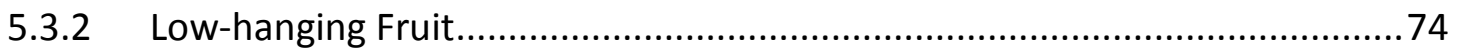

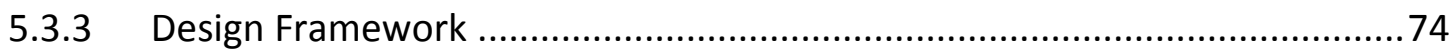

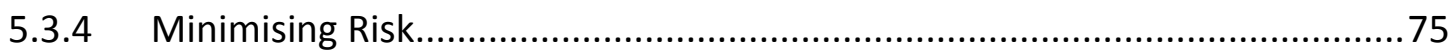

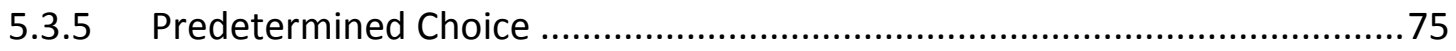

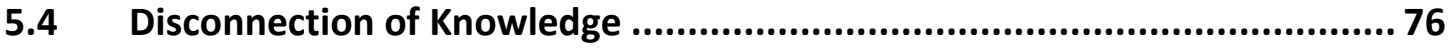

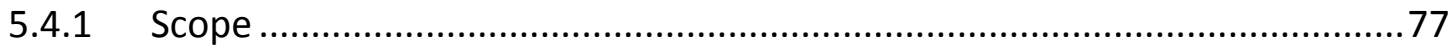

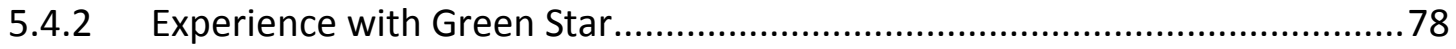

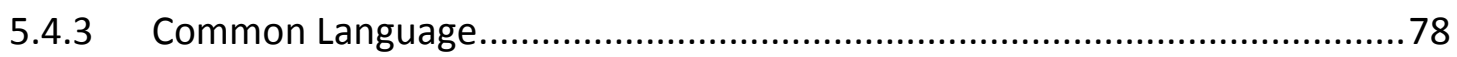

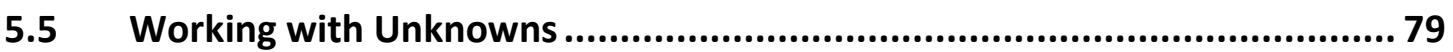




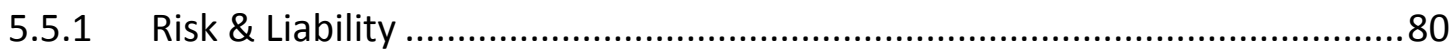

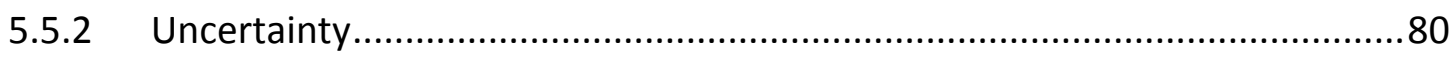

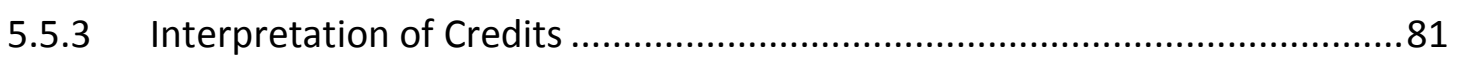

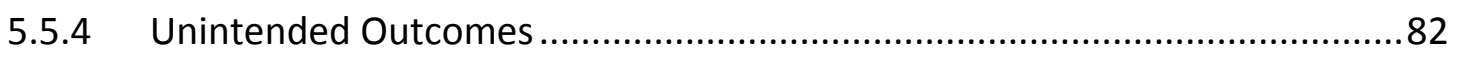

5.6 Balancing Project Requirements ............................................................ 82

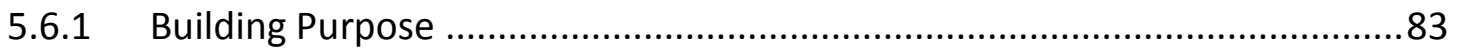

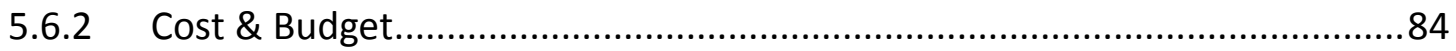

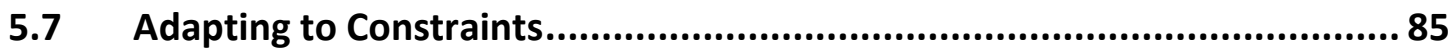

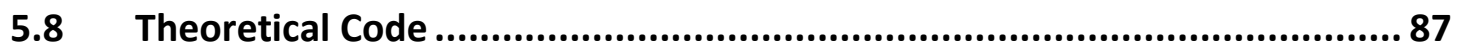

5.9 Summary of Findings ................................................................. 90

Chapter 6 - Discussion...............................................................................................91

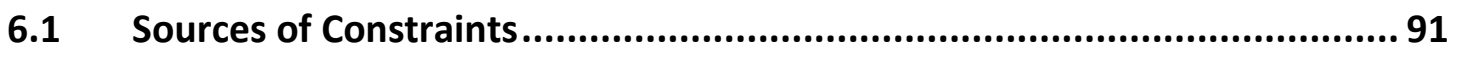

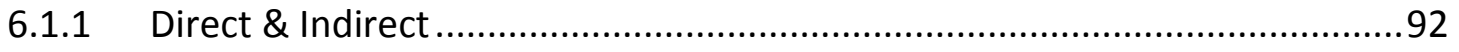

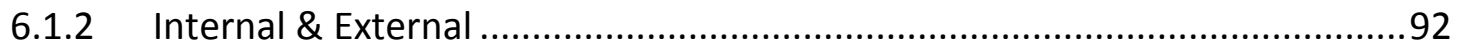

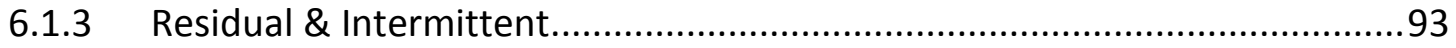

6.2 Relation to Existing Literature .......................................................... 94

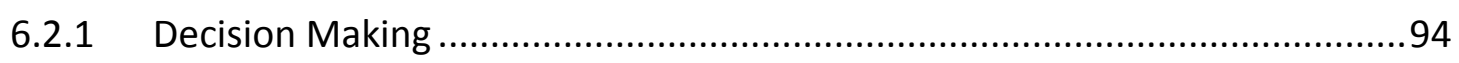

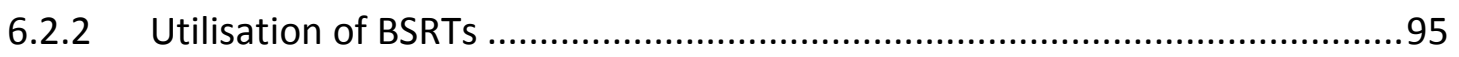

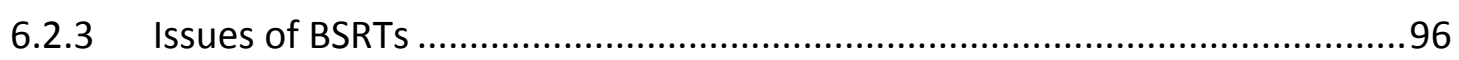

6.3 Relation to a General Decision Making Process and its Stages ................... 97

6.4 Applicability to Other BSRTs ..................................................................99

6.5 Discussion of Classic Grounded Theory ................................................ 100

6.5.1 Comparison to other Methodological Approaches ....................................100

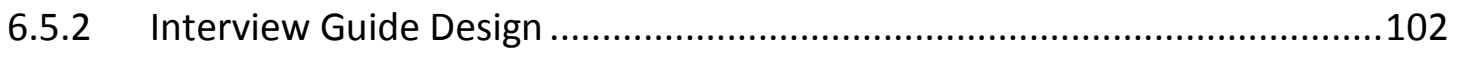

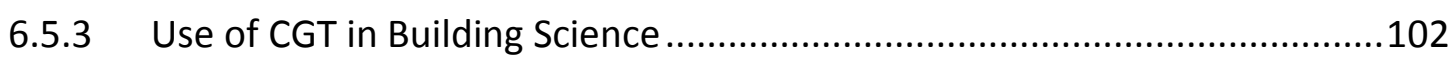

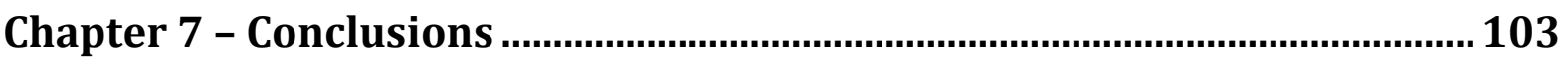

7.1 Effects of Green Star on Decision Making .......................................... 104

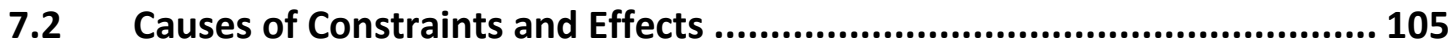

7.3 Implication of the Resultant Outcomes............................................... 106

7.4 Implication of Findings to BSRTs .................................................... 107

$7.5 \quad$ Potential for Future Research ............................................................ 107

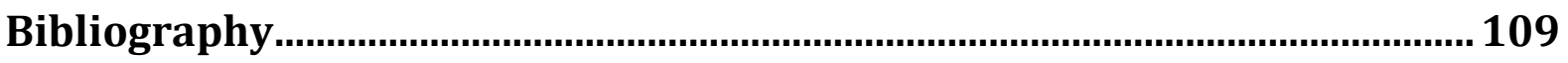


Appendix A - Human Ethics Committee Approval ............................................ 116

Appendix B - Participant Information Sheet ............................................... 118

Appendix C - Participant Consent Form ......................................................... 120

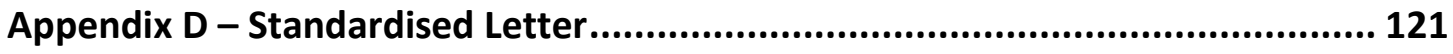

Appendix E - Initial Interview Guide ...................................................... 122

Appendix F - Final Interview Guide............................................................ 125

Appendix G - Transcription Template ........................................................ 130

\section{Table of Figures}

Figure 1: Components of a BSRT using Green Star New Zealand as an exemplar ............4

Figure 2: $\quad$ Core structure of Green Star Office Design. ................................................. 36

Figure 3: Categories of the core variable 'adapting to constraints' ...............................66

Figure 4: Concepts of 'managing Green Star requirements' .........................................66

Figure 5: $\quad$ Sub-category and concepts of 'credit targeting' ..........................................72

Figure 6: Concepts of 'disconnection of knowledge' ..................................................77

Figure 7: Concepts of 'working with unknowns' ........................................................ 79

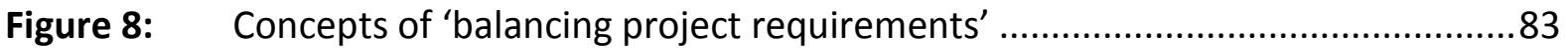

Figure 9: Categories of the core variable 'adapting to constraints' (repeat of Figure 3) .85

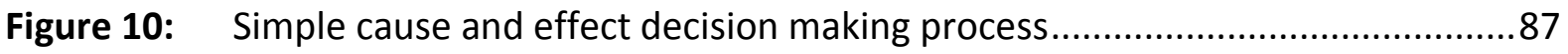

Figure 11: Application of Green Star to the decision making process...............................88

Figure 12: Application of categories to the decision making process .............................. 89

\section{Table of Tables}

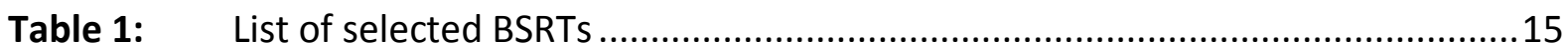

Table 2: $\quad$ BSRTs chosen for investigation in the literature review .................................17

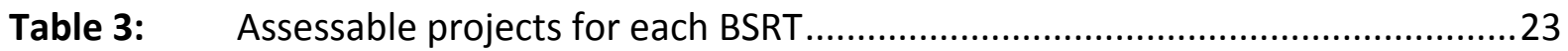

Table 4: Investigatory areas and an example of core questions ....................................45

Table 5: Initial categories and how they emerged from the data .................................57

Table 6: $\quad$ Summary of the core variable and its main categories ....................................103 



\section{Chapter 1 - Introduction}

There is a broad array of methods available which assess various aspects of sustainability in the built environment. This includes simple systems or conditions incorporated into regional requirements and building codes, methods of assessing the operational performance of a building or a part of, and Building Sustainability Rating Tools (BSRTs) which assess, quantify, and rate the environmental design of a project. Green Star New Zealand is one of many BSRTs globally and is the dominant system in New Zealand.

Since its release in 2007, Green Star New Zealand has seen significant growth in both the promotion and development of sustainable construction in the industry. Like other BSRTs it provides quantification of a building's sustainability, recognising those that rate highly. Much of the industry has grown to embrace it, from clients and tenants to designers and builders and even to suppliers and manufacturers. The process of gaining a formal rating from a BSRT such as Green Star is highly involved throughout the design and construction. Consisting of a number of credits across nine different categories, each project has to provide enough documentation and evidence to prove compliance with these different aspects of sustainability.

Using BSRTs such as Green Star can affect the way in which decisions on a project are made; different requirements are applied, design options created to achieve the aims of the rating system, a structured submission created and submitted, and the entire process managed. Each of these requirements, and many others, consist of a series of decisions which are conceptualised, explored, refined, and executed. With the addition of a set of overall requirements in order to achieve certification, the decision making process is likely to be affected in some way that differs from what would be done in the absence of a BSRT. 
This chapter provides the context for this thesis, giving an overview of the existing studies relating to the use of BSRTs and their effects on decision making along with the definition of BSRTs, rating systems, and rating tools. The aim and objectives to study Green Star's effect on decision making are detailed, and the methodology used to investigate them is then summarised. Limitations of the research are then addressed, followed by the outline of the context of this thesis to conclude the chapter.

\subsection{Background}

The last 25 years have seen the increase in growth and promotion of sustainable development driven by BSRTs. 1990 saw the release of the Building Research Establishment Environmental Assessment Method (BREEAM) in the United Kingdom as the first BSRT (Crawley \& Aho, 1999), with many more having been developed over the following years. Among the most popular are: Leadership in Energy and Environmental Design (LEED) in the United States; the Comprehensive Assessment System for Building Environmental Efficiency (CASBEE) in Japan; Green Star in Australia; and the Sustainable Building Tool (SB-Tool) as a global system.

Most BSRTs and their rating tools assess the sustainability of a building against a series of different categories and credits, rating them with an overall score which recognises their performance as a green building. By creating a standard measure administered by a third party, these buildings can be compared and their sustainability quantified. Discussion and research of these systems and their set of rating tools has been growing since the release of BREEAM, touching on various facets regarding their structure and use.

\subsubsection{Summary of Existing Research}

The field of research regarding BSRTs and their associated rating tools covers a number of topics. These include discussion of the structure and weighting of BSRTs, industry uptake and usage, drivers and barriers, comparisons of the different systems, actual performance of rated buildings, and effects on decision making.

The structure of the more popular and well researched BSRTs focus on new and as built buildings, generally originating with office buildings (Siew, Balatbat, \& Carmichael, 2013) but 
since expanding to encompass a variety of different project types such as interiors, schools, and hospitals. Some BSRTs have also released tools which assess a wider aspect of sustainability, such as the various community tools and CASBEE's tool assessing effects on the heat island effect. Category weightings and the allocation of points are determined relative to local conditions and requirements (Cole \& Mitchell, 1999; Reed, Bilos, Wilkinson, \& Schulte, 2009), with the weightings themselves generally established through a mix of scientific justification and industry surveys (Cole, 1998; HK-BEAM Society, 2005).

The growth of BSRTs is affected by different drivers and barriers. Some drivers include the shift of real estate to favour rated property, risk minimisation, and long term cost and environmental savings (Cole, 2005; Liang, 2012). Barriers, however, include individual perception of BSRTs and their requirements and difficulty, as well as increased cost and a lack of common understanding (Gou, Lau, \& Prasad, 2013; Häkkinen \& Belloni, 2011).

Comparisons of BSRTs often evaluate different tools to identify which ones 'perform best', such as through assessing a standardised building (Papadopoulos \& Giama, 2009), or by comparing tools to pre-established criteria (Nguyen \& Altan, 2011). When investigating the performance of BSRTs, some studies found that lower rated buildings do not necessarily perform better than non-rated buildings and that a higher rating provides better environmental performance (Scofield, 2009; Stein \& Reiss, 2004; Wedding \& CrawfordBrown, 2007).

Literature has identified and briefly explored the effects that BSRTs can have on decision making processes. In particular this found a variation of the processes involved across the different surveyed projects (Schweber \& Haroglu, 2014) and the focus on single criterion evaluators, such as cost-benefit analysis, in decision making processes (Ding, 2008).

Undertaking this research also revealed a number of limitations regarding what has been studied. These limitations include the lack of common ground in comparing different BSRTs due to the variance in local conditions for which they are designed, varied data collection method for quantitative analysis, and lack of research into the effects of BSRTs on decision making processes. This last limitation of the research calls for the investigation into why different outcomes occur, and is what forms the aim of this thesis. 


\subsubsection{Defining Building Sustainability Rating Tools}

Giving a strict definition to the terms 'BSRT', 'rating system', and 'rating tool' is important due to the number of interchangeable names which generally refer to the same thing. This interchangeability of terms is apparent both in literature and different BSRTs themselves. Literature and research often use the terms 'assessment system', 'rating system', 'rating scheme', or 'rating tool'. This term varies between the different BSRTs themselves, with the more popular rating tools using 'rating system' (BREEAM, LEED, Green Globes), 'assessment method' (BEAM Plus), and 'rating tool' (Green Star Australia, Green Star New Zealand, CASBEE). 'Environmental', 'sustainability', and 'green' are each used as prefixes, which also varies across the literature.

The definition of BSRT used for this thesis is taken from the definition of an "assessment method" given by Cole (2005). He describes assessment methods as having structured frameworks, using points or weightings, classifying environmental performance, and being managed by third party organisations. Cole also states that the full use of a method leads to the registration or verification or a project and citing BREEAM and LEED as examples. Additionally, he defines the term "assessment tool" as being focused on one or more environmental performance characteristic, such as embodied energy or greenhouse gas emissions. This could lead to assessment methods to include assessment tools as a way of scoring a particular credit, but not to the same extent. The WAT-1 credit calculator as part of Green Star is an example of a less complex assessment tool which is part of a larger system.

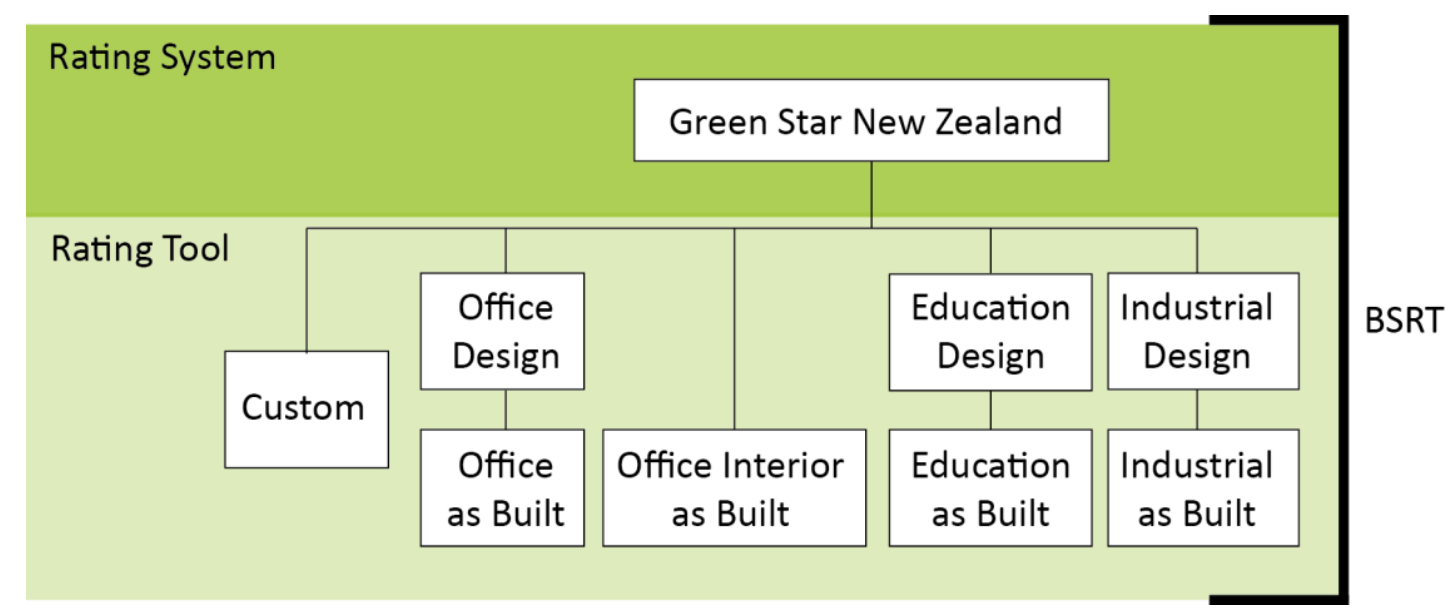

Figure 1: $\quad$ Components of a BSRT using Green Star New Zealand as an exemplar 
While 'BSRT' encompasses the entire process and structure, the term 'rating system' defines the overall system, group, or family of individual tools, as well as their typical structure and relation to one another. 'Rating tools' are the individual assessment tools that are organised into a rating system, making up a BSRT. Figure 1 presents the different relationship between these terms and what they refer to, illustrating how BSRTs encompass both systems and tools.

\subsection{Aim and Objectives}

The overall aim of this thesis is to investigate the effects that Green Star New Zealand has on decision making processes in design teams. This brings focus onto the different aspects of the decision making process such as how solutions are decided upon, what causes and influences the decisions being made, and in what way Green Star is integrated into the project. It is highly likely that there will be a large variation in the different experiences had by different design teams as projects are rarely the same, resulting in a variety of different outcomes and decisions made on those projects.

\subsubsection{Research Objectives}

To achieve this overall aim, this research has the following objectives:

1. Investigation of Green Star's effect on decision making processes during a project;

2. Identification of the different causes, effects, and outcomes resulting from these processes and the reason for their occurrence;

3. Development of theory and concepts which explain behaviour and effects relative to the aim;

4. Exploration of other BSRTs to identify the context and extent of existing research relative to this research.

\subsection{Methodology Summary}

The substantive area of Green Star's effect on decision making is investigated using classic grounded theory (CGT) to direct and analyse a series of interviews. CGT is an inductive qualitative research method which generates conceptual theory from the data itself, rather 
than testing a preconceived hypothesis. This inductive analysis is achieved through its comprehensive processes, including the constant comparison method, theoretical sampling, memoing, and coding.

The constant comparison of data is what drives the development of categories and concepts, which emerge and are continually compared with other incidents in the data and other concepts to ensure validity. This also drives the data collection to use theoretical sampling, where additional participants and sources of data are sought based on what previous data and analysis requires, pushing these concepts and theories to theoretical saturation - the point at which new data no longer sheds new insight or information. Memos are constantly written which discuss, compare, and analyse the different abstractions, and provide the basis of many of the findings.

The participants of the interviews were all Green Star Accredited Professionals (GSAPs) who had experience in one or more Green Star rated projects where they were heavily involved in the submission process and met most of the following inclusion criteria:

1. Worked on the design team of a Green Star accredited project;

2. Were involved in the environmentally sustainable design of an accredited project;

3. Were involved in the Green Star submission of an accredited project, though not necessarily the individual submitting it;

4. Were accredited GSAPs at the time of the project.

After the initial interview, many of the participants were followed up on later in the research with additional questions to help saturate or otherwise expand on existing concepts and categories. Due to limitations regarding contacting and accessing the participants as well as travel requirements, the theoretical sampling focused less on the person to interview, and more on the questions which were asked to push concepts and categories towards saturation.

Interviews were done using a guide which was adjusted between interviews to ensure that data was being pushed towards theoretical saturation. In all cases, however, the interview guides were similar and followed the same general format and question areas. These areas 
focused on the participant's history and experiences with Green Star during the design, construction, and occupancy of a project in addition to their background with sustainability.

The collected data was analysed using the aforementioned CGT procedures as it was gathered. Concepts and categories emerged from the coding of the data; these concepts and categories are patterns and relationships which are present in the data (Glaser, 2002), and were compared amongst each other and across other incidents between data sets. As these approach theoretical saturation, the core variable - which explains most of the issues relating to the research area - emerges (Glaser \& Holton, 2004). Lastly, the theoretical code was developed, representing the relationship that the different categories, concepts, and core variable have to one another (Glaser, 1978; Hernandez, 2009).

Much of this analysis was done through the constant comparison of the concepts and categories to other incidents in the data and to one another, mostly done through discussion and analysis in the memoing process.

The findings are presented mainly through abstracted theory and categories which explain different patterns and relationships amongst the data. These will represent how the different processes unfolded during projects; in particular focusing on what caused these processes to occur, how they were managed by the design team, and the different outcomes achieved.

\subsection{Limitations}

Limitations are part of all research, they exist either directly imposed by the researcher, or indirectly by the environment in which the research is taking place. This research is no exception. The major limitations are described here, along with a description on their potential issues and how they were addressed to minimise their impact.

\subsubsection{Participant Access}

Participant access was considered to be one of the primary limitations of this thesis. This is centred around the availability of the participants, how many there were, and the ability to identify and contact them. At the outset of this thesis, many of the GSAPs who were 
interviewed were not known and difficult to identify as meeting the sampling requirements. Furthermore, once identified these participants were occasionally difficult to contact individually, relying on getting in touch with them through the company or organisation they worked at.

The potential issues relating to this limitation revolve around the number of participants that can be interviewed due to the lack of identifiable information. Overall this reduced the number of participants available to be interviewed. This issue is minimised naturally, however, through the use of grounded theory. In CGT, there is no requirement for setting a large sample size at the outset of the research in order to prove the results are valid and representative. Instead the focus is on gathering rich data from knowledgeable participants to inductively deduce categories and theory, which in turn moves the data collection forward to gather and analyse more data to reach theoretical saturation (Glaser \& Strauss, 1967, pp. 60-61).

This tied into another issue which is how the limited access to participants might affect the theoretical sampling. Theoretical sampling, as mentioned before, drives the data collection process through determining what data should be gathered next to move the emerging categories and theories towards saturation. With many of the participants being unknown and occasionally difficult to contact and make arrangements with, deciding who to interview next based on their knowledge becomes much more difficult. To resolve this issue, the interview guide and its questions were adapted for each new interview, and focused on asking questions to investigate the emerging categories as opposed to who the information was gathered from.

\subsubsection{Time and Budget Considerations}

With much of the interview population being located in Auckland and some in Christchurch - as opposed to Wellington where the researcher was based - limitations regarding time and costs for travel became an issue. Time limitations were primarily due to the time taken to organise an interview with a participant, in particular those located outside of Wellington. Cost limitations were associated with travel expenses as the project was entirely self-funded. 
These limitations share many of the issues as participant access due to the affect it would have on the number of interviews that can feasibly be carried out and how it might affect the theoretical sampling and the analysis. To minimise the impact on travel cost and time, participants located outside of Wellington were interviewed in stages. Each stage was a single day where multiple interviews were organised and carried out. Unfortunately, it did leave occasions where participants had agreed to the interview but the interview did not take place until sometime had been passed due to difficulty securing additional participants. On some occasions, participants were interviewed by phone if the travel limitations proved too much, such as for a single participant outside of Wellington.

\subsubsection{Interviewer Experience}

At the time of this research, the researcher had little experience not only in conducting interviews, but also in analysing them and using appropriate methods. As the researcher's background - and the subject of this thesis - is in building science, much of the social research methods and information were unknown or largely unfamiliar, with the result that additional time had to be spent learning and understanding CGT and other relevant social research information.

This limitation mainly affected the interview process and the data analysis. In particular this related to issues such as missing information or areas to follow-up on during interviews, and accidental misuse or misunderstanding of social research methods. In order to alleviate these issues extensive research was done into relevant areas of social research to familiarise the researcher, in conjunction with discussion with knowledgeable people for their experience and advice. The transcriptions were also checked in order to see what opportunities might have been missed to account for in future interviews.

To minimise issues regarding the interview process, a semi-structured interview guide was used as opposed to a more open ended interview to reduce the chance of questions or cues being missed. This interview guide was piloted and practiced to further ensure that it was relevant and the researcher was familiar with it. 


\subsection{Thesis Outline}

This thesis is constructed into seven different chapters including this one.

Chapter 1 has introduced the research aim and objectives of this thesis. It has given the background of the research which led to the creation of the aim and provided a definition of the core terms BSRT, rating system, and rating tool used. The methodology to carry out a CGT study has also been summarised. Research limitations regarding participant access, time and cost considerations, and interviewer experience were identified and methods to minimise the risk has been described.

Chapter 2 presents a systematic review of literature pertaining to the current field of BSRTs. This encompasses a review of the existing literature related to different facets of BSRTs. This is focused on seven of the established and well researched BSRTs: BREEAM, LEED, CASBEE, Green Globes, Green Star Australia, BEAM Plus, and SB-Tool. The discussion of the reviewed literature focuses on the development, structure, and weighting of rating systems, industry uptake, BSRT and rating tool comparisons, building performance, and the effects of BSRTs on decision making. Green Star is then described after its determination for being the focus BSRT for the methodology employed to focus investigation on the facet of 'why' different outcomes may occur.

Chapter 3 presents the methodology for a classic grounded theory study, presenting the process by which a series of interviews were carried out with Green Star Accredited Professionals. This process includes the rationale for selecting the interviews as the research process, how and why CGT was used, sampling considerations, how the interview was designed and executed, and how the interviews were coded and analysed inductively through CGT. The different aspects of CGT are also described in detail to ensure that the reader understands the process and results in the following chapters. The different processes described in this chapter include theoretical sampling, coding, the constant comparison of data, and memoing.

Chapter 4 illustrates and carries the reader through the CGT process described in the previous chapter in order to provide some transparency to the process. Presented is the 
development of the different concepts and categories, which progressively built up and identified the core variable of 'adapting to constraints' and the theoretical code of the adaptation process employed due to the conditions and requirements of Green Star.

Chapter 5 presents the core variable, the overall theory, and the different concepts and categories in a description of the findings. The chapter is broken down into description of these categories and their related concepts, the core variable, and the overall theoretical code. The categories and concepts are described in terms of how and why they occur, what effects and outcomes they have, and any relationships to other categories. The core variable is described regarding its relationship to the other categories and how it is integrated into the decision making process. Lastly, the overall theoretical code is described and detailed.

Chapter 6 begins by presenting and discussing the six different causes of constraints and conditions applied. A critical discussion of the findings along with their relation to the existing literature follows. This discussion includes reference to the literature review done in Chapter 2 and how the different findings relate to the existing trends and issues which were identified in the review. This is also compared to additional literature and research which was investigated during and after the data collection and analysis, particularly theory regarding decision making. The applicability of the findings to other rating systems is also critiqued along with emergent effects of Green Star on the New Zealand construction industry. Finally, the usage and applicability of CGT within this field of research is discussed.

Chapter 7 concludes the thesis, summarising the previous chapters, describing their implications, and providing discussion of further research possibilities. 


\section{Chapter 2 - Literature Review}

Chapter 2 presents the literature review undertaken to explore the field of research pertaining to BSRTs. A methodology which outlines which BSRTs was primarily investigated is established, identifying those which have been extensively researched. Following that is a brief summary of the history, usage, and development of the studied systems, and then investigation into their structure, uptake, and usage. Literature and research which compare the different BSRTs are also examined, identifying common concerns and trends, followed by an investigation into performance of rated buildings. Once summarised, Green Star New Zealand's structure is described along with why it is the BSRT investigated in this research and how the findings from this chapter inform the methodology.

\subsection{Literature Review Methodology}

The purpose of the literature review is three-fold: The first is to investigate the scope of the existing field of research relating to BSRTs, rating systems, and rating tools; the second is to summarise and discuss the existing literature; and the third is to identify what trends and issues are present.

The existing field of research being investigated incorporates literature and information pertaining to the development, application, and use of BSRTs. This investigation is intended to give an overview of the aforementioned field of research, detailing the range of information and literature available. The literature is then analysed, compared, and discussed to expand on and summarise these fields. Trends and issues which were identified across the different research will then be summarised briefly.

The following sections detail the methods used in carrying out this literature review. It includes the selection of BSRTs chosen for comparison and discussion, method of data gathering, and how the data is discussed and analysed. 


\subsubsection{Rating Tools Selection}

Different BSRTs were selected to be those primarily investigated, compared, and discussed in accordance with the purpose of the literature review, as described earlier. BSRTs were selected based on different criteria. This was both to reduce the impact of limitations regarding available information and to avoid scope creep which would impact on the quality of the discussion.

Five criteria were created for determining which BSRTs would be studied in the literature review, based on the considerations above. These are described as follows:

1. The BSRT is required to be one of the primary rating systems used in one or more countries, indicating that it is likely to have seen extensive use in its climate;

2. The BSRT must have a tool which can rate office design projects, such as a dedicated office design tool or non-residential tool which can be used to rate office design projects. This is to allow a comparison between systems on equal grounds. Office design rating tools are the most extensively used and researched;

3. The BSRT should have been released at least ten years ago giving sufficient time for updates to address initial issues in order to improve the tools, as well as for information to be available. This would be 2004 at the time of this research;

4. There must be sufficient literature pertaining to the BSRT and that it needs to be available in English. This includes discussion of the tools and their comparison to other BSRTs, systems, and tools of a similar scale. What is considered to be 'sufficient' is largely subjective, but must be enough so that it can be analysed and discussed fairly;

5. The BSRT must not be a direct conversion of another tool to a new country. This keeps the systems investigated as more original developments rather than conversions, such as BREEAM Netherlands or LEED France, which are largely the same as the original. Information from these conversions will still be included in the discussion of the parent system should they be applicable and relevant. 
The first four criteria were used to select 21 BSRTs. The fifth criterion is excluded from the following table; this is due to it being simple to exclude conversions as they carry the same name as the parent tool, just with the name of the country added to it. As stated, these conversions will instead be used to supplement the information available to the parent tool in this chapter. These are listed in Table 1, where ' $X$ ' means the BSRT fully meets the criterion while ' $/$ ' means it only partially meets. A blank box is used when a criterion was not met.

It should be noted that this is not an exhaustive list of BSRTs available, though the focus on more established BSRTs over newer or lesser known ones should minimise the impact of little information being available. Additionally, it is unlikely that a BSRT which met all the criteria would still be obfuscated to a point where it would not be identified for screening.

\begin{tabular}{|c|c|c|c|c|c|}
\hline \multirow{2}{*}{ BSRT } & \multirow{2}{*}{ Country } & \multicolumn{4}{|c|}{ Criteria } \\
\hline & & 1 & 2 & 3 & 4 \\
\hline BDM & $\begin{array}{c}\text { France / the } \\
\text { Mediterranean }\end{array}$ & & $x$ & & \\
\hline BEAM Plus & Hong Kong & $x$ & $x$ & $x$ & $x$ \\
\hline BERDE & Philippines & $x$ & $x$ & & \\
\hline BREEAM & United Kingdom & $x$ & $x$ & $x$ & $x$ \\
\hline CASBEE & Japan & $x$ & $x$ & $x$ & $x$ \\
\hline $\begin{array}{l}\text { DGNB Certification } \\
\text { System }\end{array}$ & Germany & $\mathrm{x}$ & $x$ & & \\
\hline GBAS & China & I & $x$ & & \\
\hline Green Building Index & Malaysia & $x$ & I & & \\
\hline Green Globes & Canada / US & $x$ & $x$ & $x$ & I \\
\hline Green Mark & Singapore & $x$ & 1 & & \\
\hline Green Star & Australia & $x$ & $x$ & $x$ & $x$ \\
\hline G-SEED & South Korea & $x$ & $x$ & $x$ & \\
\hline $\mathrm{HQE}$ & France & $x$ & $x$ & $x$ & \\
\hline LEED & US & $x$ & $x$ & $x$ & $x$ \\
\hline LiderA & Portugal & $x$ & $x$ & & \\
\hline Lotus & Vietnam & $x$ & I & & \\
\hline Minergie & Switzerland & $x$ & 1 & $x$ & \\
\hline PEARLS & $\begin{array}{c}\text { United Arab } \\
\text { Emirates }\end{array}$ & $x$ & $x$ & & \\
\hline SB-Tool & Global & $\mathrm{N} / \mathrm{A}$ & $x$ & $x$ & $x$ \\
\hline TQB & Austria & $x$ & $x$ & & \\
\hline TREES & Thailand & $x$ & 1 & & \\
\hline
\end{tabular}

Table 1: $\quad$ List of selected BSRTs 
As Table 1 shows, most of the BSRTs were one of the primary systems used in the country of origin. The exceptions to this are Sustainable Buildings Mediterranean (BDM), the Green Building Assessment System (GBAS), and the SB-Tool (formerly the GB-Tool). BDM was noted to not be as established or as old as the other BSRTs available in France or in the wider region of countries bordering the Mediterranean Sea. BDM is also developed and intended for use by other countries which border the Mediterranean, though there does not seem to be much usage in these countries. The full extent of the use of GBAS is difficult to measure due to the lack of available information in English, meaning that it cannot reliably be determined as either being one of the primary rating systems or not being established at all. SB-Tool is marked as not applicable as it is designed to be used globally.

All of the BSRTs have a method of assessing office buildings. Systems which have a dedicated office design tool are marked as fully meeting the criterion, while those which partially meet have a rating tool which includes, or otherwise can be adapted to include, office design projects.

The third and fourth criteria are what most tools seemed unable to meet. There was a distinct relation between the age of a BSRT and the amount of information available, with older BSRTs being researched more than newer ones. Many BSRTs that did not meet the fourth criterion failed to do so due to a lack of information available. For some tools this was due to only the basic information being available in English. The seven BSRTs that did meet the fourth criterion have extensive literature available in a variety of sources. Minergie from Switzerland was the only BSRT surveyed which met the third criterion but had insufficient information to meet the fourth.

The seven BSRTs which meet each criterion - either partially of fully - are listed in Table 2. This table outlines the basic information, including release date, managing organisation, and primary website. 


\begin{tabular}{|l|c|c|c|c|}
\hline BSRT & $\begin{array}{c}\text { Country of } \\
\text { Origin }\end{array}$ & $\begin{array}{c}\text { Managing } \\
\text { Organisation }\end{array}$ & $\begin{array}{c}\text { Year of first } \\
\text { tool's release }\end{array}$ & Website \\
\hline BREEAM & $\begin{array}{c}\text { United } \\
\text { Kingdom }\end{array}$ & BRE & 1990 & http://www.breeam.org/ \\
\hline LEED & $\begin{array}{c}\text { United States } \\
\text { of America }\end{array}$ & USGBC & 1998 & $\begin{array}{c}\text { http://www.usgbc.org/lee } \\
\text { d }\end{array}$ \\
\hline CASBEE & Japan & JSBC & 2004 & $\begin{array}{c}\text { http://www.ibec.or.jp/CAS } \\
\text { BEE/english/ }\end{array}$ \\
\hline Green Globes & Canada / US & BOMA / GBI & 2000 & $\begin{array}{c}\text { http://www.greenglobes.c } \\
\text { om/home.asp }\end{array}$ \\
\hline Green Star & Australia & GBCA & 2003 & $\begin{array}{c}\text { http://www.gbca.org.au/gr } \\
\text { een-star/ }\end{array}$ \\
\hline BEAM Plus & Hong Kong & $\begin{array}{c}\text { BEAM } \\
\text { Society }\end{array}$ & 1996 & $\begin{array}{c}\text { http://www.beamsociety.o } \\
\text { rg.hk/en_index.php }\end{array}$ \\
\hline SB-Tool & Global & iiSBE & 1995 & http://www.iisbe.org/ \\
\hline
\end{tabular}

Table 2: $\quad$ BSRTs chosen for investigation in the literature review

Many of the BSRTs listed in Table 2 have had extensive literature published about them relating to a combination of aspects such as performance, comparison to other systems, development, and application to other countries. BREEAM, CASBEE, SB-Tool, and LEED have seen extensive use since their creation. They are also the BSRTs which are considered to be largely original and have acted as the base for the development of other systems (Fowler \& Rauch, 2006).

The three remaining BSRTs - Green Globes, Green Star, and the Building Environmental Assessment Method (BEAM) Plus - have been included in the surveyed literature fairly regularly and have existed for long enough to offer sufficient information to be compared and discussed with the other four.

\subsubsection{Search Criteria}

The scope of information being investigated included literature and information on the development, application, and use of rating systems. The information searched for focused on research pertaining to green building rating systems as a whole, in particular information and literature relating to the different trends and issues between the chosen rating systems. Literature regarding the issues stemming from the use of BSRTs as well as the comparison of different rating tools and systems was also investigated as part of the literature review. 
Information was primarily sourced from the following media:

- Journal and scholarly articles - the most referenced and useful articles were from 'Building Research \& Information', 'Building Environment', and 'Energy and Buildings';

- Bibliography of reports and other literature which contained relevant citations;

- Online databases accessible through the University library - the most useful and relevant information was from ProQuest, Sage, ScienceDirect, Scopus, and Taylor \& Francis;

- Online search engines, in particular Google and Google Scholar;

- Printed material, available in libraries or otherwise;

- Websites of organisations managing rating systems, specific Green Building Councils (GBCs), and the World Green Building Council (WGBC). This includes technical manuals, research reports, and case studies.

These media were searched for information relevant to the scope of this thesis. The keywords and search terms, as well as their synonyms, used in this search include:

- Aspects relating to design, construction, and usage - e.g. performance, health, simulation;

- Building sustainability rating tools, rating tools, rating systems, and other combinations;

- Green building, sustainable building, sustainable construction;

- Names of the different rating systems and associated projects - e.g. BREEAM, CASBEE, LEED;

- Trends, issues, limitations.

Note that this list is not exhaustive and that there are keywords and search terms which are not listed above, though they will generally fall into these categories. Additionally, information about the negative aspects of rating systems were anticipated to not be as well documented as benefits or other related areas. 


\subsubsection{Discussion and Analysis}

The gathered data was analysed through discussing the literature in different sections relating to different aspects of sustainability and BSRTs. These sections are about the development, structure, and weighting method of BSRTs, industry uptake, BSRT and rating tool comparisons, building performance, and the effects of BSRTs on decision making. These are chosen for the following reasons:

- The development, structure, and weightings serves as a method of investigating some of the rationale and criticisms behind the design and growth of BSRTs;

- Uptake and usage identifies ways in which BSRTs are utilised in addition to the different drivers and barriers present;

- Investigation of literature pertaining to BSRT comparisons allows discussion on the differences between the tools and relevance and reliability of the research;

- Building performance summarises research related to the actual performance of rated buildings, and what discrepancies there might be;

- Investigation into decision making and the influence of BSRTs allowed discussion as to reasons why different outcomes or actions occur.

\subsection{Existing BSRTs}

The seven BSRTs identified as being widely used and represented among literature and research form the core of the information for the literature review. Individual systems and tools are similar for some due to their evolution from more established BSRTs - BEAM Plus drawing heavily from BREEAM for example (HK-BEAM Society, 2005) - and having comparable assessment methods. This section briefly summarises the origins and rating method of each BSRT to provide some background into their operation. 


\subsubsection{Building Research Establishment Environmental Assessment Method (BREEAM)}

The Building Research Establishment (BRE) introduced BREEAM as a voluntary rating tool to the United Kingdom in 1990 (BRE, 2014; Crawley \& Aho, 1999). It was the first rating tool to be released and has since been adapted and used in over 50 countries, including those in Europe and many other parts of the world (BRE, 2014).

BREEAM uses a point and credit based scoring system split into different categories which are individually rated, giving a total score ranging from 0 to $100 \%$ (BREEAM International New Construction Technical Manual, 2013). This score corresponds to one of five ratings, ranging from 'pass' ( $\geq 30 \%$ ) through to 'outstanding' ( $\geq 85 \%$ ). Ratings also require certain credits to be met in addition to the percentage score, with those above 'pass' having more requirements (BREEAM International New Construction Technical Manual, 2013).

\subsubsection{Leadership in Energy and Environmental Design (LEED)}

The pilot version of LEED was released in 1998 by the United States Green Building Council (USGBC) with the refined release version introduced in March 2000 (Lee \& Burnett, 2008; Todd, Pyke, \& Tufts, 2013; USGBC, 2014d). It is currently the primary rating tool used in the United States and is seeing use in other countries (USGBC, 2014a, 2014b).

Similar to BREEAM, LEED uses a point and credit based scoring system with multiple weighted categories (USGBC, 2014c). The total weighted score ranges from 0 to $100 \%$ with projects earning one of four certification levels: Certified (40 - 49 points), Silver (50 - 59), Gold 60 - 79), and platinum (80+) (Todd et al., 2013; USGBC, 2014d).

\subsubsection{Comprehensive Assessment System for Building Environmental Efficiency (CASBEE)}

CASBEE was developed in 2001 by the Japanese Sustainable Building Consortium (JSBC) in 2001 as a joint project between government, academia, and industry (CASBEE for New Construction, 2010). The first tool, focusing on office design and construction, was released in 2004. Since then the 'CASBEE family' has expanded to encompass all scales of 
construction, including tools for rating cities and assessing heat-island effects (CASBEE for New Construction, 2010; Murakami et al., 2011).

CASBEE uses a weighted point based scoring system organised into six categories; these categories - three to each - are split between the environmental quality and environmental load of the building. This weights the impact of the building on the site and immediate context (environmental quality) against the effect on the wider environment and infrastructure (environmental load) (CASBEE for New Construction, 2010; JaGBC, 2014). This creates a 'building environmental efficiency' rating and an associated score ranging from $C$ to S (C, B-, B+, A, S) (CASBEE for New Construction, 2010).

\subsubsection{Green Globes}

Green Globes is the current iteration of what was originally BREEAM Canada, which was first published in 1996 by the Canadian Standards Organisation. Green Globes was developed in 2000 by ECD Energy and Environment Canada, and now licensed and administered by the Building Owners and Managers Association (BOMA) in Canada, and the Green Building Initiative (GBI) in the US (GBI, 2014; "Green Globes," 2014).

Green Globes is a self-assessment using an online questionnaire broken into 1000 points across non-weighted categories, awarding a one globe (35-54\%), two globes (55-69\%), three globes $(70-84 \%)$, or four globes (85-100\%) rating (GBI, 2014). The design of Green Globes focuses on simple-use and continual project integration, with its simpler method contrasting with other more complex BSRTs (Smith, Fischlein, Suh, \& Huelman, 2006).

\subsubsection{Green Star}

Green Star was launched in 2003 by the Green Building Council of Australia (GBCA) where it is currently the dominant BSRT (GBCA, 2014). Originally focusing on office design, Green Star has since grown to encompass the majority of building uses, including education, healthcare, and industrial, and has begun consolidating many of these tools into a single, adaptable design and as built tool ("A Decade of Green Building," 2013; GBCA, 2014).

Green Star uses a weighted points and credit based scoring system, broken into nine categories, which is assessed externally by the GBCA. This gives a score between 0 and 100 
plus 10 innovation points, awarding an overall score of either four $(45-59)$, five $(60-74)$ or six stars (75+) (GBCA, 2014).

\subsubsection{Building Environmental Assessment Method Plus (BEAM Plus)}

BEAM Plus originated as the Hong Kong Building Environmental Assessment Method (HKBEAM) which was released in 1996, and influenced heavily by the structure and methodology employed by BREEAM (HK-BEAM Society, 2005). BEAM Plus succeeded this in 2010 where it launched with version 1.1. It is managed by the Hong Kong Green Building Council (HKGBC), and focuses on rating new and existing buildings (BEAM Society, 2014; HKGBC, 2014).

As BREEAM and many other BSRTs do, BEAM Plus uses a weighted point and credit based scoring system across six categories. The overall score achieved awards a final rating, including bronze, silver, gold, and platinum (HKGBC, 2014).

\subsubsection{Sustainable Building Tool (SB-Tool)}

SB-Tool was developed from the Green Building Tool (GB-Tool), with the first version of the new development releasing in 2007 (Larsson, 2007). Unlike the other surveyed BSRTs, the SB-Tool, and its predecessor GB-Tool, was designed as a global framework that is adapted to local requirements and is managed by the International Initiative for a Sustainable Building Environment (iiSBE), an international organisation (Larsson, 2012; Larsson \& Cole, 2001). The SB-Tool can be used to assess new construction and renovations of a variety of usages and sizes (iiSBE, 2014).

Weightings in SB-Tool are adjusted to the local requirements of the climate in which it is being applied (Larsson, 2012). The scoring system itself assesses credits as deficient (-1), minimum/acceptable performance $(0)$, good practice $(+3)$, or best practice $(+5)$. These are accrued across seven different categories and the average of which is used to calculate the overall project score (Larsson, 2012). 


\subsection{Structure and Development}

As defined in Section 1.1.2, BSRTs consist of an overall rating system and the individual rating tools which construct it. The overall structure of the seven surveyed rating systems focuses first on the design of individual buildings before branching out to other aspects of sustainable design and being refined over time. The BSRTs each originated with a tool used to assess the design of office buildings (Siew et al., 2013), with initial development usually focusing on smaller scale sustainability at a project scale (Todd, Crawley, Geissler, \& Lindsey, 2001). Over time the larger BSRTs have grown to assess different aspects of building design and usage, including performance and operation, refurbishments, interior projects, and wider community or city projects. Table 3 presents the different assessable project types for the different BSRTs as they are currently (2014/2015).

\begin{tabular}{|l|c|c|c|c|c|c|c|}
\hline & BREEAM & LEED & CASBEE & $\begin{array}{c}\text { Green } \\
\text { Globes }\end{array}$ & $\begin{array}{c}\text { Green } \\
\text { Star }\end{array}$ & $\begin{array}{c}\text { BEAM } \\
\text { Plus }\end{array}$ & SB-Tool \\
\hline New & $\mathrm{X}$ & $\mathrm{X}$ & $\mathrm{X}$ & $\mathrm{X}$ & $\mathrm{X}$ & $\mathrm{X}$ & $\mathrm{X}$ \\
\hline As-built & $\mathrm{X}$ & $\mathrm{X}$ & $\mathrm{X}$ & $\mathrm{X}$ & $\mathrm{X}$ & $\mathrm{X}$ & $\mathrm{X}$ \\
\hline Refurbishment & $\mathrm{X}$ & $\mathrm{X}$ & $\mathrm{X}$ & $\mathrm{X}$ & $\mathrm{X}$ & $\mathrm{X}$ & $\mathrm{X}$ \\
\hline Operation & $\mathrm{X}$ & $\mathrm{X}$ & $\mathrm{X}$ & & $\mathrm{X}$ & $\mathrm{X}$ & \\
\hline Interiors & $\mathrm{X}$ & $\mathrm{X}$ & $\mathrm{X}$ & $\mathrm{X}$ & $\mathrm{X}$ & $\mathrm{X}$ & \\
\hline Communities & $\mathrm{X}$ & $\mathrm{X}$ & $\mathrm{X}$ & & $\mathrm{X}$ & & \\
\hline Other & $\mathrm{X}$ & & $\mathrm{X}$ & & $\mathrm{X}$ & & \\
\hline
\end{tabular}

Table 3: $\quad$ Assessable projects for each BSRT (adapted from information from their respective website and rating tools)

Each BSRT contains a method for assessing various new, as-built, and refurbished projects.

These have developed over time with numerous editions being released, refocusing the goals of the tools in the system to keep up with industry developments. Some systems have also consolidated different tools into a single, more adaptable tool. Green Star Australia is an example of this development, with the merging of different tools which assess education, healthcare, offices, and industrial projects into a single 'Design \& As Built' tool (GBCA, 2014). Additionally, Zuo and Zhao (2014) discuss the growing focus of BSRTs on life cycle analysis in their newer versions. While these BSRTs may have originated assessing a limited aspect of design (Todd et al., 2001), some have since expanded to encompass wider aspects of construction sustainability through the introduction of community assessment methods. 
As outlined in Section 2.2, each BSRT contains a different method and set of requirements which constitutes its structure. Many BSRTs focus on assessing individual credits against their criteria, generally though the provision of proof in the submission, with certain credits requiring more in-depth quantitative evidence such as energy or daylight simulations (Forsberg \& von Malmborg, 2004). Despite the differences in the structure and design of BSRTs, they are all observed to focus on similar environmental aspects (Zuo \& Zhao, 2014). Based off their categories which encompass the different credits being achieved in a project, BSRTs address construction management, energy consumption, water usage, material usage, and indoor environmental quality (Giama \& Papadopoulos, 2012). The importance of these, other categories, and their credits in rating tools are dependent on the local requirements and are generally what form the credit allocation and the credit and category weightings (Reed et al., 2009).

\subsubsection{Category Weightings}

The term 'weighting' is used for the method of adjusting the points awarded to credits in a category due to most BSRTs aggregating the scores into an overall percentage. Each of the surveyed BSRTs have a weighting applied to each category with the exception of Green Globes (Green Globes for New Construction - Technical Reference Manual - Version 1.3, 2014; Siew et al., 2013). This is generally relative to the overall importance of the category on what the BSRT aims to achieve, such as passive design or energy efficiency (Ferreira, Pinheiro, \& de Brito, 2014). Local conditions such as industry, infrastructure, environment, and available resources, are potentially the primary influence on the different weightings (Cole \& Mitchell, 1999). To give an example of this, water is an extremely limited resource in Jordan, which is represented by its high weighting of $27.7 \%$ in a BSRT developed for it (Ali \& Al Nsairat, 2009; Chandratilake \& Dias, 2013).

To put this into context of some of the more popular BSRTs, the Green Star - Office v3 Scorecard for Green Star Australia is an example of the effects of different category weightings based on the local environment and requirements. This is illustrated through the scorecard automatically altering weightings depending on the State of Australia that the project is located. Continuing with water as an example, the category weighting can change from $10 \%$ to $15 \%$ due to water availability. Reed et al. (2009) reinforce the importance of 
local conditions on weightings, identifying the importance of water conservation in Australia, particularly due to its droughts. Another example of addressing local concerns is the importance of site selection in both the UK and the US, due to higher population densities (Chandratilake \& Dias, 2013; Reed et al., 2009). Weightings are also adjusted to local context in SB-Tool due to it being a global BSRT (Larsson, 2012). This allows rating systems to be adaptable across larger countries with various climates and requirements and focus on local issues, rather than applying an external system which could be inappropriate for a particular environment.

The application of category weightings is often seen as being subjective (Cole, 1998; Lee, Chau, Yik, Burnett, \& Tse, 2002), with a lack of transparency regarding how weightings are derived and credit allocation being seen in research by Siew et al. (2013). Although there is the use of scientific method and validation, it can be impractical to use a single method, or set of methods, to evaluate the weightings required for an entire rating tool (Lee et al., 2002). As such, the final weightings are often decided based on consensus of industry survey where knowledgeable professionals are surveyed, using a large enough sample that the effects of subjectivity are minimised (Ferreira et al., 2014; Reed et al., 2009). It is noted that BEAM Plus also used analysis of similar methods to assist in determining its weightings along with surveys (HK-BEAM Society, 2005), which may indicate that other BSRTs do the same. In any case there does not seem to be a consensus determining the best way to apply weightings to the different categories though industry and professional surveying is seemingly the most common and discussed.

\subsubsection{Relation to Sustainability}

Sustainable development was defined in 1987 in a report published by the World Commission on Environment and Development, defining it as "development which meets the needs of the present without compromising the ability of future generations to meet their own needs" (Drexhage \& Murphy, 2010; Poveda \& Lipsett, 2011; World Commission on Environment and Development, 1987). Sustainability encompasses economic, social, and environmental concerns and relationships (Drexhage \& Murphy, 2010). BSRTs can be seen to be primarily focused on assessing the sustainability of a building through its effects on 
environmental impacts (Cooper, 1999; Ding, 2008), as represented by the different credits and categories of the tools, primarily site, ecology, energy, water, and materials.

Across the different BSRTs the direct assessment or integration of social factors primarily covers internal comfort and occupant health though credits such as indoor environment quality and materials (Zuo \& Zhao, 2014). Economic and other social factors are rarely present, though the SB-Tool has been developed to address this (Mateus \& Bragança, 2011). Cole (1999) notes that this focus on environmental performance is due to the "health of the biosphere" being the limiting factor of sustainable design.

\subsection{Industry Uptake and Usage}

BSRTs have seen different levels of usage and engagement throughout the world. While the initial uptake of BSRTs is observed to be slow, they generally show a gradual growth in usage after a couple of years (Cole, 2005; "A Decade of Green Building," 2013; JaGBC, 2014). Cole (2005) describes the high risk aversion of the construction industry and its preference for simpler, unambiguous methods in regards to developing sustainable buildings. Furthermore, Cole describes the success of many of the BSRTs at the time - primarily LEED and BREEAM - being due to their "perceived simplicity" in presenting a quantified standard of Green Building to the industry, among others. It is possible that the described high risk aversion accounts for the gradual uptake of BSRTs.

The way in which BSRTs are utilised is something that would vary between projects and teams. A commonly cited concern is how BSRTs are not being used as they are intended to be, often as a design tool rather than the original aim of assessing the developed design (Cole, 1998; Gibberd, 2014; Nguyen \& Altan, 2012; Schweber \& Haroglu, 2014). Despite regular mention of BSRTs being used as a design tool, there is little research available which actually studies it. Related to this are issues regarding solutions, such as the viability of solutions based on location and items being added to a design specifically to achieve points (Cole, 2005; Gibberd, 2014; Reed et al., 2009). 


\subsubsection{Drivers and Barriers}

Numerous studies exist which identify the costs of sustainable development and its advantages (Fullbrook, Jackson, \& Finlay, 2006; WGBC, 2013; Zuo \& Zhao, 2014). BSRTs therefore establish a voluntary rating system which encourages industry growth and development (Todd et al., 2013). As they are constructed to be voluntary in their use, their uptake is therefore dependent on any requirements presented by different parties or related factors. This has seen commitment by clients to sustainable buildings to showcase commitment to sustainability, shifting real estate focus to properties with formal rating, risk minimisation, and the study and inclusion of aspects of BSRTs into local requirements as some examples (Cole, 2005; Liang, 2012; NZGBC, 2010; Retzlaff, 2009; Todd et al., 2013). This further drives sustainable design as these factors become engrained into the industry, in turn making the use of BSRTs more common.

While BSRTs have seen a growth in usage and uptake since their release, barriers relating to perception of the requirements and inputs exist (Gou et al., 2013). Perception regarding cost and difficulty is an often cited issue of sustainable design, such as the greater upfront cost of more efficient systems and green materials (Gou et al., 2013; Liang, 2012; Papadopoulos \& Giama, 2009). It should be noted that cost is progressively becoming less of an issue as the long term benefits of environmentally sustainable design (ESD) are beginning to emerge, supporting long term financial benefits and client attraction (Wedding \& Crawford-Brown, 2007; WGBC, 2013). Research by Häkkinen and Belloni (2011) identified several barriers within both the literature and local industry through a review of existing literature, industry surveys, and interviews. The findings echoed the barriers imposed by additional cost, as well as indicated process related barriers, lack of common understanding, availability of information, and issues regarding tendering.

The actual methods to assess the different levels of uptake and usage - barriers in particular - vary between the studies. Literature reviews were found to be common methods of assessment (Gou et al., 2013; Häkkinen \& Belloni, 2011; Siew et al., 2013; Zuo \& Zhao, 2014), providing a summary and consolidation of the information available. However, this is limited to the information available. While discussion and consolidation of the literature and research can provide different insights, as evidenced by the cited research, many of these 
studies proceed to use surveys or interviews as a method of further investigating the research field. The advantages of social research such as surveys and interviews is often due to being able to gain insight into the experiences of individuals (Creswell, 2009; Kvale, 2007). As such, this method of research allows for the experiences and views of those who are knowledgeable and experienced in the research area to be gathered, something which is appropriate given the limitations of the research available.

\subsection{Discussion of BSRT Comparisons}

Due to the varying structures of BSRTs and their growing uptake in the construction industry, it is no surprise that comparisons of their rating tools are a common research area. The seven BSRTs focused on in this literature review are among the primary systems discussed and compared. It is observed that BREEAM and LEED are by far the most discussed systems, likely due to their age and extensive use both in their respective countries and internationally.

Different methods to compare how BSRTs rate buildings exist. Some focus on comparison through assessing a standard reference building with different BSRTs. This has led to different results regarding the building's performance, and has provided a number of varying outcomes regarding which BSRT 'performs best'. For example, a comparison of a building between LEED and BREEAM identify that the building would score a low LEED rating while failing to meet the requirements for BREEAM (Papadopoulos \& Giama, 2009), indicating a lower level of entry for LEED projects which is supported in a study by the BRE (2008). Contrasting the BRE findings is a comparison of a building in Japan which rated highly under CASBEE and BREEAM, but only achieved a silver rating under LEED (Aotake, Ofuji, Miura, Shimada, \& Niwa, 2005). This variance could be due to the building itself, differences in the tool, or the method of comparison itself - the validity of which is discussed in Section 2.5.2.

Other methods of comparison involve comparing different tools using a pre-established set of criteria, such as that included in a study by Nguyen and Altan (2011), one by Fowler and Rauch (2006), and another by Reed et al. (2009). Other comparison methods include discussion of the structure of the tools, preferring this discussion and analysis of different 
BSRTs over assessing them with a set of criteria (Liang, 2012; Retzlaff, 2008; Zuo \& Zhao, 2014). Additionally, some studies investigate different BSRTs, though focus on a single one as a central to compare others to (BRE, 2008; Todd et al., 2001). The purpose of these comparisons varies between the studies. Some focus on reviewing and summarising the literature (Liang, 2012; Zuo \& Zhao, 2014), while others investigate a specific aspect of BSRTs; for example, Chandratilake and Dias (2013) investigate different category weightings while Lee (2012) compares energy usage and assessment.

\subsubsection{Assessment Method}

The assessment method revolves around how a rating tool assesses a submission to grant a final score and the associated rating. The methods of assessment vary across the different BSRTs though most involve a submission that addresses a number of the points and credits within a tool which is assessed by registered assessors. BREEAM and LEED can be seen to be the main drivers of this method of assessment due primarily to their age and having significant influence on the design of other BSRTs. Nguyen and Altan (2011) provide a quantitative comparison between BREEAM, LEED, CASBEE, Green Star, and HK-BEAM, investigating nine different categories which includes the assessment method and its rigour. BREEAM and LEED were both identified as the most popular BSRTs due to their age and usage, and rated highly overall while the other three scored lower.

Despite the similarities in the final scores, the assessment illustrated that BSRTs have a range of strengths and focuses, something which would be indicative of the local requirements of the environment or industry. CASBEE is an excellent and often cited example of this (Nguyen \& Altan, 2011; Siew et al., 2013), due primarily to its highly complex rating system which assesses both the building performance and environmental load where both have to be addressed to achieve a high score. However, this complexity comes at a cost of understanding - the survey by Nguyen and Altan showed a correlation that CASBEE's complex nature results in it being harder to utilise and understand than others.

In regards to assessing energy usage, Lee (2012) identifies the different methods of assessment of five tools, finding a variance in the assessment method and the simulation tools allowed. The methods of assessing energy usage can be seen to vary the most between the different assessment methods involved in rating a building. These differences 
emerge from the simulation requirements of each region where a BSRT is employed, incorporating benchmarks, commonly used simulation tools, and performance criteria, into the assessment method; something which can also be seen in an earlier study by Lee and Burnett (2008).

Aside from this the assessment methods seemingly vary in regards to what is required by the tools. Since many BSRTs follow some form of points based structure, either weighted or non-weighted, most of the credits are assessed by checking the submission against the requirements. As mentioned, the strengths, local requirements, and foci of the different tools and systems greatly affect what they assess and how they assess it.

\subsubsection{Relevance and reliability of comparisons}

Before continuing it is important to discuss the relevance and reliability of comparing BSRTs. Each BSRT is generally designed to specific climates, each containing different industry and environmental requirements (Bond, Morrison-Saunders, \& Pope, 2012; Ding, 2008; Nguyen \& Altan, 2011), something which is discussed throughout earlier sections of the review. Many of the comparisons surveyed in this literature review focus on the overall structure and performance of a specific tool, ignoring any requirements of the local industry that the tool is developed around. It would be more relevant to compare Green Globes and LEED due to the usage of both in the US than it would be to compare either to BREEAM, CASBEE, Green Star, or BEAM Plus, since they would have been developed and adapted to different climates. Reed et al. (2009) ascribe this to the different building code requirements of each country and how they differ, affecting the baseline assumptions which construct a tool.

Research by the BRE (2008) carried out a comparison of BREEAM, LEED, CASBEE, and Green Star, citing the difficulty in providing a fair comparison due to the differences between each BSRT and their design to local requirements. A standard office building was designed to meet the relevant office design tool for each system, with the resulting building then being rated and compared to BREEAM. This was one method of addressing the differences between BSRTs, with the results indicating that BREEAM requirements were highest to achieve, followed by LEED, Green Star, and CASBEE. This is acknowledged by the BRE to require more detailed analysis before conclusions can be drawn. Also noted is that there are 
several issues regarding the comparison, again including the complex and occasionally unique requirements of CASBEE's system compared to the others.

Other comparisons included in this literature review can be seen to echo these findings (Haapio \& Viitaniemi, 2008; Papadopoulos \& Giama, 2009), where the comparisons produce various results due to the design of the tool. Cole (2005) notes that the different comparisons at the time focused on the technical content of the tool with minimal reference to local organisational or market requirements, and stating the problem regarding comparisons which do not include these and other contextual considerations. This is evident in the later studies examined which also lack extensive investigation into the local requirements when comparing BSRTs, though these limitations are acknowledged.

It is noted that many of the comparisons do not focus on SB-Tool, and its relevance in this discussion of comparison can be of interest due to its nature as an international system. Unlike other BSRTs which are designed for specific climates, the SB-Tool has provisions, as part of its design, to be easily adapted to suit the location of a project. While it might be almost impossible to establish a fair comparison between localised BSRTs, using an international tool like SB-Tool to provide this comparison could be worth investigating to use as a common ground. Even so, the SB-Tool requires adaption to a country or region before it can be used (Larsson, 2007), so might be unsuitable for this purpose.

\subsection{Building Performance}

The energy performance of rated buildings was identified to be one of the common methods of assessing the effectiveness of BSRTs. Comparable metrics exist from the submission process where effectively all tools require some sort of simulation of energy performance. As energy performance and simulation is a major category across many BSRTs it has since become the focus of a number of studies (GhaffarianHoseini et al., 2013; Lee, 2012; Lee \& Burnett, 2008; Stein \& Reiss, 2004; Wedding \& Crawford-Brown, 2007), and is mentioned or described by many others.

LEED, in particular, has had multiple studies done regarding the resulting energy performance of the rated buildings, concerned with whether or not LEED buildings perform better than non-rated buildings. Newsham, Mancini, and Birt (2009) studied 100 buildings 
rated under the LEED system. They found that LEED rated buildings used, on average, $18-$ $39 \%$ less energy per floor area; something which is contrasted with their finding that $28-$ $35 \%$ of LEED buildings used more energy than non-rated buildings were measured to do. Scofield (2009) re-examines these buildings after questioning the validity of the study. Schofield found, through creating a comparable re-examination, that the lower scoring buildings generally used more site and primary energy while higher scoring buildings used $13 \%$ less.

Another study by Zheng (2013) also investigated this question, analysing three rated buildings at UC Berkeley in the US, and finding that they did perform better than average though cites the limitations of a small sample size. Therefore, how and what data is collected for these studies is highly important. Small sample sizes hold little representation in a BSRT with thousands of rated buildings, while Scofield (2009) states that the gathered data should be independently audited to be fairly comparable.

These studies indicate that rated buildings do perform better than average, though there can be a range of discrepancies in both outcomes and analytical processes. The actual usage might differ when compared to what the building was designed to achieve, allowing postulation that there are many more variables to consider when operating and maintaining a rated building compared to a non-rated building. Even so, higher rated buildings have been found to perform better than average (Lee \& Burnett, 2008; Scofield, 2009), with Lee and Burnett noting that the highest scoring buildings are generally within the top $5 \%$ of the market in regards to building performance.

\subsection{Effects of BSRTs on Decision Making}

The effects that BSRTs have on decision making are explored little in the current frame of literature. While mentioned in various reports (Haapio \& Viitaniemi, 2008; Häkkinen \& Belloni, 2011; Mateus \& Bragança, 2011; Schweber \& Haroglu, 2014; Zuo \& Zhao, 2014), in most cases it is either a brief reference to there being an effect or that it is a subject for further research. Ferreira et al. (2014) mention the complexity as well as the importance of decisions regarding building performance and how they might be affected during the design stage of a sustainable building. They also mention that the primary decision makers, such as 
clients or real estate developers, generally do not have specialist knowledge, and focus on maximising profits and investments. In relation to material choices, Umar, Tukur, Khamidi, and Alkali (2013) describe the selection process which occurs as being broken into three stages: research, evaluation, and selection; though little else is discussed or researched to further explore this process.

Ding (2008) discusses the analytical and judgemental processes that are employed when approaching the design. Ding calls into question the focus on single-dimension approaches to the decision making processes, focusing on single criterion evaluators such as cost benefit analysis or energy performance. This was found to be due to the focus of BSRTs on the environmental performance and not addressing social or economic concerns, as comparable to what was discussed in Section 2.3.2.

The furthest the effects that a BSRT has on design decisions is investigated by Schweber and Haroglu (2014), who studied the effects of BREEAM on design decisions and how it fits into the design process. This was undertaken using comparative case studies of selected projects, interviewing the BREEAM assessor, client, architect, project manager, design manager, and engineers who were involved. As such, that research was focused on the wider effects of BREEAM on design decisions and design processes, and found a large variation across different projects.

\subsection{Summary of the Literature Review}

This chapter has presented the different findings in the research and literature pertaining to BSRTs. Numerous studies exist which assess the structure and uptake of BSRTs, how similar systems operate and compare, and what drivers, trends, issues, and barriers exist. The actual relevance and reliability of these comparisons can be questioned, however, due to the focus of BSRTs on a single climate and the lack of this consideration in many comparisons.

For the most part these studies were undertaken using a combination of three different methods. While each study contained a review of relevant literature, some used a more extensive and systematic review as the primary research approach. Others used data of buildings, projects, or BSRTs to provide comparison and analysis. In other cases, surveys or 
interviews of individuals with sufficient knowledge and experience were used, gaining insight which was otherwise unavailable. Different trends and issues were identified, the most commonly occurring being:

- Higher initial cost of sustainable design and achieving a formal rating;

- Discrepancies between design and performance;

- Whether rated buildings are better than non-rated buildings;

- Comparability of buildings rated by different BSRTs;

- Understanding of client and other involved individuals;

- Unintended use of performance based tools as design tools;

- Focus on achieving points over applicability to the project.

In addition, various pieces of research mention that BSRTs can significantly affect aspects of decision making though only Ding and Schweber \& Haroglu actually explore this in any depth.

\subsubsection{Influences on Research Direction}

The literature review identified minimal existing research pertaining to how BSRTs might affect decision making processes. As there is little background research to expand upon, the research method and direction will be focused on identifying the effects at a more macro oriented level as opposed to specific case studies or similar and a local or micro level. The other research presents various outcomes from the use of BSRTs and how their different aspects and construction influence these, though there is less exploration of 'why' these outcomes occur. Investigation of how BSRTs influence decision making can therefore elucidate this somewhat, giving better understandings of the processes that occur.

Qualitative interviews or quantitative surveys are therefore the best methods available to investigate this, as was demonstrated by existing research at the end of Section 2.4.1. Investigation of the effects at a macro level will provide an exploration into this area and produce more representative findings relative to the industry.

Primarily due to its locality, Green Star NZ is best suited to be the focus of this study, where its applicability, background, and structure are described in the following section. 


\subsection{Green Star New Zealand}

Green Star NZ forms the focus area for this investigation due to its locality and similar construction to other BSRTs as a result of its adaptation from Green Star Australia. As mentioned, Green Star NZ was chosen to be the focus research area because of its locality and the ability to directly access participants and information on the system. Due to the similarity in the overall structure and assessment method to other BSRTs, the resulting investigation into Green Star NZ may be comparable to other systems, something which is discussed later in Chapter 6. Other BSRTs like BREEAM and LEED were considered but ultimately excluded due to the likely difficulty in getting information or securing participants. Investigation of Green Star NZ instead is more reliable, likely to be thorough, and beneficial to the local construction industry.

\subsubsection{Description of Green Star New Zealand}

The first Green Star NZ tool assessed office design and was launched in 2007, adapted to local requirements from the Australian Green Star system by the New Zealand Green Building Council (NZGBC). Green Star NZ focuses on assessing multiple aspects of a building to award a rating. These aspects are formed into different categories, which are: Management, Indoor Environmental Quality (IEQ), Energy, Transport, Water, Materials, Land Use and Ecology, Emissions, and Innovation (NZGBC, 2014). Each of these categories consists of a number of credits, with each credit containing a number of points relative to its intentions. Each category has a weighting applied, meaning the overall contribution of an individual point to the overall rating varies between categories. Figure 2 illustrates the weighting of each category in addition to the weighted score required for a rating, a method which has been presented to be common among other BSRTs. As can be seen, the number of 'stars' awarded increases in multiples of 15, though a formal rating is only awarded for projects that score 45 or more. A score less than 45 is not awarded a Green Star rating. 


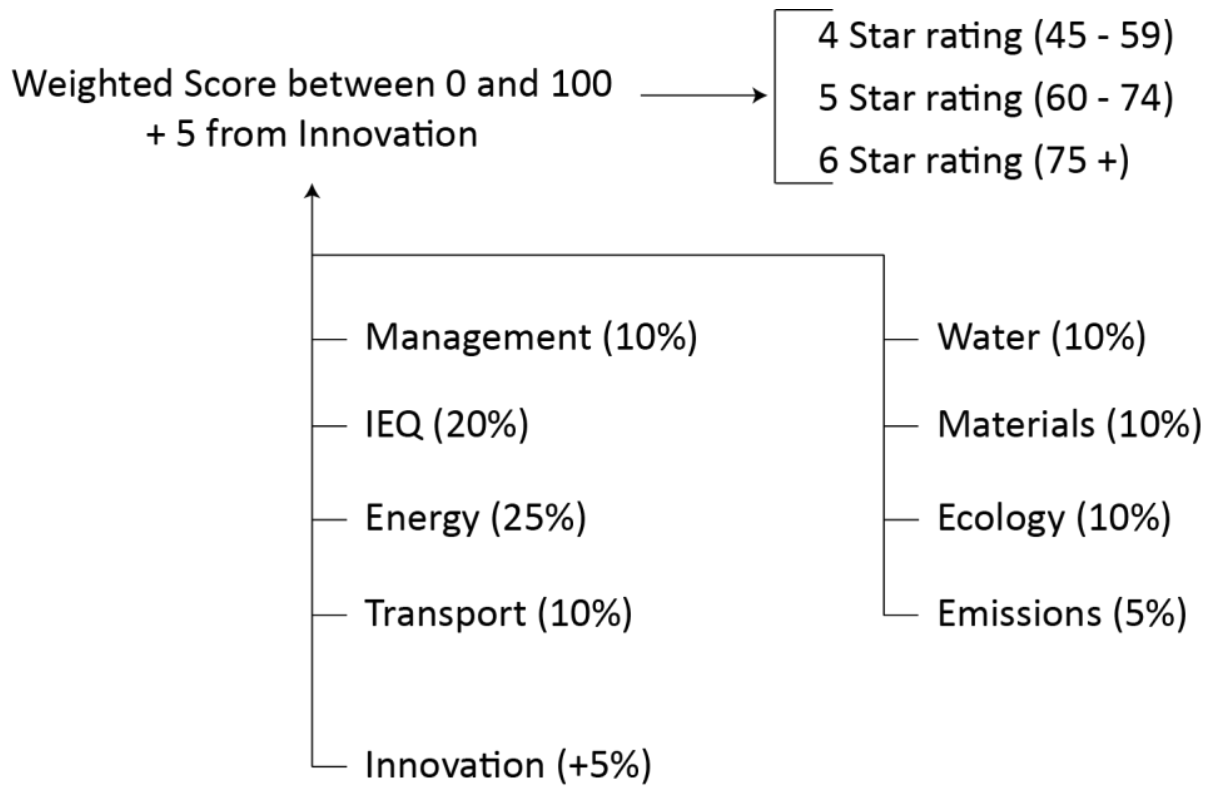

Figure 2: $\quad$ Core structure of Green Star Office Design, adapted from the Green Star NZ Office 2009 tool.

Additional tools have been released in subsequent years, consisting of office as built, office Interiors as built, education design and as built, and industrial design and as built. The different categories, their weightings, and credits vary between the tools; Green Star NZ Interiors 2009 has no Land Use and Ecology category for example. While the design rating tool assesses the different planned aspects of design, the built rating tools assess that the different sustainable design has been carried out on site and are present in the building. A custom rating tool has also been launched, allowing Green Star NZ to be adapted to unique projects without having to create multiple niche tools. Over 100 ratings have been done across all of the tools since 2007 (NZGBC, 2014), with the number of rated projects showing a growing uptake. 


\section{Chapter 3 - Methodology}

This chapter details the methodology developed to carry out this research. It describes the use of classic grounded theory as the means to investigate the largely unknown substantive area identified in the literature review, including the rationale for selecting this method, what it entails, and how it was utilised. Also described in this chapter is the interview protocol developed, the interview process, and ethical considerations.

\subsection{Data Collection Method}

In order to investigate the overall aim of this thesis - the effect of Green Star on design decisions - a qualitative interview was chosen as the method of data collection. Interviews can provide an in-depth exploration of a participant's experiences on a subject (Charmaz, 2006, p. 25); furthermore, interviews allow for deeper exploration of participant knowledge while giving the participants the freedom to tell and reflect on their experiences (pp. 26-27). As such, interviewing knowledgeable people who have been involved with Green Star was likely to identify different experiences, reasons, opinions, and theories relating to the aim.

This method was chosen over another proposed method of investigation. The other method would have involved surveying individual buildings to identify trends and issues, using a number of screening criteria. This was not pursued for three reasons. The first was that the development of the screening criteria would be difficult and incomprehensive as initially the trends and issues would be unknown. The second was that while this process may identify trends and issues, it would not be able to define why they exist. Thirdly was the predicted difficulty in getting sufficient information and permissions from the multiple parties involved. 
Interviews of people experienced with Green Star, however, would be able to investigate these three problems in addition to the core aim looking at the decision making process. Participants may give information on some trends and issues in their experiences and these can be followed up on. They are also able to identify why these trends and issues exist, or at least give their theories and hypotheses should they not know exactly. Permissions are also less of an issue since the participants can be kept anonymous and are the only party involved who needs to give consent.

\subsection{Classic Grounded Theory}

Grounded theory (GT) is the research method used for the framework of this methodology. It is a qualitative research method which generates conceptual theory and categories from information that is 'grounded in' the gathered data (Schutt, 2012, p. 341). A research area known as the substantive area - is investigated using the procedures of GT in order to discover the participants' main concern as well as how this concern is processed, resolved, or otherwise occurs (Breckenridge, 2014). These procedures include theoretical sampling, memoing, constant comparison of data, and coding process (Elliott \& Higgins, 2012).

Concepts and categories emerge through these systematic procedures of GT and are parts of what explains the participants' experiences and concerns with the substantive area; the substantive area for this research being the effect of Green Star on decision making. As this continues, a core variable emerges as well as an overall theory which explains the relationship between the different concepts and categories. These different aspects are described in more detail throughout this chapter.

A GT study was chosen over other qualitative research methods primarily due to its focus on continual inductive analysis and theory development to explain patterns. The inductive analysis is especially important due to how little was known about the substantive area at the outset of the research, and being able to develop a theory from the information is a significant strength. Barney Glaser (1978), who developed GT along with Anselm Strauss, describes the goal of GT as "generating a conceptual theory that accounts for a pattern of behaviour which is relevant and problematic for those involved (p. 78)." Being able to develop a theory that accounts for behaviour from the information 'grounded in' the data is 
one of the drawing points and strengths of GT and another reason that it was chosen. Glaser goes on to state that "the goal is not voluminous description, nor clever verification (p. 78)," which is often a focus of other methods.

\subsubsection{Different Methods of Grounded Theory}

Specifically, classic grounded theory (CGT) was chosen over two other GT methodologies: Straussian grounded theory and Constructivist grounded theory. Straussian grounded theory is significantly more structured than CGT and has additional focus on deduction, verification, and validation - something which has been criticized for moving away from the core inductive generation of classic grounded theory (Evans, 2013). For Constructivist grounded theory, one of the primary differences is the researcher starting with specific questions on the substantive area and looking to investigate those, with the core belief that concepts are constructed by the researcher instead of discovered inductively from the data (Evans, 2013).

Ultimately the CGT method was used due to its more adaptable and flexible construction than the more structured Straussian method. For a novice user of GT, CGT was more easily understandable and workable than the Straussian method. It was also chosen over the constructivist method due to the power of CGT in discovering theories through inductive reasoning, rather than through construction. As stated prior, with much of the substantive area unknown, being able to provide a framework to identify reasons for these occurrences and behaviours in an inductive manner fits the aim of this thesis best.

\subsubsection{Use of Existing Literature}

At this point it is important to address the act of doing a review of relevant literature before carrying out a GT study. CGT actively discourages extensive review of existing literature before the data collection process. This is to help minimise the risk of preconceptions affecting the researcher's ability to remain open to data, instead using the literature as part of the data collection and treating it as another source of information (Evans, 2013; Glaser \& Holton, 2004). 
In this research the literature review was done to investigate the usage and construction of BSRTs globally rather than review the literature on effects of such systems on decision making processes. The substantive area of this investigation was identified during the literature review due to the lack of information on it, and CGT was chosen as the method to investigate it along with a series of interviews.

'All is data' is a dictum of CGT. It simply means that any piece of information - be it an interview, an observation, or literature - are all valid pieces of data to be analysed, reflecting on CGT's flexibility (Holton, 2008). While the primary source of data used was from interviews, relevant literature and other studies were also analysed. As such, literature which pertained to the substantive area was investigated as part of the GT process and will be part of the following chapters to aid the emergent theory, used as another form of data.

\subsection{Sampling}

Sampling methods and related considerations were investigated and decided before the interview process began. An initial population was decided along with the initial sampling methods to assist the theoretical sampling process of CGT. Sample size considerations were also made and are discussed in relation to the GT process.

\subsubsection{Population}

The population for the interviews were Green Star Accredited Professionals (GSAPs). GSAPs were chosen due to their deeper understanding of Green Star than other professionals who have worked in the same or similar area. Additionally, due to their knowledge and involvement in Green Star processes, they were judged more likely to have experiences and expertise to provide detailed information.

This population is quite broad and was likely to contain members who may not have the required experiences appropriate for the interview. A set of inclusion criteria was therefore developed to help focus the sampling process on those members who most likely had the required knowledge and experiences (Robinson, 2013). 
The inclusion criteria were:

1. Worked on the design team of a Green Star accredited project;

2. Were involved in the environmentally sustainable design of an accredited project;

3. Were involved in the Green Star submission of an accredited project, though not necessarily the individual submitting it;

4. Were accredited GSAPs at the time of the project.

This initial population was simply a guideline and not a definitive list of requirements. While this set of criteria helped in establishing the initial interviews, participants were sought based on their knowledge and experience rather than just whether they met the requirements or not.

\subsubsection{Sample Size}

At its core, sample sizes in qualitative research depend on several variables including what it seeks to investigate, its purpose, credibility, use, and limitations regarding time and other resources (Patton, 1990, p. 184). They are often small in size (Morgan, 2008a), with minimal guidance for determining a sample size being provided despite their purported importance in improving credibility (Marshall, Cardon, Poddar, \& Fontenot, 2013; Patton, 1990). Ultimately, theoretical and practical considerations are often the determinant of a sample size (Robinson, 2013).

This is a point where GT differs from other qualitative research methods. As the focus of GT is on gathering rich data to inductively deduce categories and theories rather than testing a hypothesis, it is unknown how many participants will be required to provide their experiences and knowledge to develop these theories at the outset of a project (Glaser \& Strauss, 1967, pp. 60-61). As data is continually analysed and compared, the theoretical sampling process, as described in Section 3.3.3, moves the data gathering towards providing theoretical saturation. Reaching theoretical saturation refers to the different categories, particularly the core variable, having emerged from the analysis and where no new information is revealed from further data collection and analysis (Glaser \& Strauss, 1967, p. 61). 
The number of interviews and participants required to achieve theoretical saturation is something that will vary greatly from project to project, relying on the different factors such as the project aims and practical considerations as mentioned before. This variance can be seen in some recommendations and studies. Riley (2008) describes most studies taking eight to 24 interviews to reach theoretical saturation (as cited in Evans, 2013), while a survey of 83 qualitative research reports by Marshall et al. (2013) identified that those using GT ranged from six to upwards of 100 interviews, and suggesting $20-30$ interviews based on a range of recommendations. In any case, a goal of GT is to reach theoretical saturation, with the number of interviews required to reach it being reflected in this variance.

A sample size was not set for this research though an initial estimate of between 10 and 20 interviews or respondent encounters was considered achievable due to practical limitations regarding identifying and contacting participants, travel costs, and time. Even with a lower sample size, it was anticipated that interviewing the more experienced GSAPs would provide a fairly representative overview of the projects in New Zealand. In any case, the focus was not on numbers but on achieving theoretical saturation.

\subsubsection{Theoretical Sampling}

There are a variety of sampling methods which have their place in social research. These range from highly systematic quantitative sampling methods, such as simple random sampling (Bloor \& Wood, 2006), to more open qualitative sampling methods, such as purposive sampling (Morgan, 2008b). Theoretical sampling is an open process which differs from more traditional sampling methods and is core to CGT.

Theoretical sampling is the process where data is continually collected, coded, and analysed in order to generate theory (Glaser \& Holton, 2004). It is this generation of theory which controls what and how data is gathered; as theories and categories emerge from the analysis, the researcher decides what data should be collected to investigate these emerging categories and theories to move them towards saturation (Glaser \& Strauss, 1967, pp. 45-46). Theoretical sampling primarily controlled what was asked and talked about during the interview process rather than trying to interview specific people with a specific experience. As such the focus was on what information was gathered in order to investigate 
and saturate the emerging categories as opposed to who the information was gathered from.

\subsection{Human Ethics Considerations}

Ethical considerations must be observed for participants in interviews where people are asked to provide information, their experiences, and their opinions on a specific topic (Walliman, 2006). The primary ethical concern for this research was the recording and reporting of sensitive information given by the participants during the interviews. The interview guide developed asks participants for information, experiences, and opinions which may contain sensitive information, have a potential risk of damaging their professional career or reputation. Likewise, information they provide could also be detrimental to other individuals, organisations, or companies depending on how it is reported and interpreted.

For example, a commonly asked question on the design stage queries if they set a target rating at the beginning of the project, following up on their decisions for including or excluding certain credits. Information given about client or design team choices could be sensitive or otherwise damaging to the designer, the design teams, or the client due to decisions made, opinions expressed, or principles held. These decisions were also made under confidentiality within the design team, and it would be disrespectful for these to be presented in the findings of this research. Furthermore, a different question asks about experiences regarding changes during the construction stage while another asks about issues identified during the occupancy stage. These run the same risks to the aforementioned parties involved, but also for the building owner should any information be identifiable.

To resolve this concern all identifiable information mentioned remains confidential to the researcher and the supervisor. All interviews have identifiable information removed through aggregating data and using pseudonyms, particularly when using direct quotes (such as replacing names with "this participant", "a project", or "building A"). Additionally, none of the names of participants, buildings, projects, organisations, or other bodies of people are identified in any of the findings. Participants were also given a copy of the interview 
transcription to check over, allowing them to make any changes or clarify any points to avoid misinterpretation. Furthermore, identification is less of an issue in CGT as more theoretical concepts, categories and theories emerge from the data, which are the core part of the analysis and subsequent reporting and discussion, rather than extensive analysis of specific quotes or pieces of data.

Participants were given the required information about the research to give their informed consent, stating that they were aware of and understand the research and risks involved. The participant information sheets, provided to participants, and the consent form, which was signed in face-to-face interviews, can be found in Appendix B and C respectively. The approval notification from the Human Ethics Committee is found in Appendix A.

\subsection{The Interview Process}

The purpose of this research was to investigate and describe the effect of Green Star on design decisions and decision making processes. As identified in the literature review, there was little published information regarding this, with a large portion of the related discussion dedicated to assessing the structure and use of BSRTs, how similar systems operate, and what barriers, trends, and issues exist.

As such, the interview was not designed to investigate a hypothesis or other predetermined idea or statement, but rather to use interviews and CGT to inductively deduce categories and theory from the data while avoiding preconceptions. An adaptable interview guide was therefore developed to allow participants to share their experiences and knowledge and enable the interviewer to follow-up with questions designed to provide more insight.

\subsubsection{Interview Design}

The interview questions and structure were focused around four different areas:

1. The effect of Green Star on design decisions made during a project;

2. The effect of variations during the construction process;

3. The effect of Green Star on the operation of the building;

4. General experiences with Green Star and sustainability. 
This can be summarised as investigating the participant's history and their experiences with Green Star during the design phase, construction phase, and the occupancy phase of a project in addition to their background is sustainability.

These areas were chosen for the interview guide as they cover a range of experiences relating to Green Star and sustainability in general. The background of a participant could provide insight into other work they've done which they would consider sustainable and would be useful to compare to their current experiences.

The interview guide, found in Appendix $\mathrm{E}$ and $\mathrm{F}$, follows design considerations for a semistructured interview. In particular this consists of the use of initial questions, follow-up questions, and probing questions. This provides an initial open question for the participant to expand upon, and having follow-up questions available to delve deeper into their responses (Kvale, 2007, pp. 60-61). The initial questions were developed based on the aforementioned areas with some potential follow-up and probing questions created to focus in on specific areas. Five initial core questions were created and cover the following areas with the question from the appended guide provided as an example, as shown in Table 4.

\begin{tabular}{|l|l|}
\hline Area & Core Question Example \\
\hline Background Questions & $\begin{array}{l}\text { Could you describe to me your history with sustainable } \\
\text { design? }\end{array}$ \\
\hline $\begin{array}{l}\text { General Green Star } \\
\text { Questions }\end{array}$ & What is your experience with Green Star? \\
\hline Design Stage & $\begin{array}{l}\text { What are your experiences with Green Star's integration } \\
\text { with the design process? }\end{array}$ \\
\hline Construction Stage & $\begin{array}{l}\text { How did you feel about the construction process of these } \\
\text { buildings? }\end{array}$ \\
\hline $\begin{array}{l}\text { Operation and } \\
\text { Maintenance }\end{array}$ & $\begin{array}{l}\text { What are your thoughts on Green Star's effects on the } \\
\text { operation and maintenance of the building? }\end{array}$ \\
\hline
\end{tabular}

Table 4: $\quad$ Investigatory areas and an example of core questions 
Follow-up and probing questions were designed to expand on these areas, in particular focusing on the effects of Green Star on design decisions as it was considered unlikely that the participant would explain that initially. For example, expanding on the initial question regarding the design stage are questions relating to setting a target rating, the influence of Green Star on decisions made, and what exclusions and inclusions were made. These were not formatted as strict questions, but rather as a frame of inquiry used to create a question as required.

The interview guide was not exhaustive or inclusive of all questions asked during the interview. Some of these questions were not asked due to participants already having provided information or the question not being applicable to their described experiences; on the other hand, some questions not on the interview guide were asked to further investigate an area which was not known prior. As such, despite it being developed as a semi-structured interview, it was not used as a list to read questions off but as a guide to assist the interviewer.

\subsubsection{Interview Execution}

Interviews were undertaken face-to-face as much as possible to maximise the response and interest of the participant. With most of the participants being located outside of Wellington, time and cost considerations were constraints when organising interviews and were one of the primary limitations of this research, as discussed in Section 1.4. In the event where it was too impractical to travel and interview a participant in person, they were interviewed by phone.

Participants were initially contacted either through email, using a standardised letter which can be found in Appendix D, or by telephone. In each case, the project's purpose, objectives, and interview areas were outlined. Upon indicating an interest in being interviewed, the participants were provided with a copy of the participant information sheet. A date, time, and location were later negotiated with each participant. This was important to do early for those outside of Wellington so that a schedule could be organised around any travel requirements. 
The interviews were each recorded using a digital sound recorder for their transcription which was used for coding later on. The model of the recording device was a SONY ICDPX440 MP3 IC Recorder. In order to minimise the risk of data loss through technical issues, two recording devices were used - one as the primary and the other as a back-up. Notes were occasionally taken during an interview, though this was done sparingly to avoid providing a distraction to both the researcher and the participant. Any notes taken were focused on following up with certain questions or areas which would be worth going back to later in the interview. After each interview a series of notes was made on what the participant described and explained - these were developed into a series of memos.

\subsubsection{Bias}

Bias - or the act of identifying bias and minimising its impact - is briefly addressed here. Bias is brought to the research both by the researcher and the participants, and may be impactful on the gathered data and the analysis (Corbin \& Strauss, 2008, p. 80).

Participant bias was considered to be a potential issue. Confidentiality of the participant's interviews avoids biases influenced by external parties, such as employers or building owners. This helps minimise issues with participants not wanting to provide full or entirely accurate information in order to avoid the issues discussed in Section 3.4.

Bias introduced by the interview process was addressed by making the questions as open as possible, keeping the wording neutral, and not asking leading questions. Questions were designed to ask about general experiences while not inferring whether something was good or bad in the questions. The exception to this was with follow-up and probing questions which only inferred information that the participant already had. The researcher's responses were also kept as neutral as possible through attentive listening and confirmation as opposed to negative responses.

Researcher bias in CGT is treated differently than in other methods which traditionally seek to remove any preconceptions held by the researcher. In GT the researcher must stay open to what is happening rather than applying preconceived hypotheses or bias to the data collection (Glaser \& Holton, 2004). During analysis, researcher bias is treated as another 
source of data to be managed to allow the researcher to become more theoretically sensitive where any issues that do arise are revealed and controlled through the constant comparison of data and when categories begin to emerge (Deady, 2011).

Even so, potential researcher bias was identified and monitored. In many situations it assisted the memoing by offering different perspectives to discuss the data against. Any issues which began to negatively affect the analysis were revealed as the memoing process continued. As the data was continually compared with itself and information emerged inductively from it, these harmful biases and preconceptions revealed themselves when they began to conflict with the data. Since remaining open is important in GT analysis, these situations were addressed when they emerged to identify the source of the bias and its implications. Even in these situations, discussing the issue in memos led to new insights into the relationship between the data. An example of this is presented in Section 4.2, which discusses how preconceptions from earlier data pertaining to the emerging category of 'tool construction' were affecting how newer data was analysed.

\subsubsection{Validity and Reliability}

Validity relates to whether the research is fully investigating the aim of what it set out to do while reliability refers to the consistency and accuracy of the findings (Kvale, 2007, p. 122). Different methods approach validity and reliability differently, but all generally focus on ensuring the accuracy of the data.

CGT treats validity and reliability differently than other methods of social research, which seek to prove that their data and results are valid and reliable. In CGT, validity is engrained in the entire research process from start to finish where the constant checking, comparing, theorising, and analysis of data discuss aspects such as plausibility, validity, and credibility (Kvale, 2007, pp. 123-124). This forces the emergence of categories from the data and ensures that forcing other ideas or themes into the research only works if they have an emergent fit (Glaser \& Holton, 2004).

While CGT ensures that the outcomes are valid and fit with the data, the reliability of the interview data was also considered. This was done through making sure that the 
transcriptions and any interpreted information was correct and in line with what the participant said. Returning transcriptions to their respective participants after they were completed and coded for them to check - if they wished - was one way of any errors being identified. Additionally, any areas of the data which was unclear to the researcher was also followed up on to ensure accuracy. At the conclusion of the research, two of the ten participants had taken the opportunity to provide amendments of feedback on the transcriptions.

\subsection{Data Analysis}

Data in GT is analysed as it is gathered. As it was discussed and analysed through theoretical memos it directed further information gathering to saturate the core variable and other concepts and categories. The data analysis started from when the first interview was completed and was carried through until the categories, core variable and the theoretical code were determined and saturated.

\subsubsection{Transcription}

Each interview was transcribed using a standard template organised to assist with the coding process. All interviews were transcribed verbatim by the researcher. Any quotations taken from the interview transcription in the following chapters were tidied by removing minor grammatical errors or messiness that is inherent in conversation. Holstein and Gubrium (2003) note that this disjuncture between casual conversation and written text raises ethical concerns regarding making participants appear inarticulate or otherwise makes their quotes difficult to read; they suggest that any tidying up of quotations for publishing be done after the transcription process - as was already decided - and done so in a way as not to remove or alter the meaning of the quotation used.

The transcription itself was kept simple. As there was no need to analyse the interviews for anything other than the verbal content a complex notation system was not required. Identifying information was not removed in order to keep with the verbatim transcription and assist in analysis, though any such information was either removed or replaced with 
pseudonyms when presented in the following chapters or any other non-confidential circumstance, as was stated previously regarding ethics consideration.

Microsoft Word was used to write the transcription while the audio file was listened to in VLC media player. A working copy of the audio file was used during the transcription, keeping the original backed-up elsewhere.

The transcription template can be found in Appendix G.

\subsubsection{Substantive Coding}

Once complete, the transcription was coded line by line to start generating codes. This is the first of two coding stages in CGT, called substantial coding, and is the process where the initial codes and categories emerge (Evans, 2013). Each transcription was printed off and coded manually by writing in margins and between lines, highlighting and linking together relevant pieces of data. To assist in inductively draw out information, Glaser and Holton (2004) provide some questions to be applied during the coding process, stating that:

"From the start, the analyst asks a set of questions - 'What is this data a study of?' 'What category does this incident indicate?' 'What is actually happening in the data?' 'What is the main concern being faced by the participants?' and 'What accounts for the continual resolving of this concern?"”

Applying questions such as these to the data are what created the initial codes and categories which represented and helped explain different facets of the substantive area.

\section{Concepts and Categories}

Concepts in CGT are the names of patterns and relationships that are grounded in the data (Glaser, 2002). These were some of the first pieces to emerge from the coding process. Several concepts were identified early on in the analysis where they showed a pattern or explained a common occurrence between and within interviews. Many of these concepts were 'in vivo', meaning it comes from the participant's words (Glaser, 2002), while the others used a word or phrase which best explained the pattern it was representing. 
Categories are a higher level of concept, being those that have begun being conceptually saturated through the constant comparison and analysis of data and emergence of patterns between different concepts (Glaser, 2002). As such, the different categories emerged from different concepts which had similarities, patterns, and relationships between them. The created categories encompass these concepts, with each one being moved towards saturation through further data collection.

\section{The Constant Comparison Method}

The constant comparison method is one of the core components of CGT, involving three different levels of comparison. These were: incident to incident comparison, where concepts begin to emerge; concepts to more incidents, which expand on the existing concepts and categories, moving them towards saturation; and concepts to concepts, where the theoretical coding begins to draw out the central theory (Evans, 2013; Glaser \& Holton, 2004).

It is through this process where the data was continually analysed and allowed for the concepts, categories, and theories to emerge. These were discussed and critiqued across several memos to further their development and validity.

\section{Identifying the Core Variable}

As the data was coded and concepts and categories were created and compared, the core variable began to emerge. This core variable was what began to explain most of the issues pertaining to the substantive area and the emergent relationships between other categories and concepts. Establishing the core variable required it to be central, that it relates to many of the categories and concepts, and was one of the primary explanations regarding variation (Glaser \& Holton, 2004). Once identified, the core variable is pushed towards saturation through further substantial coding and data collection (Evans, 2013). 


\subsubsection{Memo Writing}

Memo writing - or 'memoing' as it is often referred to - is a vital part of GT and is where the concepts and theories are generated and expanded (Glaser, 2013). It is a continual process that happens throughout the research. At its core, a memo, as defined by Holton (2008), is a "theoretical note about the data and the conceptual connections between categories".

A memo can range in size and scale. One might be a single paragraph while another might be a several page discussion. Memos allow the researcher to continually discuss and record their thoughts and reasoning when it occurs to them, rather than adhering to a schedule. It is through this process that the constant comparison of data and concepts occurs and is moved towards an overall theory during the theoretical coding (Glaser, 2013). They also slow down the analysis, forcing the researcher to reason and verify the concepts and categories through discussing aspects such as plausibility, as well as how they fit and how relevant they are to ensure that these concepts, categories, and theories are not prematurely determined (Glaser \& Holton, 2004).

As specified by Glaser and Holton, memos were written throughout the research process. No specific requirements for formatting or content for each memo were specified beyond including the memo number, title, date, and note of what data or other memos it may be related to, primarily to assist in comparing and linking memos in the theoretical coding process that follows. Memos ranged from a single paragraph to multiple pages of discussion, both of which often led to additional memos to further the analysis.

\subsubsection{Theoretical Coding}

The second phase of coding is theoretical coding. It began after the substantive coding as well as the memoing process where all of the memos were continually sorted through and compared, resulting in a single code. This theoretical code is the relationship that all of the different categories and concepts have with one another and how they relate to the core variable (Hernandez, 2009). This is the point where the data is integrated into an overall theory and hypothesis that explains the substantive area and the participant's main concerns (Glaser \& Holton, 2004). 


\subsection{Summary of Methodology}

In summary, a CGT study to investigate the effects of Green Star on decision making was designed. The different processes of CGT have been described in relation to carrying out and analysing a number of interviews with GSAPs. Sampling and ethical considerations have been addressed, as well as the interview design itself, focusing on gathering data pertaining to:

1. The effect of Green Star on design decisions made during a project;

2. The effect of variations during the construction process;

3. The effect of Green Star on the operation of rated buildings;

4. General experiences of the participant with both Green Star and sustainability.

The data is continually gathered and analysed, with concepts and categories being developed to explain the different effects that can be had by Green Star, forming the core of the findings presented in Chapter 5. Following this methodology, Chapter 4 describes how these concepts and categories emerged from the data and were developed as more were collected. 


\section{Chapter 4 - Theory Development}

A common concern with the CGT process is how trustworthy the results are when they emerge from the researcher's private memos and analysis rather than definitive or quantitative measures. This is especially true with those who are unfamiliar with GT methodology. As such, this chapter aims to provide some transparency by describing how the different concepts and categories - including the core variable and theoretical code were identified.

This is supplemented by some excerpts from memos to provide further insight into the development of abstracted theory and categories where appropriate. As these excerpts might illustrate, memos are often written relatively informally since they are usually kept private and not shared or included in formal academic publications, their focus being on furthering analysis and capturing ideas as they arise. They are presented in this chapter verbatim, only edited to provide clarification and context when necessary.

\subsection{Initial Codes and Concepts}

Once the data collection and analysis began, many of the initial codes identified in the early interviews focused on explaining what was happening in the data, how this related to the main concern of the participants, and how it was being resolved. Most codes represented either (a) an outcome or consequence of something happening, such as 'drawing a line in the sand' and 'not improving the sustainability'; or (b) created a cause or reason for something to occur or other decisions to be made, such as 'prescriptive design' and 'minimising risk'. Other codes were a combination of the two while others were general observations. 
Several concepts were created from these codes, many of which were in vivo and had yet to be fully abstracted. These codes and concepts were what formed the basis of the theoretical memos which are produced in GT to discuss, compare, and evaluate different concepts and incidents in the data, as described in the previous chapter. The following is an excerpt from an early memo which was analysing the codes relating to cost, budget, risk, and liability as an example of this development.

\section{Memo 10: Cost, Budget, and Liability}

It seems that this [referring to budget limitations] may affect the decision making process through imposing limits on the design options available - possibly just reducing them to the cheaper or easier options. Whichever ones are the least expensive or risky. This might not just apply to developers and clients either - designers and other team members or companies might personally avoid some of the risky credits so they don't have to deal with liability.

Additionally, the liability seemingly stifles the designs that are currently being done. People are unwilling to try different design options or be more experimental in what they do because of liability concerns on their part. Again, this is expected and reasonable - people are unwilling to do something (slightly) better or different as they risk being involved in lawsuits or anything else if something goes wrong.

This was one of the memos which led to the development of 'cost and budget' and 'risk and liability' as two of the initial categories. This was due to much of the data from the earlier interviews and analysis indicating restrictions and limitations from how the cost, budget, risk, and liability affected what could be done. The memo itself demonstrates how data are beginning to be abstracted beyond the specific incidents where they occur to become categories explaining these incidents and how they are managed or resolved.

Other categories which were developed from the different codes and concepts were 'uncertainty', 'points buying', and 'tool construction'. Like 'cost and budget' and 'risk and liability', these categories emerged from analysis and discussion across multiple memos to explain recurring processes and patterns, similar to what was presented in Memo 10. 
Table 5 presents these five initial categories, the codes which related to them, and the patterns in the data which formed the foundation for the category's emergence.

\begin{tabular}{|c|c|c|}
\hline Category Name & Related Codes & Patterns leading to category creation \\
\hline Tool Construction & $\begin{array}{l}\text { Prescriptive Design, } \\
\text { Compliance Model, } \\
\text { Pigeonholing, } \\
\text { Documentation, } \\
\text { Requirements, } \\
\text { Unintended Usage, } \\
\text { Using Green Star as a } \\
\text { Design Tool }\end{array}$ & $\begin{array}{l}\text { Much of the data relating to the } \\
\text { construction and requirements of Green } \\
\text { Star identified that a lot of the design is } \\
\text { being done around the prescriptive nature } \\
\text { of the tool. This was often contrasted } \\
\text { against more open tools, Living Building } \\
\text { Challenge in particular. Much of the data } \\
\text { indicated and referred to the different } \\
\text { limitations which prescriptive tools, like } \\
\text { Green Star, lead to which can affect design } \\
\text { choices. }\end{array}$ \\
\hline Points Buying & $\begin{array}{l}\text { Target Rating, } \\
\text { Low Hanging Fruit, } \\
\text { Design Framework, } \\
\text { Target Easy Credits, } \\
\text { Restricted Design }\end{array}$ & $\begin{array}{l}\text { Participants often talked about target } \\
\text { ratings and points that they achieve as well } \\
\text { as indicating that there are some that are } \\
\text { never targeted. Many projects set a rating } \\
\text { and what credits to achieve at the outset } \\
\text { and work towards those, occasionally not } \\
\text { looking at other solutions. }\end{array}$ \\
\hline Risk \& Liability & $\begin{array}{l}\text { Risk, Liability, } \\
\text { Minimising Risk, } \\
\text { Experience }\end{array}$ & $\begin{array}{l}\text { Several pieces of data linked to how risk } \\
\text { and liability can affect design decisions, } \\
\text { often in terms of restricting design to less } \\
\text { risky options. }\end{array}$ \\
\hline Uncertainty & $\begin{array}{l}\text { Grey Areas, } \\
\text { Uncertainty, } \\
\text { Interpretation }\end{array}$ & $\begin{array}{l}\text { Participants described a lack of clarity or } \\
\text { certainty in some aspects of work relating } \\
\text { to Green Star requirements. This led to } \\
\text { safer choices being made and occasionally } \\
\text { strange decisions when trying to minimise } \\
\text { the impact. }\end{array}$ \\
\hline Cost \& Budget & $\begin{array}{l}\text { Line in the Sand, Cost, } \\
\text { Effect of the Recession, } \\
\text { Government } \\
\text { involvement, time, } \\
\text { Payback, Credit Value, } \\
\text { Scope }\end{array}$ & $\begin{array}{l}\text { The increased cost was often described by } \\
\text { participants as limitations in design and } \\
\text { affects the extent that Green Star was } \\
\text { used. In situations where this cost is offset } \\
\text { or influenced somehow, such as } \\
\text { government funding, then Green Star was } \\
\text { integrated a lot more. }\end{array}$ \\
\hline
\end{tabular}

Table 5: $\quad$ Initial categories and how they emerged from the data 


\subsection{Category Development}

These five categories were not fully developed at this stage. While they represented patterns in the data, they provided limited insight into decision making processes and how they were affecting design decisions being made. As such, they formed the foundation of what was to be investigated further in the data collection and what the different concerns of the participants were, therefore becoming the primary driver behind the theoretical sampling. As mentioned in Section 3.3.3, the focus of the theoretical sampling was on what additional data was gathered as opposed to who it was from. Questions were added or adjusted in the interview guide to investigate these categories further. In particular questions regarding how uncertainty and risk is encountered and managed on projects were added. The final interview guide can be found in Appendix F.

As new data was gathered and analysed, the different categories changed as new insights began to emerge. Some categories moved towards theoretical saturation as similar incidents were found in new data while others changed as different insights emerged, adding and altering different concepts and categories. A fifth category, 'disconnection of knowledge', emerged from codes and incidents in newer data which was represented in previous interviews.

The first category, 'tool construction', initially focused on the more negative effects of Green Star. This was primarily due to much of the initial data from the interviews being critical in their evaluation of Green Star and how it is being used, often focusing on more negative aspects. As this category emerged from the data itself, it began to focus on the more negative aspects of the construction and requirements of the different tools rather than how the requirements of the tool were managed as a whole, creating a source of researcher bias. This bias was discussed in a memo once it was noticed to be affecting the analysis. 


\section{Memo 32: Bias in Tool Construction}

I think that I've identified a growing source of bias in relation to the category of tool construction. It seems that the bias is causing analysis to focus on more negative aspects of the tool's construction and outcomes rather than staying open to what the newer data is describing. This is apparent in how earlier data often discussed the use and construction of Green Star as something negative, especially in relation to its use as a design tool, while later data is beginning to view it differently. By not staying open I'm risking limiting the emergent results to one area of the category.

Once identified, this bias was addressed by ensuring that analysis of the data looked at relevant areas outside of the negative and critical discussion it began to focus on. As additional data was gathered this category focused less on the construction of the tool and more on how the construction and requirements of Green Star were managed. Different incidents across the interviews identified not just the effects which formed the categories, but began to indicate different ways in which these effects were managed and influenced decision making. Thus this became representative of a process seen to be undertaken by participants, as opposed to its early rendition as an influence, through abstraction of the initial category. This led to the development of the category 'managing Green Star requirements', which encompassed the primary concepts relating to the act of pigeonholing, the construction and use of the tools, documentation requirements, and misuse of the tool.

As analysis progressed, it became apparent that the category 'points buying' began to shift the focus of what was actually happening - determining which credits to achieve on a project - to the preconceptions regarding what 'points buying' entails. In order to remove preconceptions away from the category, the name of the category was shifted to the process of 'targeting credits'. Different factors of 'points buying' were still a significant aspect of this category, leading to 'points buying' becoming a sub-category due to its relation with both the overall category and its concepts.

As further data was gathered both from the interviews and literature regarding decision making processes, it became apparent that 'risk and liability' and 'uncertainty' were two 
different parts of a single category. This category, 'dealing with unknowns', emerged from the different ways in which participants mentioned how aspects like risk and uncertainty emerged in projects and how they were managed. The excerpt from Memo 68 presents the rationale for doing so after some debate across earlier ones regarding whether or not to merge the categories.

\section{Memo 68: Dealing with Unknowns}

I have decided to merge the categories of 'risk and liability' and 'uncertainty' into a newer category: 'dealing with unknowns'. This newer category encompasses the other two as concepts and is better able to represent how people manage constraints on projects which create unknown variables or outcomes, either as risk or uncertainty. This is especially important when tied into the article by Ward Edwards (1954) which explains the differences between risk and uncertainty in regards to decision making. In addition, liability can be separated as more of an outcome or secondary constraint influenced by the amount of uncertainty and risk present.

'Dealing with unknowns' emerged as the name of the category due to how the phrase 'dealing with' represents how unknowns were interacted with in decision making across the data. Unknowns were generally not ignorable thus they were dealt with in some manner, which varied between projects and people.

The category 'cost and budget' developed into 'project requirements' as additional data was collected. Initial data relating to different requirements determined by clients and developers often focused on how much something costs or what the budget allows for. Further data indicated that there were requirements other than cost which were affecting design decisions, in particular the building's purpose. The change to 'project requirements' was able to account for these different aspects of restrictions applied to what can be done on a project, something that was represented across much of the data.

While other categories emerged from the initial data, the final category 'disconnection of knowledge' emerged further on. Multiple incidents across the data were noted to indicate that different levels of knowledge and understanding of Green Star led to different 
occurrences, some of which affected decision making processes. These incidents primarily included people's experience and knowledge with Green Star affecting different deliverables or imposing constraints on what was included, primarily that of clients, developers, and other parties who might not have much knowledge of Green Star but can greatly influence requirements and outcomes. To further establish this as a category older data was investigated, revealing similar or related incidents. Some initial codes, such as 'scope' and 'experience with Green Star', were found to fit with this category better than others and were therefore included. This was pushed towards saturation through further interviews like the other categories.

\subsubsection{Developing the Core Variable}

The core variable, which explains most of the issues related to Green Star's effect on design decisions and the relationships between the different categories, emerged as additional data was gathered and analysed. This was the concept of 'constraints', which was a common occurrence across each of the categories which emerged early in the analysis. Participants often discussed how undertaking a Green Star rating on a project restricts what they feel able to do, with other incidents related to or indicating these restrictions occurring regularly in the data. As this was investigated and analysed through memos, six ways in which constraints were applied to a project were identified; these effects were direct and indirect, internal and external, and residual and intermittent. By being able to apply these effects to different pieces of data and to compare and relate the different categories through them, 'constraints' was identified as the core variable.

While much of the data could be related to constraints in some way, there was little representation as to how it was managed by participants. It developed similarly to other categories where its application was discussed across memos to investigate what it was that participants did when constraints were applied. 'Dealing with', 'adaptation', and 'assimilation' were the three processes that best represented this, with each processes represented different actions. 'Adaptation' was identified as best representing this process as participants were found to be more likely to adapt to meet the different constraints. This aligned best with incidents in the data compared to 'dealing with', which indicated a more 
passive approach to managing constraints, and 'assimilation', which implied surrendering to the constraints and working everything around them.

This was when the core variable was identified as 'adapting to constraints', signifying how constraints which emerged from the use of Green Star were managed by participants and how they might affect design decisions. The requirements given by Glaser and Holton (2004) for the core variable to be central to the data, relate to many of the categories, account for variation in a pattern of behaviour, and occur frequently in the data were found to be met. Constraints, and the process of adapting to them, emerged from common occurrences in the data and relationships between categories. Likewise the process of adapting to constraints was identified to best represent the variation in how design decisions were affected by Green Star.

\subsubsection{Reaching Theoretical Saturation}

Once the categories and the core variable were identified, further interviews focused on reaching theoretical saturation - the point where new data no longer offered additional insight or development. Each of the categories and the core variable emerged within the first six interviews through consistent representation across the data. After another four interviews, for a total of ten, theoretical saturation was felt to have been reached. While each of these interviews offered unique experiences and perspectives, coding of the data did not reveal any codes or common incidents that would form new categories. This was also experienced during some of the interviews where some information or experiences felt repeated or similar to that of prior interviews. This experience of reaching theoretical saturation was consistent with what was described in the literature (Breckenridge, 2014; Glaser \& Strauss, 1967).

\subsection{Developing the Theoretical Code}

The theoretical code was developed similarly to the core variable where it was identified after much of the analysis was complete. Going over, comparing, and linking the different memos, notes, and theories were key in its development. Potential theoretical codes and 
relations emerged from the data analysis as a way of linking the categories and core variable to the substantive area, exemplifying how everything relates to one another.

Based on the different coding families first described by Glaser (1978), the theoretical code focuses on the 'process' and 'strategy' families. The process family focuses on grouping sequencing stages while the strategy family contains different behaviours for interacting with something. The code identified was the adaptation process, which was determined to best represent integrated aspects of both families; adaptation presents a strategy while the process can model the relationship to the categories and core variable. Other families can also be represented by it, such as 'the six C's'. 


\section{Chapter 5 - Findings}

This chapter presents the core findings developed through analysis using CGT, as described in the previous chapter. The five categories which emerged cover different areas of concern and present the different patterns of behaviour related to the effects of Green Star on decision making. These categories are described in detail along with their primary concepts and what they entail. This is followed by a description of the core variable 'adapting to constraints' and how it relates to the different categories, decision making, and other outcomes through using Green Star. Finally, the theoretical code of the adaptation process is described through how it relates to the decision making process.

\section{$5.1 \quad$ Concepts and Categories}

Over the course of the data collection and analysis a number of concepts began to emerge, forming categories that represented patterns across the data and methods by which participants were managing Green Star on projects. Many of these categories originated as effects or causes apparent in the data, such as 'tool constriction' or 'risk and liability'. As the analysis progressed and additional data was collected, these categories were developed to provide better representation of the effects that Green Star was having on the decision making, as detailed in Chapter 4. This resulted in five different categories, each representing a different focus or aspect of the substantive area commonly represented in the data. These were 'managing Green Star requirements', 'credit targeting', 'disconnection of knowledge', 'working with unknowns', and 'balancing project requirements'. 


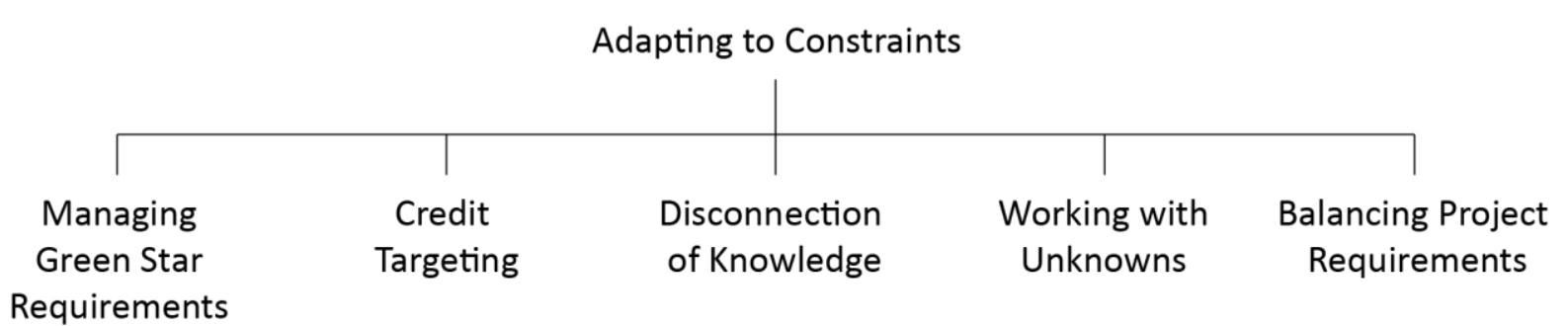

Figure 3: $\quad$ Categories of the core variable 'adapting to constraints'

All of these categories led to the identification of 'adapting to constraints' - or just the process of 'adaptation' - as the core variable. This represents most of the issues pertaining to the effect of Green Star on design decisions and the emergent relationships between other categories and concepts. As such, constraints and how they are adapted to were found to be the primary effect on the decision making processes, and each of the categories represents this differently. This is presented in Figure 3 along with the categories.

\subsection{Managing Green Star Requirements}

Each BSRT contains a number of requirements that have to be met in order to achieve certification. These include the number of credits being targeted, the requirements of each credit, and the final submission requirements. These and other such requirements of the tools place a number of different constraints upon a project that have to be managed in some way. When compared to the requirements of a project not working to achieve Green Star, the additional requirements of Green Star were found to be managed in a way in which getting certification was a priority, and design processes were adapted around that.

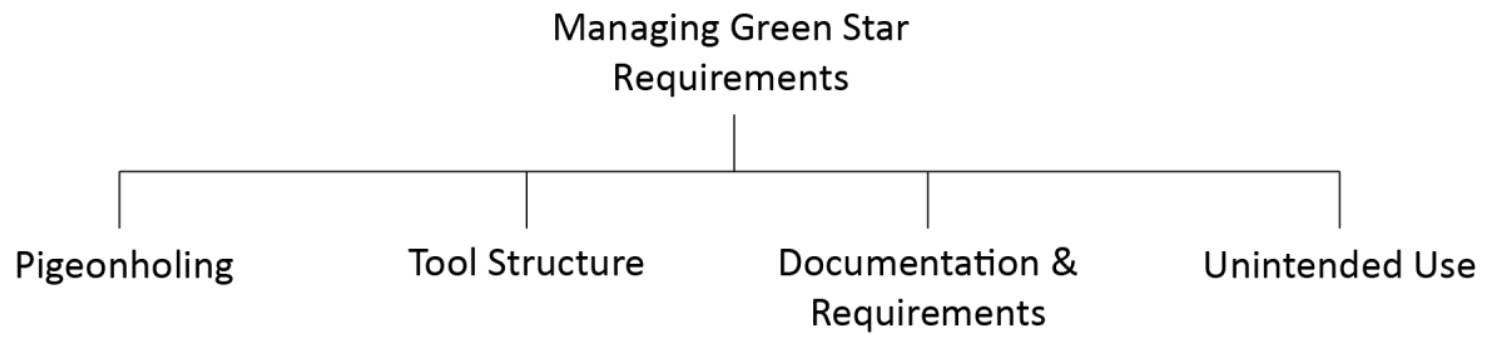

Figure 4: $\quad$ Concepts of 'managing Green Star requirements'

Managing different Green Star requirements is a continual process, not something which is carried out once and established at a single point in a project. Failing to provide proper 
management on projects can greatly impact the ability to achieve a rating, as many people doing the work will not fully know what is required outside of given specifications. These requirements are one of the primary factors which influence design processes and any related decision making, with the way they apply constraints dependent on the project, its aims, and the design team. Figure 4 presents the concepts that relate to how Green Star is managed, representing common processes and their outcomes.

The act of management best represents how people on a project control the different conditions applied by Green Star. Most of the management focuses on ensuring that all of the requirements of Green Star that are targeted are being met by the different parties involved. This is primarily done by the GSAP in charge of organising and compiling the submission, therefore making sure that any required actions are correctly carried out and the different requirements are met. The extent of the management would depend on how invested the project is in Green Star, as a six star rating would require considerably more management of requirements than a four star building might.

\subsubsection{Pigeonholing}

'Pigeonholing' was an outcome where decisions might be forced down specific routes due to restrictions from the requirements of Green Star. These specific routes would be those that are able to meet the requirements, helping ensure that any targeted points will be achieved. However by forcing decisions, such as what to include or how to include a particular solution, to focus on meeting these requirements, other options would often be ignored; not because they are not viable or applicable, but because they would be less likely to meet the requirements of the credit.

A common concern relating to 'pigeonholing' was how it impacted on the innovation of design solutions. This impact varies between projects and people, indicative of its dependence on the internal processes of design teams, variables on a project, and on client and developer views. In some cases this pigeonholing of the design to meet Green Star requirements would reduce the number of innovative options and solutions while in others it might not be an issue. While there might be a reduction in innovation on some projects, these projects might not be aiming for much innovative design. On the other hand, projects 
that are seeking higher ratings, particularly six stars, might incorporate more innovative solutions and adapt them to meet the requirements.

\subsubsection{Tool Structure}

A major factor in the use of different rating tools is whether or not it is a performance based tool or a design tool. Green Star, as with most other rating tools, is performance based. This means that it presents a set of objectives and requirements for each credit which must be met in order for it to be considered achieved. Design tools, however, are closer to a guide or set of instructions that direct the design in a certain way so as to achieve its aims. While they might appear similar, their usage and structure are very different. By focusing on performance, ratings can be met through various designs and applications which are assessed in a submission to prove compliance while design tools would check that each instruction was followed as required, being far stricter and guided.

While most of Green Star is used as a performance based tool, with projects establishing aims to achieve the different credit requirements, some aspects are used as if it were a design tool. This entails that rather than working to meet the requirements, some credits are used as a set of instructions about what to design. This limits design to focus strictly on what the credit requires and what solution earns the most points, potentially ignoring the requirements of the project and creating a solution which might not fit with or be appropriate to the project's requirements. This emerged as a process primarily from the requirements of the tools themselves. While the intent is for it to be performance based, sometimes a credit can be difficult to achieve due to uncertainty in its interpretation and intent, how it is assessed, or ambiguity in what is actually required. In these cases, it is less risky and easier to design a solution using it as if it were a design tool.

\subsubsection{Documentation \& Requirements}

'Documentation \& requirements' denote the different effects that Green Star's submission process and its requirements have on different processes and decisions. Each Green Star submission contains the documentation to prove compliance with a number of credits in order to achieve a rating. A commonly held view of this process is the complexity and ambiguity involved. Complexity arises from the strict requirements for each credit and 
ensuring that its aims have been proven. Ambiguity refers to certain parts of the requirements given by Green Star as being unclear in their intentions or difficult to understand.

Design processes are affected through these different documentation requirements in order to achieve certification. This often involves an additional layer of considerations and processes to be created which ensure that the requirements are met. Checking specifications, monitoring certain construction processes, and keeping certain receipts and signed forms are all examples of this. The complexity of the tool affects these further through how robust the processes need to be. Any ambiguity makes these processes more difficult since that adds uncertainty in whether or not something will be achieved even if the process is followed, simply due to interpretation. While uncertainty is a significant part of the category 'working with unknowns', it relates to this and several other categories and concepts due to the extent to which processes and decisions are affected.

The amount of documentation required is also a significant factor, something which is often regarded as one of the primary barriers when undertaking a Green Star rating. Combined with any complexity or ambiguity, it can affect design processes, monitoring, and decision making further by focusing them on solutions and processes to achieve a rating. As a result it can become an exercise of not just incorporating ESD solutions which fit into the intent of Green Star, but being able to prove that it has been done. This is one of the major factors relating to how being able to prove compliance could be viewed just as, and potentially more, important than the actual solution.

Recent years have seen the improvement in this since its inception in 2007. The addition of streamlining of certain credits of the design and built tools greatly reduced the amount of effort in following through with a built rating. Identical or similar credits just need confirmation from specific parties saying that it has been carried out in accordance with the design credit, rather than having to reprove compliance. The wording and structure of some parts of the tool has also been improved through feedback to the NZGBC, reducing the aforementioned tedium in proving compliance in certain areas plus understanding submission and credit requirements. However, many felt that while it was a significant 
improvement, there is still room for further clarification, particularly regarding specific definitions, in order to further reduce the amount of interpretation required.

\subsubsection{Unintended Use}

'Unintended use' is something that occurs on occasion as a specific way of managing requirements. It is not a common occurrence across multiple projects but represents a specific choice being made due to using Green Star. Different examples of this unintended use were often mentioned by participants in order to manage something. This seemed to be primarily because it is easier or cheaper to do so. An example of this unintentional use being the in-built calculator used to award points for rain water harvesting being used to calculate a tank size for maximum points rather than sizing according to the project requirements. The results of these decisions are generally that the outcomes are not properly applicable to the project, as they have been specified based on achieving points rather than designed for the project. These outcomes from the unintended use are also comparable to those emerging from the use of parts of Green Star as a design tool, which is itself an unintended use.

Another aspect of unintended use of Green Star is not a direct effect on design decisions from the tool, but its effect on the industry itself which, in turn, can affect decision making. An intention of BSRTs is to encourage ESD in projects and provide a method to quantify it. However, some aspects of the market have led to situations where the use of the tool produces unintended results which negatively affect the overall sustainability of the building while still meeting Green Star requirements. This is not a common occurrence, and occurs primarily with materials credits where the substitution to meet requirements is comparatively less environmentally friendly than the original material or similar alternatives. Substitution of materials for PVC is one example. This creates a conflict in choice where the overall ESD of the building is weighed against the requirements for the rating. 


\subsection{Credit Targeting}

'Credit targeting' represents the processes which occur on projects to establish a method of obtaining a rating, often through determining which credits to meet on a project and which to avoid. Like the category 'managing Green Star requirements', this is a significant process which occurs when using BSRTs through impacting related design decisions and solutions. The primary effect of this category is on what credits are achieved, thereby affecting the different design choices made about what to include and how to adjust it for Green Star.

The act of determining which credits to target emerged primarily as a result of the different constraints of Green Star, allowing those involved to better manage the requirements of the system. It quickly became apparent that projects that brought Green Star late into the design or development often found it difficult to adapt to the new requirements. In these cases aspects of the design had to be retrospectively changed and adjusted to fit with Green Star with great difficulty for those involved, rather than being a simple adjustment to provide documentation needed for the submission. Determining what credits to attain at the outset of the project makes it easier and less risky to achieve a rating than trying to retrospectively assess what had been done, and has essentially become common practice. Additionally it makes all members of the design team aware of these requirements and targets, making sure that people are aware of their responsibilities and what to achieve.

This establishes design frameworks in different ways, varying between projects and those involved. However, two main approaches to incorporating Green Star into the design to target credits were identified. These were through assessing which credits could be achieved based on early conceptualisation and planning, along with determining which credits can be added or otherwise included into the design.

The first approach presents a more open method for incorporating Green Star into the design, causing design decisions to focus on the design of the building before determining what credits to target. Once credits begin to be targeted, however, design can begin being restricted to meeting credits, especially if the initial design does not meet a targeted rating. The second approach can impact design decisions through a reduction in innovation, the creation of standardised solutions across projects, and begin to limit ESD to what achieves 
points. These approaches are not mutually exclusive and they can both be applied to projects to different degrees, as many participants described. It was common to see designs using the first approach to determine what could be met and then targeting any remaining credits using the second.

Additionally, as people get progressively more familiar with Green Star, often through being involved with multiple projects, they begin to understand more about the requirements and input for different credits. What credits are easier and which are harder, which ones require more documentation, which are cheaper or more expensive, and which are not applicable to certain projects, are all common examples. This has the potential to cause focus to shift from what to include on a project to figuring out how to manifest these credits in the overall design.

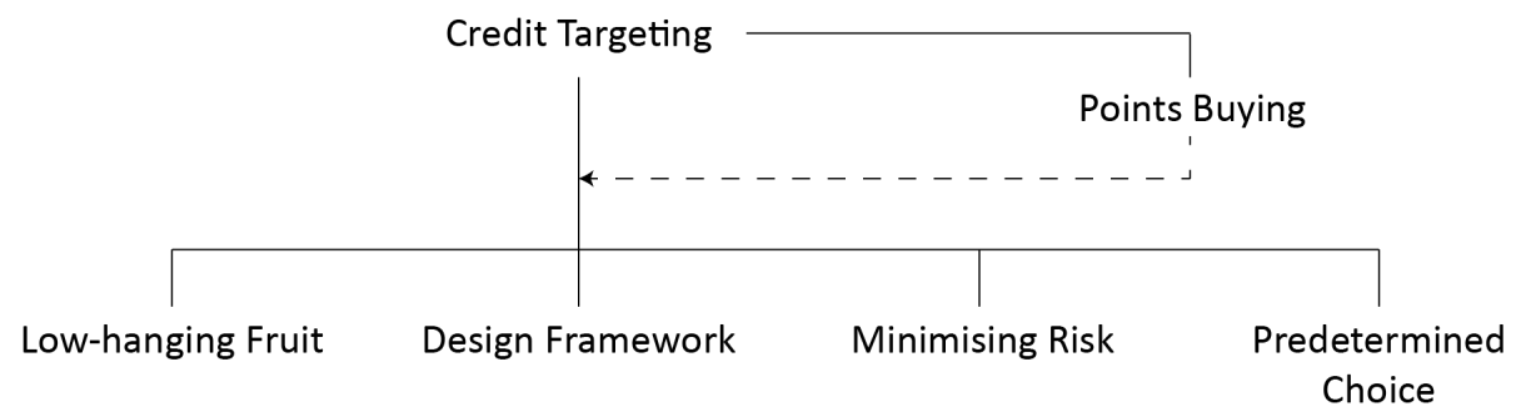

Figure 5: $\quad$ Sub-category and concepts of 'credit targeting'

Figure 5 shows the four core concepts which construct the category of 'credit targeting', expanding on the aspects which have already been described. This is also the only category to have a sub-category. This sub-category is 'points buying', which represents a significant aspect of targeting credits that is much more ingrained into the category than it would be as a concept. While 'credit targeting' represents the entire process of determining what to aim for to achieve a rating, 'points buying' refers to the act of strategically choosing points to achieve a rating rather than what might be determined through standard design. It represents a change in the focus of decision making from what might suit the project best to what would efficiently earn points. This has the result of restricting the design choices to ones that get more credits rather than those which might be best for the building. 


\subsubsection{Points Buying}

'Points buying' strongly correlates with the previous category relating to the structure and requirements of the Green Star rating tools. It is a term commonly associated with BSRTs regarding solutions being chosen by what points in a credit are available and how they can be met rather than identifying their appropriateness to the building. These are often those which are the cheapest or easiest, commonly referred to as low-hanging fruit, but can be done for as many of the credits as desired. The primary action involved in points buying was found to be the evaluation of what points are achievable and are worth achieving on a project. This entails a series of decisions which determine which solution is best and which aspects of Green Star to focus on, helping create the design framework. The extent to which obtaining points directs the design impacts how much 'points buying' occurs.

An outcome of both points buying and targeting credits is when solutions are proposed and pursued for Green Star credits rather than what might be best for the building. These are often required to meet requirements but might be of little value. This arises from decisions relating to the more efficient ways of gaining a rating, balancing the investment into the requirements of Green Star and the needs of the project, the developer, and the client. By focusing on the different points available, designers might also begin to constrain design to what achieves points and starting there, rather than approaching it holistically and looking at options outside of Green Star's scope.

Opinions regarding points buying and targeting credits at the outset of the project differed between the participants. Many were neutral or supportive, citing the difficulty and risk of deciding on a design and then retroactively applying it as reasons why both 'points buying' and 'credit targeting' occurs. Some stated that other BSRTs, often citing the Living Building Challenge, are more applicable to designs focusing on a holistic approach. A few participants, however, opposed these as going against the purpose of using a BSRT, instead supporting the incorporation of Green Star late into the design to assess what has been done and not be something to target directly. 


\subsubsection{Low-hanging Fruit}

Low-hanging fruit was a commonly used term regarding credits which are cheap or easy to achieve when compared to others. This was given in the context of developers, clients, and professionals potentially focusing primarily on these credits, avoiding the more difficult or expensive ones where possible, leading to those that might be more applicable or best for the building being ignored in lieu of others. Furthermore, this can also lead to credits being ignored because they are seen as too much work to document regardless of their cost or difficulty.

Participants also noted that over time this low-hanging fruit has almost become standard in most designs. This is due to growth in the construction industry, assisted by Green Star, moving these credits into standard practice for what a good building should be incorporating regardless of whether it is Green Star rated or not. Having some cheaper and easier credits in the tools was also considered important, one participant stating:

"To a certain extent you want to leave some easy points in Green Star so that it's not too hard. It's always got to be pushing the envelope a bit, especially to get five and six stars, but not every point has to be difficult."

While having these easy credits in the tool can cause people to focus on attaining those, achieving a rating, particularly one higher than four stars, cannot be accomplished with simple credits alone. Even if a four star rating can be achieved comparatively simply or easily, the intent is for a four star rating to represent "best practice" in New Zealand, rather than "New Zealand Excellence" or "World Leading" for five and six stars respectively (NZGBC). As such, achieving a four star rating from mostly cheap and easy credits can produce a building that would be considered "best practice", while these credits form the foundation for higher ratings.

\subsubsection{Design Framework}

The design framework is what is established through the process of targeting credits. It is this framework that presents the different requirements that have to be met in order to gain the targeted rating as well as what is expected of the different members of the design 
teams. The actual structure of the framework varies between projects as it is approached differently by different GSAPs or companies. This is the primary link between this category and 'managing Green Star requirements', as this framework can represent an intermediary between determining what credits will be met and how the requirements are achieved.

This framework influences design decisions by establishing a baseline of what has to be met. Once established, the different credits to be met have been decided and the actual design to achieve the credits is left to the respective parties to carry out. This is where different restrictions on the design emerge as the requirements are adhered to. Ultimately it does not matter what is done provided that it complies, and proves compliance, with the credit. Therefore the restrictions will depend primarily on what can be done within the scope of the credit. Decision making therefore focuses on determining the different solutions and then how solutions have met requirements. How this is done will depend on the individuals involved and the project requirements, but will generally be constrained to Green Star's conditions and requirements.

\subsubsection{Minimising Risk}

One of the primary reasons to establish a design framework early on in the project is to minimise risk, in particular the risk of not achieving credits or a rating. As mentioned earlier in this category, participants often mentioned the importance of bringing Green Star into the design and deciding on what to achieve early in the project to ensure that requirements will be met; trying to fit work into the assessment requirements after it has been developed becomes increasingly difficult. A significant outcome in minimising risk is the decision to aim for extra credits over the target to act as a contingency. Even when credits are targeted early, there is still the risk that any of them can drop out during the design, the construction, or not be awarded in the assessment. This has produced a commonality that most projects now aim for additional credits since it is almost guaranteed that some will not be achieved due to various reasons.

\subsubsection{Predetermined Choice}

'Predetermined choice' is the act of avoiding most or all of the decision making involved for a particular choice or set of choices. Different situations described across the interviews 
revealed that some solutions or processes, often when deciding which credits to target, were narrowed down to a single option and made without much consideration for other alternatives, essentially eliminating any conflict of choice. In some cases this came from the establishment of continual patterns and processes that carry on from project to project where certain options have been defaulted to a specific solution.

Examples of this were found in standardised frameworks that are applied to projects or learning which credits are simple or cheap to achieve through experience. In others this refers to what was originally a set of choices being restricted to a single option from other constraints applied, also removing or otherwise minimizing any decision making. This was common for material choices at the outset of Green Star where certain credits only had one or very few options available, such as FSC certified timber and low-VOC materials. It is also currently present where some credits have become so commonplace that achieving them happens without much additional design or choices being applied, such as including lowfrequency ballasts, recycling construction waste, and low-ODP refrigerants.

\subsection{Disconnection of Knowledge}

'Disconnection of knowledge' represents how much different members involved in a rated project know about Green Star, its requirements, and what to expect when targeting a rating. In most incidents it is the GSAP who holds the most understanding of Green Star processes who assists and informs other team members, such as through specifying requirements or providing information as needed. The term 'disconnection' thus refers to how much particular parties might lack in their understanding and experience, with parties being further disconnected the less they understand. This disconnection can be seen to be what leads to different uptakes and involvements during a project.

Different members of the design team, including clients, developers, architects, and engineers, each have different levels of knowledge about Green Star. This varies greatly across projects and incidents in the data making it difficult to standardise. In many cases, however, clients and developers generally have less knowledge of Green Star, though this grows over time based on their involvement and interest. Architects and engineers generally have a better understanding of what Green Star is, although this is often only a base 
understanding unless their work, interests, or experiences lead them to learn more. Most builders were described to have little to no knowledge, however in projects seeking a built rating an onsite GSAP with sufficient knowledge manages the different processes occurring to ensure that they are being carried out in accordance with the built rating requirements. Changes made by different parties lead to a cause and effect situation, where disconnected knowledge can cause something which then affects most of the design team.

Restrictions emerge through this variance in knowledge, often in relation to how much key decision makers like clients and developers understand. Generally the primary GSAP was seen to act as intermediary here, informing them and assisting in creating goals and deliverables along with the design team. Even when being informed, these key decision makers can create requirements or objectives that cause restrictions on what the design team has to work to that might not exist should they hold further knowledge and experiences. Other members like architects and engineers can also apply constraints that have to be worked around which emerge from their respective knowledge.

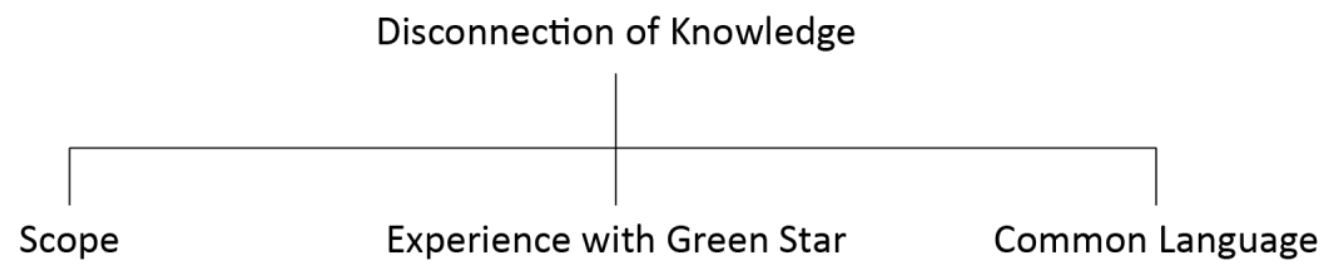

Figure 6: $\quad$ Concepts of 'disconnection of knowledge'

Overall, varying knowledge can impose on the scope of what is achievable and make it easier or more difficult. In addition this category affects decision making through the various effects of this understanding on other categories and concepts. Figure 6 illustrates the concepts of 'scope', 'experience with Green Star', and 'common language' in relation to this category.

\subsubsection{Scope}

'Scope' as a concept represents the range of different solutions designed for in a project. In particular it represents what is required in order for the established scope to be achieved within the project aims. The relation of scope to this category is due to how it can be 
narrowed and constrained based on the knowledge that is held by the different members of the design team - key decision makers in particular. Green Star itself already provides constraints on the scope of the project and thus the understanding of it plays a large factor in how the scope if formed.

Key decision makers who have an understanding of Green Star processes and requirements were less likely to narrow the scope based on preconceptions. This is particularly true of those who look to push towards higher rated projects. Those with a lower level of knowledge or lack of experience with Green Star generally constrain or otherwise impact the scope, narrowing design options available to achieve the requirements. There is also the middle ground where key decision makers do not possess deep knowledge but are interested in a higher rating, requiring time to understand the required processes but not constraining the scope as much through their decisions. As such, the scope can be seen to be affected in combination of the project requirements, decision maker and design team knowledge, and the goals and interest of the client and developers.

\subsubsection{Experience with Green Star}

Experience with Green Star is one of the major factors relating to how different parties involved are affected by or create different requirements and constraints on a project, in turn affecting design decisions. The experience of those on the design team as well as the key decision makers was noted to be the most impactful and varying throughout the design phase. The more disconnected that a member is, the more they can impact design decisions through how much is required to learn or be accounted for. This extends to contractors and builders within the construction phase of a project, where it is generally accepted that there will be variations made during construction due to the lack of understanding many have of the strict requirements of Green Star.

\subsubsection{Common Language}

The emergence of a common language since Green Star's release has reduced the impact of this category on projects. This represents the expectations and knowledge that is now commonly understood within the industry. Some requirements and deliverables of Green Star are a part of this common language which has made the process of undertaking a rated 
project easier and more manageable. As the common language continues to grow, decision makers and design teams will inherently know more about what is required, reducing the constraints caused by an individual's knowledge on the decisions making processes involved.

\subsection{Working with Unknowns}

'Working with unknowns' represents how the unknowns which constitute risk and uncertainty can impact decision making. Risk and uncertainty are part of every project and are not unique to using Green Star. They also emerge from using Green Star due to the additional processes it entails. These unknowns can appear from any number of sources ranging from people's understanding of Green Star and their usage of it to the understanding and interpretation of the different requirements. Unknowns are a constant variable throughout the process and can therefore be seen to interact with most, if not all, of the other categories and credits in some manner. The primary concepts of this category are presented in Figure 7.

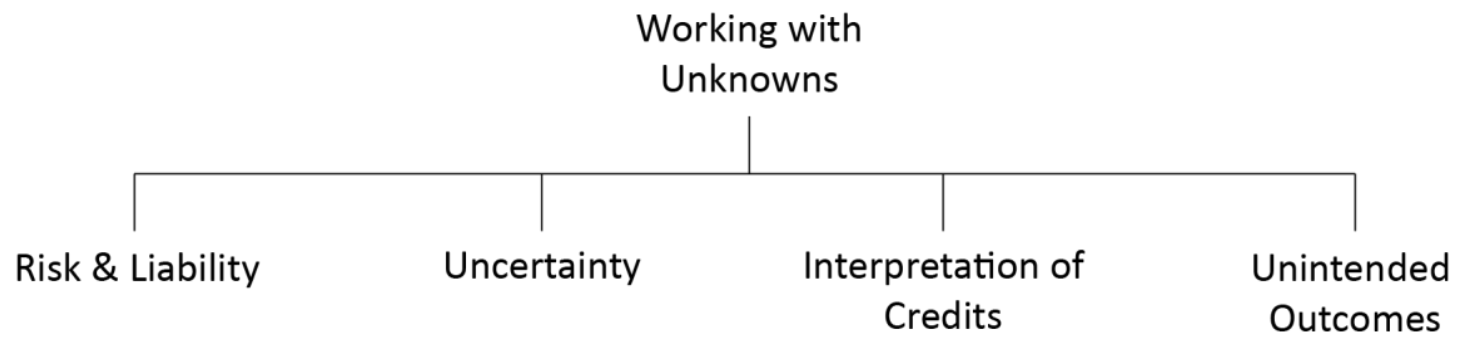

Figure 7: $\quad$ Concepts of 'working with unknowns'

Risk and uncertainty are both different decision making considerations when working with outcomes that are neither predictable nor certain. These are both representative of how unknowns emerge in projects and are each managed in different ways. Unknowns have an overall effect on decision making processes through the requirement of decision makers to account for these factors, creating a series of decisions and processes which can work through these variables. This can cause focus to be moved away from certain areas or even avoided entirely, favouring those which are generally safer and confirmable. The scale of unknowns can vary as well with the impact of the unknown being a major part of its consideration. As decision making processes revolve around ascertaining complete 
information, the effect that unknown variables can have is therefore a major factor to be considered.

Green Star creates a variety of unknowns that are unique to its inclusion, primarily in regards to how the requirements are interpreted and incorporated into design processes. The phrase 'working with' was used as it incorporates a variety of processes that will vary between projects and teams. As unknowns cannot be left alone on projects they were noted to be worked around in some way. This can be through minimisation of the risk and impact, whether they are avoided entirely, or being dealt with or managed in some way. In many cases this involves the identification of an ideal outcome which is then worked towards.

\subsubsection{Risk \& Liability}

'Risk \& liability' refers to the impact of unknowns through what can happen when they are present. Risk is managed in design decisions primarily through determining what the best outcome with the least amount of risk is. If no best outcome is available, or the best outcome is still considered too risky, then usually the least risky option is decided upon. This is something that can lead towards unintended outcomes in relation to Green Star, described in a later concept. Participants were noted to have a very low risk propensity, meaning that they are highly unlikely to decide on outcomes with high risk, something which is common throughout the industry. This low risk propensity means that many of the choices made on projects, such as ESD solutions, often do not push for much innovation or alternate solutions due to the risk involved. Likewise, this ties into points buying as determining what credits to target early on reduces the risk in not achieving them later.

\subsubsection{Uncertainty}

Uncertainty occurs similarly to risk where decisions are made in situations where something is not certain. This generally falls into whether something will happen and the outcome is neither certain nor impossible, but is not quite as quantifiable as risk (Edwards, 1954). Like risk, uncertainty affects decision making through choices being determined by what has more complete information and constitutes the ideal outcome. Participants were noted to seek as much information as possible. Given the low risk propensity of not just the participants but much of the industry, information gathering to create an informed decision 
is therefore a major part of design decisions. Naturally, key decision makers are unlikely to agree to solutions which might not achieve their aims, which is Green Star in this case.

In many cases the most common uncertainty was in regards to whether or not a credit would be achieved. While many cite the interpretation and wording of credits - as described in the following section - there is also the uncertainty that the submission is correct or the design will remain unchanged. Due to high uncertainty that all targeted credits will be met, participants state that it is almost guaranteed for at least one credit to fall through. These effects on design decisions are one of the primary reasons why projects include additional credits which act as a contingency. Designing these contingencies in, while good for the building's ESD, cost the developers extra and does not provide a benefit to the Green Star rating outside of providing contingency.

\subsubsection{Interpretation of Credits}

Credit interpretation is a significant factor relating to this category as well as Green Star requirements, risk, and uncertainty. This concept refers to how the requirements for each credit are understood by different individuals, something which emerged from participant's processes for using Green Star. The description of the credit in the manual, which includes its aim, objectives, and requirements, can be vague or otherwise difficult to understand, with one participant stating that:

"One of the risk areas is the actual interpretation of the manual. And I think that's fairly similar for all fields of development. Risk sits around unknowns and when there are unclear regulations, or you don't know how regulations are going to shift and affect you, that stops development."

In cases where some credits are difficult to understand this leads to a subjective interpretation by the user, such as an engineer, the client, or the lead GSAP. This subjective interpretation leads to uncertainties in the project and requires additional work to ensure that the credit is being achieved.

This subjectivity extends over to the assessment as well, where credit assessment can also be subjective based on the views of the assessor. This further leads to uncertainty regarding 
whether or not credits will be achieved. One participant noted that addressing the same credit over two different projects with almost the exact same solution and documentation yielded one project achieving the credit and the other failing to achieve it. Another described that assessors can end up focusing on a small part of the submission to be changed before the credit is awarded, when that change has little to no bearing on the actual performance or sustainability of the building, creating further time and cost investments to amend.

Ultimately this affects design decisions similarly to how uncertainty does. Subjective interpretation of some credits opens up uncertainty as to whether a credit will be achieved or not, as it is uncertain whether the requirements are being met. Resolving this requires additional consideration during the design to minimise any risk and uncertainty. Furthermore, making decisions based on more subjective interpretation causes added information and clarifications to be sought before decisions are made.

\subsubsection{Unintended Outcomes}

A common finding in the data was that outcomes made to counteract risk or uncertainty are not necessarily always best for the project, but are done to be most likely to achieve the related Green Star requirements, occasionally leading to unusual outcomes. These unintended outcomes emerge as a result of risk and uncertainty, where a decision was made that by minimising the risk and achieving a credit was more beneficial than not achieving a credit but having a more sensible design. In most cases these solutions would be considered less sustainable when included but more likely to meet the requirements.

\subsection{Balancing Project Requirements}

This category relates to the requirements, aims, and objectives of a project and how they are managed in relation to the goals of Green Star. The impacts of the project requirements on decision making are a given; they have to be met and therefore are designed to. It is how the project requirements interact with the requirements of Green Star that is relevant to this category. 
Project requirements consist of a variety of factors, including its intended usage, site location, available capital, intentions, and timeline for completion. These requirements are managed throughout the design where the additional requirements of Green Star are integrated into this process. The primary impact on decision making occurs from the additional factors to be managed, in particular when these additional factors begin to conflict with the project requirements. The primary process that occurs is the balance and evaluation of both the project and Green Star requirements. Conditions and restrictions emerge from this balancing and evaluation process. This is most noticeable and impactful when conflict occurs between them, resulting in decisions being made which address this balance. The overall effect on decision making therefore is the conditions and restrictions applied by this balancing process, where the ideal outcome is determined and adjusted for.

Balancing Project Requirements

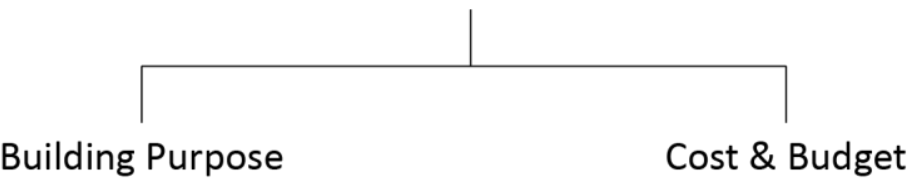

Figure 8: $\quad$ Concepts of 'balancing project requirements'

Figure 8 presents the two main concepts related to this category, which are the building's purpose and considerations relating to the cost and budget. These two represent a major part of the balancing act described and are significant factors affected by the incorporation of Green Star.

\subsubsection{Building Purpose}

Considering and designing to the building's purpose is an important factor when utilising Green Star. The reason for this is that the purpose of the building and its unique requirements can conflict with Green Star or otherwise make it difficult to achieve certain credits. This creates a conflict of choice where either the Green Star target had to be adjusted, such as through avoiding a credit, or the building purpose had to be compromised in some manner.

The effects of the building's purpose are more noticeable on projects which have very specific requirements for certain aspects. This was commonly noted by those who worked 
on industrial buildings, which have specific requirements for materials relative to their usage, or on other buildings which might require additional consideration for climate control or light access in certain spaces. Decisions then correlate to the aforementioned conflict of choice, where the effects on the Green Star rating and the building's purpose are weighed. In some cases projects avoided or abandoned designing to Green Star due to significant conflict, deciding that a Green Star rating was not worth compromising the building's usage and purpose.

\subsubsection{Cost \& Budget}

The cost and budget is one of the core considerations and restrictions on any project, and is even more so in those seeking a formal Green Star rating. Many participants cite the cost of doing Green Star as a restriction and have to adapt their design around the limitations of the budget and what the client or developer is willing to spend money on. The initial outcomes from this relate to the target rating and the credits aimed for. In many cases the cheaper credits and solutions are prioritised with higher rated projects and those seeking innovation points having the budget to adopt more costly solutions. The effect of the budget on design decisions is therefore quite significant, with designers needing to work to cost restrictions while still meeting the aims of both the project and Green Star. This has the impact of limiting design solutions to those that fit with these restrictions and focusing on the cheaper to achieve credits.

One process of note described by multiple participants is the decision on some projects to design to a Green Star standard but not pursue a formal rating. This process can be seen to evolve from the ESD requirements of the project, and potentially relate to restrictions applied by the budget. In cases like this it is a decision made by a key decision maker, either the client or the developer, which shows an interest in sustainable design but a lack of commitment in getting a formal rating. These cases were described to illustrate the credibility and robustness of the formal rating process, which ensures that the designed ESD solutions are included and constructed. Projects which do not get the formal rating lose this creditability and robustness, making it easier for the requirements of Green Star and the ESD targets of the project to fall out for various reasons. Green Star is thus shown to present 
a quantifiable standard to design to but the cost, effort, and conditions involved in achieving a formal rating can outweigh its benefits.

\subsection{Adapting to Constraints}

'Adapting to constraints' was identified as the core variable due to its representation of issues and common concerns related to the substantive area and the different relationships between categories, as was presented in Figure 3, repeated below in Figure 9 for reference.

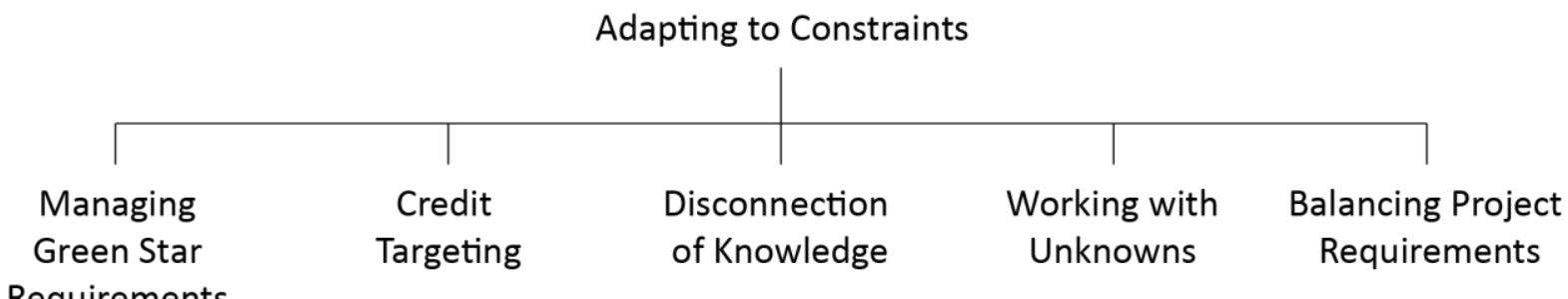

Figure 9: $\quad$ Categories of the core variable 'adapting to constraints' (repeat of Figure 3)

Participants often described restrictions and similar factors which constrain what they are able to do on projects. As such, constraints emerge from a variety of sources such as requirements, processes, and conditions. The effect of constraints themselves vary based on their source but share a common ground, which is what constructs this core variable. This is the reduction in options available for decision making due to what the sources are constraining design decisions to.

The main behaviour that was demonstrated through the data which represents this core variable was adaptation. Compared to other processes, such as 'managing' or 'dealing with', the process and term 'adaptation' demonstrates the variability that constraints affect the decision making process. In most cases participants did not let Green Star have complete control over everything, but rather altered existing processes to account for the different requirements. The openness of the adaptation process is represented by different solutions employed when facing constraints. Many describe working with the requirements of Green Star and deciding to adjust processes, targets, and solutions in relation to what is considered achievable. Some take on and integrate different conditions more heavily in a project while others avoid incorporating the conditions and restrictions into the actual 
design, and only adapting the project as necessary. This variability in approaches represents the diverse methods of adaptation adopted by different people, establishing the flexibility of the term. Each of the five categories can be seen to provide different examples of adapting to constraints which they might apply.

'Managing Green Star requirements' creates several constraints and conditions on a project which must be incorporated in order to achieve a Green Star rating. These requirements cause decisions to be made regarding the solutions to be incorporated. Adaptation occurs as design decisions focus on how to achieve these requirements successfully.

'Credit targeting' can be seen to be both a process of adapting to the requirements of Green Star and developing a source of constraints on a project to work to. The requirements of Green Star are so integral to the entire process that common practice has adapted to establish a set of target credits to be achieved, making the requirements easier to manage. They also create constraints through what credits are determined to be targeted or are targetable, requiring design teams to adapt to these constraints.

'Disconnection of knowledge' is a category which represents the constraints applied through the knowledge of various team members. This varying knowledge can affect decision making processes through less available information, constraining different outcomes and design decisions. Adaptation occurs when addressing disconnection of knowledge, where the constraints applied require additional knowledge and information to be sought by decision makers. Alternatively the project design can be adapted to fit within the applied constraints.

'Working with unknowns' inherently leads to constraints on projects. Various unknowns manifesting through risk and uncertainty can be significant sources of constraints on projects. Processes of adaptation occur through working with these unknowns, seeking additional information and minimising their impact throughout a project.

Similar to 'managing Green Star requirements', the balancing of project requirements creates constraints due to certain conditions or requirements of the project reducing options available. Decisions and processes are required to adapt to these requirements. 
The overall impact on decision making and design decisions is the reduction in options available and the resulting impact on the conflict of choice. Much of the design process is managed in more depth through the introduction of Green Star's requirements and the different conditions and restrictions this implies. Through these restrictions a myriad of different outcomes and processes occur which affect the final product. The adaptation of the processes and decision making is a constant factor, and is often managed by the primary project GSAP handling the submission and Green Star requirements, as well as others who are knowledgeable in this area.

\subsection{Theoretical Code}

Through the analysis of the different concepts, categories, and the core variable, the theoretical code identified was simply the adaptation process, demonstrating how the overall decision making process is influenced by Green Star. This incorporates the varying strategies employed to manage the different variables creating constraints, and the stages that constraints apply to during a decision making process. In regards to the examples of theoretical coding families detailed by Glaser (1978), this theoretical code incorporates aspects of both the 'process' and 'strategy' families. Additionally the different constraints can be treated as a covariance, part of 'the six C's' family, due to the number of variables which create it but affect the process differently and at different stages.

\section{Cause $\longrightarrow$ Decision Making $\longrightarrow$ Outcome}

Figure 10: $\quad$ Simple cause and effect decision making process

Figure 10 presents a simple cause and effect process, illustrating its three core stages. In this process the cause is what leads to the occurrence of decision making. This can be due to a variety of constraints and requirements that need to be addressed or an intermittent occurrence during a project. Decision making is a complex process which includes searching for information and determining an ideal outcome. This results in a number of outcomes and consequences which are then applied or can also lead to another decision making process to occur, potentially linking back as a cause. 
While each stage contains various processes, outcomes, and methods, it is the overall relation of the process that is of importance. The additional application of Green Star can influence different aspects of this process in a number of different ways. In most cases these requirements and conditions create constraints, which lead to adaptation. Figure 11 presents this as an impact which can occur on any number of the three stages.

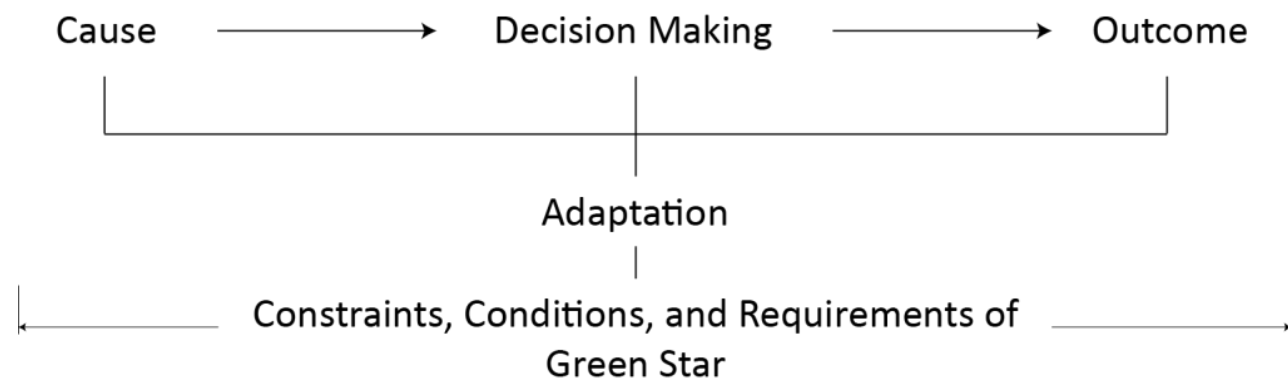

Figure 11: Application of Green Star to the decision making process

This shows that the constraints, conditions, and requirements of Green Star are a constant effect throughout the process. In this case, Green Star is the context in which the entire process takes place, and its influence can be on one part of the process or the entire process. Specific and direct effects of Green Star occur primarily as constraints, and are managed through adaptation. This is important as the adaptation process undertaken varies considerably between individuals, though remains the core strategy which occurs throughout this cause and effect process. 


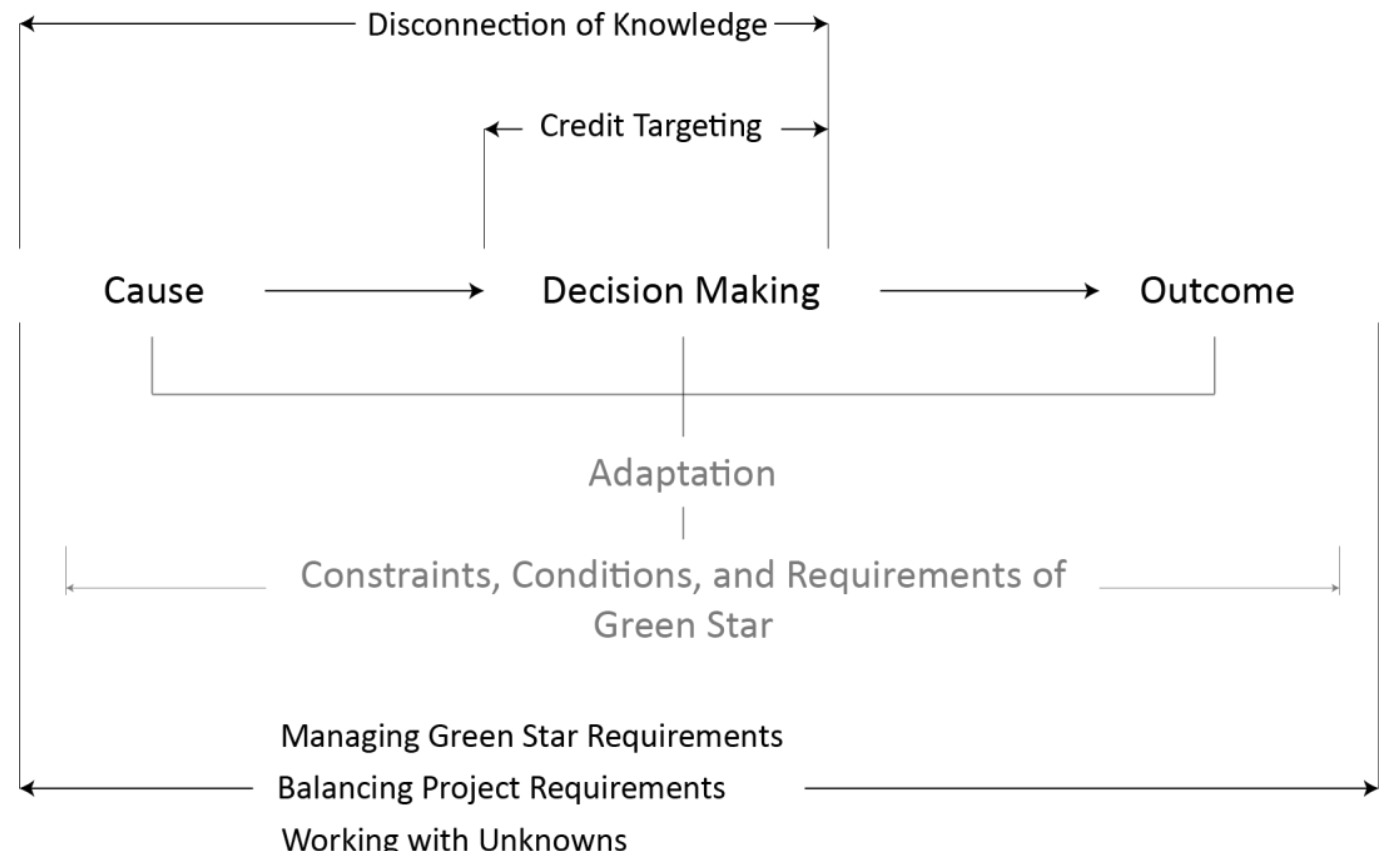

Figure 12: Application of categories to the decision making process

The different applications of the five categories on the cause and effect process are illustrated above in Figure 12. 'Managing Green Star requirements', 'balancing project requirements', and 'working with unknowns' are present throughout the entire process. They can occur from and affect the cause, the decision making process, and the decided outcome. 'Disconnection of knowledge' is primarily present during the cause and the decision making stages and holds little bearing on any outcomes or consequences. 'Credit targeting' is focused on the decision making stage where it is a unique process that emerged to adapt to the constraints and conditions of Green Star.

Overall, adaptation is the primary process which occurs predominantly due to the constraints of Green Star, but also the conditions and requirements of its integration into a project. Figure 11 shows that it is a key link between the decision making process and the effects of Green Star. However it is not present in each stage of the process each time the process occurs; it simply illustrates the overall process which does occur throughout a project, and across numerous decisions. Figure 12 illustrates this through the different categories, where each affects a number of the different stages, though they all affect the core decision making. 


\subsection{Summary of Findings}

This chapter has presented the abstracted theory developed from the interview data, investigating the effects of Green Star on design decisions. The five categories which emerged from the analysis detail commonly represented effects which were present across the data. The effect they each have differs, but ultimately they affect design decisions through the application of various constraints which emerge from a number of sources something which is discussed in Section 6.1 of the following chapter.

The core variable of 'adapting to constraints' integrates the different categories to present how they were dealt with in the data. The adaptation process emerged as the theoretical code later on, and reconstructs the categories and core variable by illustrating how they impact a simple decision making process. 


\section{Chapter 6 - Discussion}

This chapter presents a critical discussion of the findings in relation to the sources of constraints, existing literature, and the applicability of the findings to other BSRTs, such as those investigated in Chapter 2. The use of CGT is also discussed in relation to other qualitative research methods, interview guide design, and its usage within building science.

\subsection{Sources of Constraints}

The effect of Green Star on decision making processes occurs through decisions either being impacted by the effect on different outcomes available, or by being initiated due to added constraints. As an example of the former, one decision could be regarding material choice or the lighting in a room. As these are related to the requirements of Green Star, the decision making process becomes a research and evaluation of different options until an ideal outcome is determined and the final decision made. The latter occurs less and represents constraints that emerged from the use of Green Star which causes decision making processes to occur. This can be to manage the constraint or otherwise deal with something related to Green Star that occurs during a project.

This exemplifies how Green Star influences the decision making process and represents one of six sources of constraints. The above represents a direct effect, where a requirement or other part of Green Star creates a constraint on something or otherwise affects a decision or process. This section describes these sources of constraints and how they affect a project. These sources are direct and indirect, internal and external, and residual and intermittent, which can be seen to form three groups. The respective two sources in each group generally oppose one another in ways that will be represented in what follows. This means that each constraint can have a combination of these sources, such as being external and residual. 


\subsubsection{Direct \& Indirect}

As stated, a direct effect represents a constraint caused by a requirement or any other aspect of the Green Star system or tool. This is opposed by indirect effects which occur due to Green Star's requirements, but create constraints that are not caused directly from the tool requirements or similar. Direct and indirect effects are the major sources of constraints which occur due to the use of Green Star and, unlike the other four sources, generally only occur when using Green Star.

Direct and indirect constraints are represented in many of the categories detailed in the findings. 'Managing Green Star requirements' is most obvious, as the different effects of the requirements can be determined to originate as one of these. Design decisions are impacted through having to incorporate the requirements of Green Star into the design, reducing and therefore constraining the available solutions. Choosing compliant materials is another example of a direct effect, where the decisions are directly constrained by the requirements of the respective credit. As stated, indirect decisions emerge through the requirements of Green Star but are not strictly caused by these decisions. They instead can be caused by other processes which are created to adapt to the requirements of Green Star.

The category of 'credit targeting' provides a good example of this whereby the strict requirements of Green Star causes an entire set of design processes to emerge. Credit targeting processes can cause constraints not through implying strict requirements, but though influencing how the design process occurs. This affects decision making differently as design decisions are influenced by processes of adapting to the requirements of Green Star.

\subsubsection{Internal \& External}

Internal and external constraints are focused on processes and conditions applied internally by the design team or might be applied externally. Internal constraints emerge from processes such as a standardised team structure or how information is communicated between members. Other constraints can be goals or requirements of a member, such as the client or the architect who can also create constraints within the design team should the goals affect or be affected by Green Star. External constraints emerge from occurrences 
outside of the design team's control. An example of this can be seen in participants describing the effect that the recession has had on the construction industry, or the inability to source certain materials due to the lack of a supply chain, something which was common with FSC timber when Green Star launched.

Internal constraints were found to emerge in regards to 'balancing project requirements' and 'disconnection of knowledge'; two categories which can represent processes and decisions created internally by the design team which can heavily influence design decisions. The internal constraints are some of the most controllable as they are processes being set up deliberately and with intent. As such these processes can be adapted to fit any external or other conditions, though the amount that different members adapt will vary.

However, the category best representing external constraints would be 'working with unknowns'. In contrast to the more controllable internal processes and decisions, external decisions can be categorised due to their lack of control by the design team, representing additional constraints and risks that have to be accounted for. Referring to the example given earlier, the design team has little control over the economy or supply chains in place. Aside from the reduction in options which some external effects apply, the creation of risk or uncertainty from other uncontrollable factors can heavily influence decision making processes.

\subsubsection{Residual \& Intermittent}

Residual and intermittent effects are those which relate to temporality. A residual effect is something which occurred in the past, generally on a prior project, and its influence is carried over to a subsequent project. Examples of this in the data are the different processes and solutions participants describe doing on one project and applying it to the next. Intermittent effects, however, are those which occur spontaneously on a project and can create constraints or other issues. Commonly described were changes to either the scope or the design, constraining project options as they occur.

The category 'disconnection of knowledge' strongly correlates to the temporality of the residual and intermittent effects. Previous experiences, whether from Green Star projects or 
other relevant incidents, shape knowledge and opinions which can impact decision making. These can cause constraints if they work against the project or if knowledge held is not entirely correct. They can also reduce constraints if the residual knowledge and opinions of Green Star are helpful to the project, and do not conflict with the processes involved. The constraints created by intermittent effects will also depend on the amount of knowledge possessed by individuals. This primarily depends on their ability to quickly adapt to any constraints and effects applied, particularly those which might negatively impact a project. The impact of residual and intermittent effects therefore depends primarily on the knowledge and experience of the different parties involved and their ability to adapt as constraints occur.

\subsection{Relation to Existing Literature}

While the available literature pertaining to the effects of BSRTs on design decisions is limited, the findings presented in the previous chapter are discussed in the context of what was available as well as any general issues related to BSRTs. The context of this discussion is primarily the findings from the literature review.

\subsubsection{Decision Making}

As identified in Section 2.7 of the literature review, the existing field of research regarding the effects BSRTs can have on decision making is rather limited, narrowing opportunities for extensive discussion. This lack of research and its importance is acknowledged in a number of sources, however little exploration could be due to uncertainty in how to approach this research area and a lack of previous information or industry interest. The research by Schweber and Haroglu (2014) was found to be the only research focused on investigating the effects of a BSRT on design decisions.

The methodology used in this research differs from the approach employed by Schweber and Haroglu (2014) who utilised interview case studies to collect the experiences of different design team members relative to specific projects. Analysis of their collected data identified different levels of 'fit', presenting the variance of BREEAM's usage and effects across projects. The use of CGT in this research investigates the wider effects, though doing 
so meant forgoing a more focused assessment. In any case, both this and Schweber and Haroglu's research can exemplify that the actual effect of BSRTs on design decisions to vary based on the specifics of a project.

While Schweber and Haroglu identified specific levels of fit on a BREEAM project, this research identified a more macro level of management by participants through adaptation. It is likely that their findings are applicable to projects using Green Star due to similarities between both BSRTs. Likewise, findings from this research could be applied to aspects of their findings. In particular the requirements and structure of the BSRT used can impact on the scope of the design, as can varying levels of knowledge and understanding of the process. Since BREEAM is significantly older and more widely used than Green Star, the actual usage and understanding will differ, though by how much is unknown. The applicability of this research's findings is discussed later in Section 6.4.

\subsubsection{Utilisation of BSRTs}

Commonly mentioned across the literature is the utilisation of BSRTs as design tools (Cole, 2005; Gibberd, 2014), though little has been explored in current research. The findings of this research has identified that the usage of Green Star as a design tool does occur, though it is an outcome that was developed to adapt to the requirements of the system and ensure a rating would be achieved. Use as a design tool is not a binary act. The core aspects of using Green Star as a design tool occur through the establishment of design frameworks, ensuring that credits will be met due to their strict requirements. It is possible that this process of establishing a design framework can be observed as strictly utilising the rating tool as a design tool. In fact, none of the participants described situations in which Green Star was being used solely as a design tool; countering part of the claims of some research.

Part of the findings presented by Schweber and Haroglu (2014) echo this mixed usage. They describe that professionals with more commitment, knowledge, and experience looking to develop more sustainable buildings might move past the usage of BREEAM which, like many other BSRTs, holds stringent requirements to be met. This is contrasted with others who find the structure and guidance provided by such a BSRT as a more reliable method of creating a sustainable building. As they describe, this leads to the perception that projects 
utilising BSRTs integrate them more in the design. Several participants in this research reinforce this, stating that Green Star is not suitable for every project and the design requirements can hamper the ESD or the project's aim.

\subsubsection{Issues of BSRTs}

Some of the core issues of BSRTs identified in existing research include higher initial cost, knowledge of involved individuals, focus on achieving points, assessment, and unintended use as design tools. These constitute some of the core findings of the literature review and the findings from this research illustrate many of them.

In both the literature and the findings of this research, the increased cost of utilising a BSRT can reduce the willingness of clients and developers to undertake a formal rating (Gou et al., 2013; Liang, 2012). Working within the available budget can lead to key decision makers creating restrictions on what ESD and other solutions are achievable. Participants indicated that the extent that different cost barriers affect a project generally depends on the commitment by the developer and client, echoing existing literature.

As found in the literature review the actual effect of increased cost on deterring the use of BSRTs is diminishing (Wedding \& Crawford-Brown, 2007). Participants reinforce this though often state that cost and budget is still one of the main constraints on a project. Some describe projects opting to design to Green Star principles but not seek a formal rating, indicative that ESD is achievable and sought after but the increased cost and effort to achieve a rating is not considered beneficial.

The limited knowledge of individuals identified by Häkkinen and Belloni (2011) is reflected as an issue within the findings as well. They state that the ESD can be impacted by a lack of knowledge or interest by individuals involved. The findings, particularly the category 'disconnection of knowledge', identify this issue and the limitations a lack of knowledge can have on the design process. The importance of knowledge is found by Häkkinen \& Belloni (2011) to be significant across the literature they surveyed, and the concerns of the participants in this research reflect this. 
The reliability of a BSRT assessment was identified by Cole (1998) as a point of concern, stating that the potential variance between what different assessors consider to pass as a potential concern. This is represented in the findings of this research as still being an issue, leading to uncertainty in achieving an actual rating. Due to the subjective nature of assessment, this is possibly a common issue of BSRTs. Participants adapted to this uncertainty through the inclusion of design frameworks and working in the requirements of Green Star early. This was found to be necessary process of managing the restrictions imposed by the uncertainty of the credit requirements and the submission assessment.

\subsection{Relation to a General Decision Making Process and its Stages}

The structure of decision making processes used in this discussion comes primarily from Zeleny and Cochrane (1982), where they describe decision making as having three stages: pre-decision, partial and final decisions, and post-decision. This structure was chosen due to the focus on decision making as a process, something fluid and dynamic, as opposed to an act, something which is more binary and predicable. The findings demonstrated this dynamic process with various factors and behaviours being present in design decisions rather than a set of binary choices. This is due to approaching decision making though having multiple attributes rather than a single binary factor. These attributes include objectives, criteria, functions, and other variables (Zeleny \& Cochrane, 1982).

The sense of conflict is what causes decision making to occur. As described by Zeleny and Cochrane (1982), the primary source of this conflict is the "non-availability of suitable alternatives" and the "infeasibility of the ideal alternative". It is observed through the findings that the various constraints are what create an infeasible ideal solution. This then causes a decision making process to occur which starts by searching for alternatives and determining an ideal outcome (Zeleny \& Cochrane, 1982). This aspect is also affected by the constraints, reducing the options available. In some cases the findings demonstrated that the best outcome was not available or was otherwise unachievable, resulting in determining an outcome which was best for one part of the project, and less impactful on others.

Unintended outcomes and predetermined choice are the more impactful outcomes. Respectively these are where the best option for Green Star creates an unusual or otherwise 
negative occurrence, or that enough alternatives are removed that the choice becomes almost binary.

As the final decision, and thus the ideal outcome, is approached the different alternatives are compared, focusing on those which best emulate the ideal (Zeleny \& Cochrane, 1982). In many cases the findings indicate that the ideal outcome is more often focused on the achievement of a Green Star rating over other options, unless more pressing constraints such as budget and other project requirements determine otherwise. Edwards (1954) states that the ideal outcome is always pursued rationally when multiple options exist, favouring a choice which maximises something, which supports the described process.

Once an ideal solution has been identified and the decision has been made, the outcomes occur. In addition to the outcomes is the post-decision stage where the decision that was made and how it was made are evaluated and assessed, informing future decisions (Zeleny \& Cochrane, 1982). This re-evaluation assists in future decisions as well as the creation of resulting processes. The emergence of credit targeting and similar processes can be seen to relate to this stage. Experiences with previous design decisions and previous projects cause these frameworks to be established to better manage them. Re-evaluation is also beneficial when any unknowns are involved, allowing their impact to be reduced in the future.

The effect of the findings, in terms of their impact on the overall decision making process, is best represented by the theoretical code. The overall decision making process is relatively unaffected as the three different stages (cause, decision making, outcome) are influenced by Green Star. This is chiefly through the various constraints which are applied and the adaption of different factors of the process to account for them. One of the core decision making processes affected is the determination of an ideal outcome. Determining it involves significant research and other such searches for information by the decision makers, as the more information gathered, the more informed and reliable the decision. However this outcome has to conform to a variety of constraints due to Green Star - some significantly more than others - which can direct, remove, or narrow options and choices. 


\subsection{Applicability to Other BSRTs}

The applicability of the findings to other BSRTs is likely to vary in multiple ways. At its core, BSRTs have a common structure. They have a number of credits that each represent one facet of sustainability and award points, with the total number of points achieved corresponding to a rating. Each of the major BSRTs surveyed in the literature review and many others follow this structure, some more than others, likely due to the influence imparted by BREEAM's release.

When approached from a purely structural perspective, many of the findings would be applicable to other similar systems. Each of the categories would therefore be transferrable in this manner as many of their effects would occur with the use of other BSRTs. As an example each BSRT consists of credits which have to be managed along with the project's requirements to achieve a rating; something which is likely to be a common effect of utilising BSRTs and represents the two categories 'managing Green Star requirements' and 'balancing project requirements'.

Despite this commonality between systems, one of the core findings of the literature review was how comparisons between BSRTs are not always relevant due to different variables which are unique to each. One of the core strengths of a BSRT is its adaption to the local requirements and conditions of the industry and environment. However, since the effects of localised requirements vary significantly between countries, and even within a single country, comparisons are limited in the applicability of their findings. Due to this it could be argued that Green Star's adaption to the New Zealand environment and industry makes the applicability of the findings to other BSRTs minimal.

However, it can also be argued that the applicability to other BSRTs is valid. This is primarily due to the findings being reflections of processes utilised in projects and the effects had by Green Star on design decisions and decision making. By focusing on these processes the requirements of the local environment which informs the construction of BSRTs can be excluded as a major influence. That is not to say it is no longer an impact or a consideration, but it has less of an impact when discussing design processes and decisions than the construction of BSRTs. This can be supported by some participants' experiences when 
utilising an external BSRT such as LEED on a project in New Zealand. In these few occurrences it was generally described that while other systems might have credits unsuitable for New Zealand's conditions, the overall process of achieving a rating was similar.

The overall applicability of the findings would therefore depend on the construction processes present in different countries rather than the local environment's effects on the BSRT. The effect of these requirements on the BSRT used would impact design decisions through the first category 'managing Green Star requirements', or in this case 'managing BSRT requirements'. The other categories represent processes that occur when utilising a BSRT, so provided the tool being used shares a similar structure to Green Star, the other categories will likely be represented in the design process. In addition, the core variable 'adapting to constraints' is applicable due to the construction of the different rating tools which impose constraints throughout the process.

As such, the applicability of the findings to other BSRTs can be seen to be valid, though its applicability will vary. The findings would likely be applicable to BSRTs with similar structures such as LEED, BREEAM, and especially Green Star Australia. BSRTs with more unique and complex structures will potentially represent less of the findings due to less common ground in their usage. While the findings may not be entirely representative of the processes occurring outside of Green Star New Zealand, it is likely that they are common occurrences when utilising BSRTs in general.

\subsection{Discussion of Classic Grounded Theory}

The use of CGT for this research allowed a substantive area with little available information to be approached, elucidating different effects and findings, something which was likely to be more difficult to approach using other qualitative or quantitative methods. This section of the discussion allows for some of the experiences from the use of CGT to be discussed.

\subsubsection{Comparison to other Methodological Approaches}

When compared to other qualitative research approaches, CGT provides a different perspective and methodology. Rather than gathering and then analysing the data, the 
integrated approach employed by CGT facilitates continual investigation and focus on what is actually present in the data.

It is unknown whether the findings developed through this research would be the same having utilised another qualitative methodology. Given the data from the interviews, however, it is likely that the findings would be very similar though reported in a different way. In this case the processes employed by participants were abstracted into overall procedures describing how the participants dealt with the substantive area. There would certainly be less abstraction of the processes and effect on design decisions if CGT was not used, where focus would have instead been on establishing common ground through comparison of data and quotations.

CGT also provides a powerful approach to investigating an unknown area. As identified in the literature review, little information was present regarding the effects of a BSRT on decision making. While the interview guide developed would likely be utilised both for the CGT and other qualitative approaches, the theoretical sampling employed by CGT allowed for further development and focus of the questions being asked to what was emerging within the data; something that would not be possible using methods focusing just on purposive or other sampling processes. The theoretical sampling combined with the constant comparison of data allowed for a deeper level of investigation into the substantive area than otherwise would have been possible.

While it has its strengths, it also has its limitations. CGT is a far more complicated and involved methodology than others, making utilising it difficult initially when the categories and core variable have yet to emerge. The continual gathering of data makes contacting participants and arranging interviews more difficult since it is staggered until saturation is reached instead of all being carried out within a limited timeframe.

CGT was found to be a successful methodology employed in this research, but is not something that can be used for any research. Other qualitative approaches can be just as effective while some research aims might be better approached with a quantitative method. This ultimately depends on what the research aims to achieve. 


\subsubsection{Interview Guide Design}

As the interview process and analysis progressed, less relevant information emerged from questions regarding the construction and the operation and maintenance phases of projects. Particularly for the latter, many participants had limited information and experiences. While the participants stated that there is an interest in monitoring a rated project once construction had begun and especially once completed, few had the opportunity to be involved. This was apparent early in the interview process and future interviews should have focused less on these areas, and possibly even removed. This should be a consideration for researchers utilising CGT to be more critical of questions being asked within an interview as their research progresses.

\subsubsection{Use of CGT in Building Science}

CGT is a methodology that has seen little usage within the realms of architecture or building science related research, with its usage being primarily within sociology and similar disciplines. This research has presented the usage of CGT within the building science realm, giving an example of what it can be utilised for.

Research into different processes relating to building user psychology or sociology might benefit from a grounded theory approach, especially for areas where there is little preestablished information or context available. By developing a number of theories based on information grounded in the data, CGT research findings can therefore provide the foundation for future research methods, in particular those using quantitative approaches.

Ultimately this research is but one small step into possible future usage of CGT within building science. A limitation within building science is a lack of awareness of specific, qualitative research methods, despite user and design psychology being a significant aspect of a building's usage. As such, the innate difficulty in utilising and understanding CGT is compounded, likely resulting in it being unexplored or unconsidered. CGT and other methods should become a consideration of those looking to utilise a qualitative research methodology. While not appropriate for all research, it allows a different approach that might otherwise not be commonly used. 


\section{Chapter 7 - Conclusions}

The aim of this research was to investigate the effects that Green Star New Zealand has on decision making processes. A classic grounded theory study was carried out where ten Green Star accredited professionals who had experience utilising Green Star were interviewed to get their insight and experiences. The integrated analysis and data collection of CGT led to the emergence of five categories which construct the core variable 'adapting to constraints', as summarised in Table 6.

\begin{tabular}{|c|c|c|}
\hline $\begin{array}{l}\text { Core } \\
\text { Variable }\end{array}$ & $\begin{array}{l}\text { Adapting to } \\
\text { Constraints }\end{array}$ & $\begin{array}{l}\text { The primary behaviour used to adapt to various } \\
\text { restrictions and conditions applied as a } \\
\text { consequence of using Green Star. }\end{array}$ \\
\hline \multirow{5}{*}{ Category } & $\begin{array}{l}\text { Managing Green Star } \\
\text { Requirements }\end{array}$ & $\begin{array}{l}\text { The process of working to and managing the } \\
\text { different conditions and requirements of Green Star } \\
\text { to achieve a formal rating. }\end{array}$ \\
\hline & Credit Targeting & $\begin{array}{l}\text { Determination of how to achieve a formal rating } \\
\text { through establishing which credits and areas of } \\
\text { Green Star are to be worked towards within the } \\
\text { design. }\end{array}$ \\
\hline & $\begin{array}{l}\text { Disconnection of } \\
\text { Knowledge }\end{array}$ & $\begin{array}{l}\text { The effect of varying levels of knowledge and } \\
\text { understanding held by different members of the } \\
\text { design team and how they impact the design. }\end{array}$ \\
\hline & $\begin{array}{l}\text { Working with } \\
\text { Unknowns }\end{array}$ & $\begin{array}{l}\text { The impact that unknowns, primarily risk and } \\
\text { uncertainty, have on a project mainly through the } \\
\text { creation of constraints and the processes required } \\
\text { to work with them. }\end{array}$ \\
\hline & $\begin{array}{l}\text { Balancing Project } \\
\text { Requirements }\end{array}$ & $\begin{array}{l}\text { Limitations and considerations of the project, } \\
\text { particularly the goals and usage of the building as } \\
\text { well as the available capital. }\end{array}$ \\
\hline
\end{tabular}

Table 6: $\quad$ Summary of the core variable and its main categories 
Each of these categories represents different effects on decision making processes. They indicate restrictions or conditions applied to decision making which can reduce the options available. The core variable 'adapting to constraints' signifies the different relations of the categories both to decision making and to one another. Constraints were identified as the primary effect that targeting Green Star has on projects, where individuals interact with constraints through adapting them into design decisions. This can emerge through the adaptation of internal processes, targets, design choices, and other such aspects of design. This adaptation process was identified as the theoretical code, thereby representing the relationship between the categories and the core variable, as well as representing how participants interacted with the effects on decision making.

This chapter concludes this research, presenting the core findings above and following with the explanation of their relation to the project's aim and their implications. This is then finished with a discussion of options for future research.

\subsection{Effects of Green Star on Decision Making}

Green Star was found to have various effects on the decision making process. The core of these effects was:

- The potential restriction and focus of design on achieving a Green Star rating rather than the ESD aims of Green Star;

- The creation and application of constraints;

- The reduction in available options due to uncertainty and risk;

- The need for extensive knowledge on the processes and requirements involved.

Its principal effect on decision making is the application of constraints. As decision making involves a number of processes looking to identify an ideal outcome, the different restrictions applied can make its identification difficult or, in some cases, impossible to achieve. Constraints can move the best possible solution further away from the ideal, requiring decision makers to research and determine which outcomes are the most important and then focusing the solution on those. The adaptation process undertaken reduces the impact of these constraints through adjustment of different processes and 
goals. This occurs through the incorporation of Green Star's goals and conditions in addition to general ESD principles and the requirements of the project.

Other effects have emerged from the use of Green Star which represent this adaptation process. The establishment of design frameworks and the incorporation of Green Star early into the design results from the difficulty in utilising it later, minimising the risk that a rating would not be achieved. This is further exemplified through credit targeting processes and using Green Star as a design tool, minimising risk and uncertainty.

\subsection{Causes of Constraints and Effects}

Constraints were identified to occur on projects in six different ways: directly or indirectly; internally or externally; and residually or intermittently. These respectively represent the following three different factors pertaining to the requirements of Green Star:

- The different requirements and conditions of Green Star;

- Different processes and requirements established by the design team;

- Temporal occurrences and individual knowledge.

How much each factor affects decisions differs, but these six were found to encompass the primary causes of constraints. These three factors are representative of the different categories which emerged from the data.

The requirements of Green Star are a major source of constraints on a rated project. Green Star was consistently described as having strict requirements which can be difficult to interpret or understand, and it is this stringency which can apply constraints on what options are available to designers. The direct effects of Green Star's requirements are contrasted by the indirect effects resulting from the use of Green Star but not from the requirements of the tool itself. Direct effects encompass limitations on material choices and other design options to meet the submission requirements while indirect are more representative of processes established to better manage Green Star. 
Internal processes, such as the establishment of targeted credits, also apply constraints through the reduction in options that can result. Risk and uncertainty, either from internal processes or those outside of the design team's control, are some of the primary sources of constraints on a project. These impose a variety of issues and restrictions which then have to be dealt with. The external factors such as industry or economic limitations can also cause constraints and uncertainty on projects which can be more difficult or complex to manage.

The amount of knowledge held by individuals has a strong impact on decision making processes due to its importance in making an informed decision. Residual knowledge and experience can be limited or even work against Green Star, making it less likely that an ideal solution will be achieved. This knowledge is especially important for intermittent constraints which can require a quick response or are caused by decisions which lack full knowledge.

\subsection{Implication of the Resultant Outcomes}

Outcomes which can occur from these effects on design decisions vary between incidents, though there are some common occurrences. The focus on achieving Green Star can create situations in design which can lead to unintended outcomes or usage of the tool. Although this can negatively impact the sustainability of a building, it can make certain credits more likely to be achieved. An example of which is painting or providing finishes to more surfaces than is needed to ensure that the minimum area percentage is met.

In addition the findings illustrate the need for a more predictable and reliable structure, where the uncertainty in assessment and interpretation of the requirements of a tool are lessened, detailed in Section 5.5 which describes the category 'working with unknowns'. This lack of reliability in Green Star narrows scope and options, placing focus on ensuring that a rating is achieved and leading to the inclusion of additional credits which act as a contingency. They also illustrate the requirement for key decision makers to be educated in Green Star, reducing the impact of a lack of awareness or knowledge of decision making processes. 


\subsection{Implication of Findings to BSRTs}

Due to the similarity in structure that Green Star shares with other BSRTs, the findings of this research can generally be seen as applicable to the use of other tools. BSRTs are generally structured to quantify and encourage sustainable design relative to the local requirements of the industry and environment. As such, many BSRTs are likely to apply restrictions on the decision making processes so long as they require extensive documentation to meet their requirements.

BSRTs have undoubtedly pushed sustainable design into the mainstream through the different advantages that have emerged from their uptake. This research presents insight into a largely un-researched but oft-cited factor when utilising a BSRT such as Green Star. The way in which decisions are made varies greatly but can follow specific structures. The use of BSRTs - or anything with specific requirements - impacts these structures in a number of different ways, though the application of constraints emerged as being the most representative. Future iterations of BSRTs need to identify how they are being utilised and what their usage leads to beyond the submission. These findings present one aspect of this, and future research can investigate this further.

\subsection{Potential for Future Research}

This research hopes to spur further studies investigating the effects and other outcomes that BSRTs have on decision making. The findings identify how Green Star can influence the decision making process and what outcomes can occur from it. Further investigation of BSRTs, not just including Green Star New Zealand, can investigate these and identify other effects on decision making. Methodologically, CGT provides a powerful method of investigating an unknown area though is mostly unused within building science and architecture. Other qualitative methods could be used, utilising the findings of this research to influence questions and analytical processes.

Quantitative methods can also be developed to investigate specific aspects of this research area, such as specific causes and effects. A lack of established information providing context can make developing a quantitative study difficult, potentially a reason why little research 
exists. These findings hope to provide context that can inform such quantitative studies to get another perspective.

Investigation into the structure and flow of the decision making process is an avenue of investigation which would be able to better quantify how different effects and constraints affect the process. Construction of such a detailed decision making process fell outside of the scope of this research, and future investigation into different models and processes could be insightful.

A specific option for future research is the study and observation of specific projects, similar to the research by Schweber and Haroglu (2014). This can include the analysis of past projects but has the potential to observe the dynamics of decision making in active projects: those which are still in progress. The observation and analysis of how a design team utilised Green Star on a project and how it differs compared to their standard practice would allow for deeper insight into the effects that BSRTs have. Additionally, the observation of the entire design team would avoid biases in solely observing a smaller set of disciplines. 


\section{Bibliography}

Ali, H. H., \& Al Nsairat, S. F. (2009). Developing a green building assessment tool for developing countries - Case of Jordan. Building and Environment, 44(5), 1053-1064. doi: http://dx.doi.org/10.1016/j.buildenv.2008.07.015

Aotake, N., Ofuji, N., Miura, M., Shimada, N., \& Niwa, H. (2005). Comparison among results of various comprehensive assessment systems - case study for a model building using CASBEE, BREEAM and LEED. Paper presented at the World Sustainable Building Conference, Tokyo.

BEAM Society. (2014). BEAM Plus. from http://www.beamsociety.org.hk/en_index.php

Bloor, M., \& Wood, F. (2006). Keywords in Qualitative Methods London, England: SAGE Publications Ltd.

Bond, A., Morrison-Saunders, A., \& Pope, J. (2012). Sustainability assessment: the state of the art. Impact Assessment and Project Appraisal, 30(1), 53-62. doi: 10.1080/14615517.2012.661974

BRE. (2008). A Discussion Document Comparing International Environmental Assessment Methods for Buildings: BRE.

BRE. (2014). BREEAM. 2014, from http://www.breeam.org/index.jsp

Breckenridge, J. (2014). Doing Classic Grounded Theory: The Data Analysis Process. London, United Kingdom: SAGE Publications, Ltd.

BREEAM International New Construction Technical Manual. (2013). BRE Global.

CASBEE for New Construction. (2010). JSBC.

Chandratilake, S. R., \& Dias, W. P. S. (2013). Sustainability rating systems for buildings: Comparisons and correlations. Energy, 59, 22-28. doi:

http://dx.doi.org/10.1016/j.energy.2013.07.026

Charmaz, K. (2006). Constructing Grounded Theory - A Practical Guide through Qualitative Analysis. London: Sage Publications.

Cole, R. J. (1998). Emerging trends in building environmental assessment methods. Building Research \& Information, 26(1), 3-16. doi: 10.1080/096132198370065

Cole, R. J. (1999). Building environmental assessment methods: clarifying intentions. Building Research \& Information, 27(4-5), 230-246. doi: 10.1080/096132199369354 
Cole, R. J. (2005). Building environmental assessment methods: redefining intentions and roles. Building Research \& Information, 33(5), 455-467. doi: 10.1080/09613210500219063

Cole, R. J., \& Mitchell, L. (1999). Customizing and using GBTool: two case-study projects. Building Research \& Information, 27(4-5), 257-275. doi: 10.1080/096132199369372

Cooper, I. (1999). Which focus for building assessment methods - environmental performance or sustainability? Building Research \& Information, 27(4-5), 321-331. doi: 10.1080/096132199369435

Corbin, J., \& Strauss, A. (2008). Basics of Qualitative Research (3rd ed.): Techniques and Procedures for Developing Grounded Theory. Thousand Oaks, CA: SAGE Publications, Inc.

Crawley, D., \& Aho, I. (1999). Building environmental assessment methods: applications and development trends. Building Research \& Information, 27(4-5), 300-308. doi: 10.1080/096132199369417

Creswell, J. W. (2009). Research Design: Qualitative, Quatitative and Mixed Methods Approaches (Third Edition ed.). New Delhi, India: SAGE Publications, Ltd.

Deady, R. (2011). Reading with Methodological Perspective Bias: A journey into Classic Grounded Theory The Grounded Theory Review, 10(1).

A Decade of Green Building. (2013). from https://www.gbca.org.au/uploads/170/34474/A_decade_of_green_building_.pdf

Ding, G. K. C. (2008). Sustainable construction-The role of environmental assessment tools. Journal of Environmental Management, 86(3), 451-464. doi: http://dx.doi.org/10.1016/j.jenvman.2006.12.025

Drexhage, J., \& Murphy, D. (2010). Sustainable Development: From Brundtland to Rio 2012: United Nations.

Edwards, W. (1954). The Theory of Decision Making. Psychological bulletin, 51(4), 380-417.

Elliott, N., \& Higgins, A. (2012). Surviving Grounded Theory Research Method in an Academic World: Proposal Writing and Theoretical Frameworks The Grounded Theory Review, 11(2).

Evans, G. L. (2013). A Novice Researcher's First Walk Through the Maze of Grounded Theory: Rationalization for Classical Grounded Theory The Grounded Theory Review, 12(1).

Ferreira, J., Pinheiro, M. D., \& de Brito, J. (2014). Portuguese sustainable construction assessment tools benchmarked with BREEAM and LEED: An energy analysis. Energy and Buildings, 69(0), 451-463. doi: http://dx.doi.org/10.1016/j.enbuild.2013.11.039

Forsberg, A., \& von Malmborg, F. (2004). Tools for environmental assessment of the built environment. Building and Environment, 39(2), 223-228. doi: http://dx.doi.org/10.1016/j.buildenv.2003.09.004

Fowler, K. M., \& Rauch, E. M. (2006). Sustainable Building Rating Systems Summary (U. S. o. A. D. o. Energy, Trans.): Pacific Northwest National Laboratory.

Fullbrook, D., Jackson, Q., \& Finlay, G. (2006). Value Case for Sustainable Building in New Zealand. (5 April 2014). Ministry for the Environment. from 
https://www.mfe.govt.nz/sites/default/files/media/Sustainability/Value\%20Case\%2 Ofor\%20Sustainable\%20Building\%20in\%20NZ.pdf

GBCA. (2014). Green Star. from https://www.gbca.org.au/green-star/

GBI. (2014). Green Globes. from http://www.thegbi.org/green-globes-certification/

GhaffarianHoseini, A., Dahlan, N. D., Berardi, U., GhaffarianHoseini, A., Makaremi, N., \& GhaffarianHoseini, M. (2013). Sustainable energy performances of green buildings: A review of current theories, implementations and challenges. Renewable and Sustainable Energy Reviews, 25(0), 1-17. doi: http://dx.doi.org/10.1016/j.rser.2013.01.010

Giama, E., \& Papadopoulos, A. M. (2012). Sustainable building management: overview of certification schemes and standards. Advances in Building Energy Research (ABER), 6(2), 242-258.

Gibberd, J. (2014). Measuring capability for sustainability: the Built Environment Sustainability Tool (BEST). Building Research \& Information, 43(1), 49-61. doi: 10.1080/09613218.2014.930257

Glaser, B. G. (1978). Theoretical Sensitivity: Advances in the Methodology of Grounded Theory. Mill Valley, Ca.: Sociology Press.

Glaser, B. G. (2002). Conceptualization: On Theory and Theorizing Using Grounded Theory. International Journal of Qualitative Methods, 1(2), 23-38.

Glaser, B. G. (2013). Introduction: Free Style Memoing The Grounded Theory Review, 12(2).

Glaser, B. G., \& Holton, J. (2004). Remodeling Grounded Theory. Forum: Qualitative Social Research, 5(2).

Glaser, B. G., \& Strauss, A. L. (1967). The Discovery of Grounded Theory - Strategies for Qualitative Research. Hawthorne, New York: Aldine Publishing Company.

Gou, Z., Lau, S. S.-Y., \& Prasad, D. (2013). Market Readiness and Policy Implications for Green Buildings: Case Study from Hong Kong. Journal of Green Building, 8(2), 162173. doi: 10.3992/jgb.8.2.162

Green Globes. (2014). from http://www.greenglobes.com/home.asp

Green Globes for New Construction - Technical Reference Manual - Version 1.3. (2014). Green Building Initiative.

Green Star NZ - Interiors 2009. (2009). New Zealand Green Building Council.

Green Star NZ - Office 2009. (2009). New Zealand Green Building Council.

Haapio, A., \& Viitaniemi, P. (2008). A critical review of building environmental assessment tools. Environmental Impact Assessment Review, 28(7), 469-482.

Häkkinen, T., \& Belloni, K. (2011). Barriers and drivers for sustainable building. Building Research \& Information, 39(3), 239-255. doi: 10.1080/09613218.2011.561948

Hernandez, C. A. (2009). Theoretical Coding in Grounded Theory Methodology. The Grounded Theory Review, 8(3).

HK-BEAM Society. (2005). Enhancing Hong Kong's Built Environment. 
HKGBC. (2014). BEAM Plus. from https://www.hkgbc.org.hk/eng/certification.aspx

Holstein, J. A., \& Gubrium, J. F. (2003). Inside Interviewing. Thousand Oaks, CA: SAGE Publications, Inc.

Holton, J. A. (2008). Grounded Theory as a General Research Methodology The Grounded Theory Review, 7(2).

iiSBE. (2014). SB Method. from http://www.iisbe.org/sbmethod

JaGBC. (2014). CASBEE. from http://www.ibec.or.jp/CASBEE/english/index.htm

Kvale, S. (2007). Doing Interviews. London, England: SAGE Publications, Ltd.

Larsson, N. (2007). Rating Systems and SB-Tool: iiSBE. from www.otago.ac.nz/law/conferences/otago036363.ppt

Larsson, N. (2012). User Guide to the SBTool assessment framework.

Larsson, N., \& Cole, R. J. (2001). Green Building Challenge: the development of an idea. Building Research \& Information, 29(5), 336-345. doi: 10.1080/09613210110063818

Lee, W. L. (2012). Benchmarking energy use of building environmental assessment schemes. Energy and Buildings, 45(0), 326-334. doi: http://dx.doi.org/10.1016/j.enbuild.2011.11.024

Lee, W. L., \& Burnett, J. (2008). Benchmarking energy use assessment of HK-BEAM, BREEAM and LEED. Building and Environment, 43(11), 1882-1891. doi: http://dx.doi.org/10.1016/j.buildenv.2007.11.007

Lee, W. L., Chau, C. K., Yik, F. W. H., Burnett, J., \& Tse, M. S. (2002). On the study of the credit-weighting scale in a building environmental assessment scheme. Building and Environment, 37(12), 1385-1396. doi: http://dx.doi.org/10.1016/S03601323(02)00006-9

Liang, S. (2012). International Experiences on Sustainable Scoring System: Comparisons and Applications. Paper presented at the 6th International Association for China Planning Conference, Wuhan, China.

http://ieeexplore.ieee.org/stamp/stamp.jsp?tp=\&arnumber=6342969

Marshall, B., Cardon, P., Poddar, A., \& Fontenot, R. (2013). Does Sample Size Matter in Qualitative Research?: A Review of Qualitative Interviews in IS Research. The Journal of Computer Information Systems, 54(1), 11-22.

Mateus, R., \& Bragança, L. (2011). Sustainability assessment and rating of buildings: Developing the methodology SBToolPT-H. Building and Environment, 46(10), 19621971. doi: http://dx.doi.org/10.1016/j.buildenv.2011.04.023

Morgan, D. L. (2008a). Sample Size. In L. M. Given (Ed.), The SAGE Encyclopedia of Qualitative Research Methods (pp. 799). Thousand Oaks, CA: SAGE Publications, Inc.

Morgan, D. L. (2008b). Sampling. In L. M. Given (Ed.), The SAGE Encyclopedia of Qualitative Research Methods (pp. 799-801). Thousand Oaks, CA: SAGE Publications, Inc.

Murakami, S., Kawakubo, S., Asami, Y., Ikaga, T., Yamaguchi, N., \& Kaburagi, S. (2011). Development of a comprehensive city assessment tool: CASBEE-City. Building Research \& Information, 39(3), 195-210. doi: 10.1080/09613218.2011.563920 
Newsham, G. R., Mancini, S., \& Birt, B. (2009). Do LEED-certified buildings save energy? Yes, but... Energy and Buildings, 41(8), 897-905.

Nguyen, B. K., \& Altan, H. (2011). Comparative review of five sustainable rating systems. Paper presented at the International Conference on Green Buildings and Sustainable Cities.

Nguyen, B. K., \& Altan, H. (2012). Tall-Building Projects Sustainability Indicator (TPSI): A New Design and Environmental Assessment Tool for Tall Buildings. Buildings, 2(2), 43-62. doi: 10.3390/buildings 2020043

NZGBC. (2010). The Value Case for Green Building in New Zealand. New Zealand Green Building Council.

NZGBC. (2014). New Zealand Green Building Council. 2014, from http://www.nzgbc.org.nz/

Papadopoulos, A., \& Giama, E. (2009). Rating systems for counting buildings' environmental performance. International Journal of Sustainable Energy, 28(1-3). doi: $10.1080 / 14786450802452423$

Patton, M. (1990). Qualitative evaluation and research methods. California: Sage.

Poveda, C. A., \& Lipsett, M. G. (2011). A Review of Sustainability Assessment and Sustainability/Environmental Rating Systems and Credit Weighting Tools. Journal of Sustainable Development, 4(6), 36-55.

Reed, R., Bilos, A., Wilkinson, S., \& Schulte, K.-W. (2009). International Comparison of Sustainable Rating Tools. The Journal of Sustainable Real Estate, 1(1), 1-22.

Retzlaff, R. C. (2008). Green building assessment systems: A framework and comparison for planners. Journal of the American Planning Association, 74(4), 505-519.

Retzlaff, R. C. (2009). Green buildings and building assessment systems: A new area of interest for planners. Journal of Planning Literature, 24(1), 3-21.

Robinson, O. C. (2013). Sampling in Interview-Based Qualitative Research: A Theoretical and Practical Guide. Qualitative Research in Psychology, 11(1), 25-41. doi: 10.1080/14780887.2013.801543

Schutt, R. K. (2012). Qualitative Data Analysis Investigating the Social World (7 ed., pp. 320357). London: Sage.

Schweber, L., \& Haroglu, H. (2014). Comparing the fit between BREEAM assessment and design processes. Building Research \& Information, 42(3), 300-317. doi: 10.1080/09613218.2014.889490

Scofield, J. H. (2009). A Re-examination of the NBI LEED Building Energy Consumption Study. Paper presented at the 2009 Energy Program Evaluation Conference, Portland.

Siew, R. Y. J., Balatbat, M. C. A., \& Carmichael, D. G. (2013). A review of building/infrastructure sustainability reporting tools (SRTs). Smart and Sustainable Built Environment, 2(2), 106-139.

Smith, T., Fischlein, M., Suh, S., \& Huelman, P. (2006). Green Building Rating Systems - A Comparison of the LEED and Green Globes Systems in the US. 
Stein, J., \& Reiss, R. (2004). Ensuring the Sustainability of Sustainable Design - What Designers Need to Know About LEED. Platts Research and Consulting.

Todd, J. A., Crawley, D., Geissler, S., \& Lindsey, G. (2001). Comparative assessment of environmental performance tools and the role of the Green Building Challenge. Building Research and Information, 29(5), 324-335.

Todd, J. A., Pyke, C., \& Tufts, R. (2013). Implications of trends in LEED usage: rating system design and market transformation. Building Research and Information, 41(4), 385 400. doi: 10.1080/09613218.2013.775565

Umar, U. A., Tukur, H., Khamidi, M. F., \& Alkali, A. U. (2013). Impact of Environmental Assessment of Green Building Materials on Sustainable Rating System. Advanced Materials Research, 689, 398-402.

USGBC. (2014a). LEED in Motion: Greater China.

USGBC. (2014b). LEED in Motion: Sweden.

USGBC. (2014c). LEED v4 User Guide.

USGBC. (2014d). The U.S. Green Building Council. 2014, from http://www.usgbc.org/home

Walliman, N. (2006). Social Research Methods. London, England: SAGE Publications, Ltd.

Wedding, G. C., \& Crawford-Brown, D. (2007). An analysis of variation in the energy-related environmental impacts of leed certified buildings. Journal of Green Building, 2(4), 151-170.

WGBC. (2013). World Green Building Trends. from http://www.worldgbc.org/files/8613/6295/6420/World_Green_Building_Trends_Sm artMarket_Report_2013.pdf

World Commission on Environment and Development. (1987). Our Common Future: Oxford University Press.

Zeleny, M., \& Cochrane, J. L. (1982). Multiple Criteria Decision Making (Vol. 25): McGraw-Hill New York.

Zheng, D. Y. (2013). Does LEED save energy? A case study of LEED at UC Berkeley: UC Berkeley.

Zuo, J., \& Zhao, Z.-Y. (2014). Green building research-current status and future agenda: A review. Renewable and Sustainable Energy Reviews, 30(0), 271-281. doi: http://dx.doi.org/10.1016/j.rser.2013.10.021 
Appendices 


\section{Appendix A - Human Ethics Committee Approval}

TE WHARE WĀNANGA O TE ŪPOKO O TE IKA A MĀUI

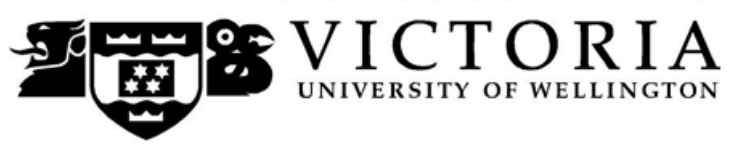

MEMORANDUM

Phone $\quad 0-44635676$

Fax $\quad 0-44635209$

Email Allison.kirkman@vuw.ac.nz

\begin{tabular}{l|l}
\hline TO & Hendrik Prins \\
\hline COPY TO & George Baird \\
\hline FROM & Dr Allison Kirkman, Convener, Human Ethics Committee \\
\hline & \\
\hline DATE & 20 June 2014 \\
\hline PAGES & 1 \\
\hline
\end{tabular}

\begin{tabular}{l|l}
\hline SUBJECT & $\begin{array}{l}\text { Ethics Approval: } \mathbf{2 1 0 1 9} \\
\text { Study of the effects of Green Star Project Design Decisions }\end{array}$ \\
\hline
\end{tabular}

Thank you for your application for ethical approval, which has now been considered by the Standing Committee of the Human Ethics Committee.

Your application has been approved from the above date and this approval continues until 4 March 2015 . If your data collection is not completed by this date you should apply to the Human Ethics Committee for an extension to this approval.

Best wishes with the research.

Allison Kirkman

Human Ethics Committee

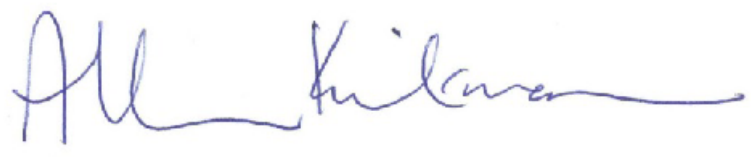


MEMORANDUM

\begin{tabular}{l|l}
\hline TO & Hendrik Prins \\
\hline COPY TO & George Baird \\
\hline FROM & Dr Allison Kirkman, Convener, Human Ethics Committee \\
\hline
\end{tabular}

\begin{tabular}{l|l}
\hline DATE & 6 March 2015 \\
\hline PAGES & 1 \\
\hline SUBJECT & $\begin{array}{l}\text { Ethics Approval: } \mathbf{2 1 0 1 9} \\
\text { Study of the effects of Green Star Project Design Decisions }\end{array}$ \\
\hline
\end{tabular}

Thank you for your request to extend your ethics approval. This has now been considered and the request granted. Your application has approval until 11 March 2015.

If your data collection is not completed by this date you should apply to the Human Ethics Committee for an extension to this approval.

Best wishes with the research.

Allison Kirkman

Human Ethics Committee

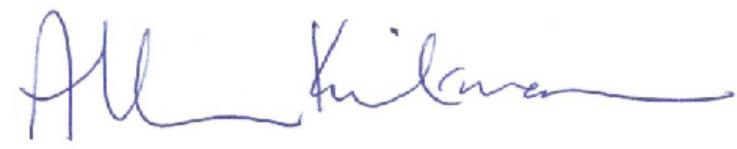




\section{Appendix B - Participant Information Sheet}

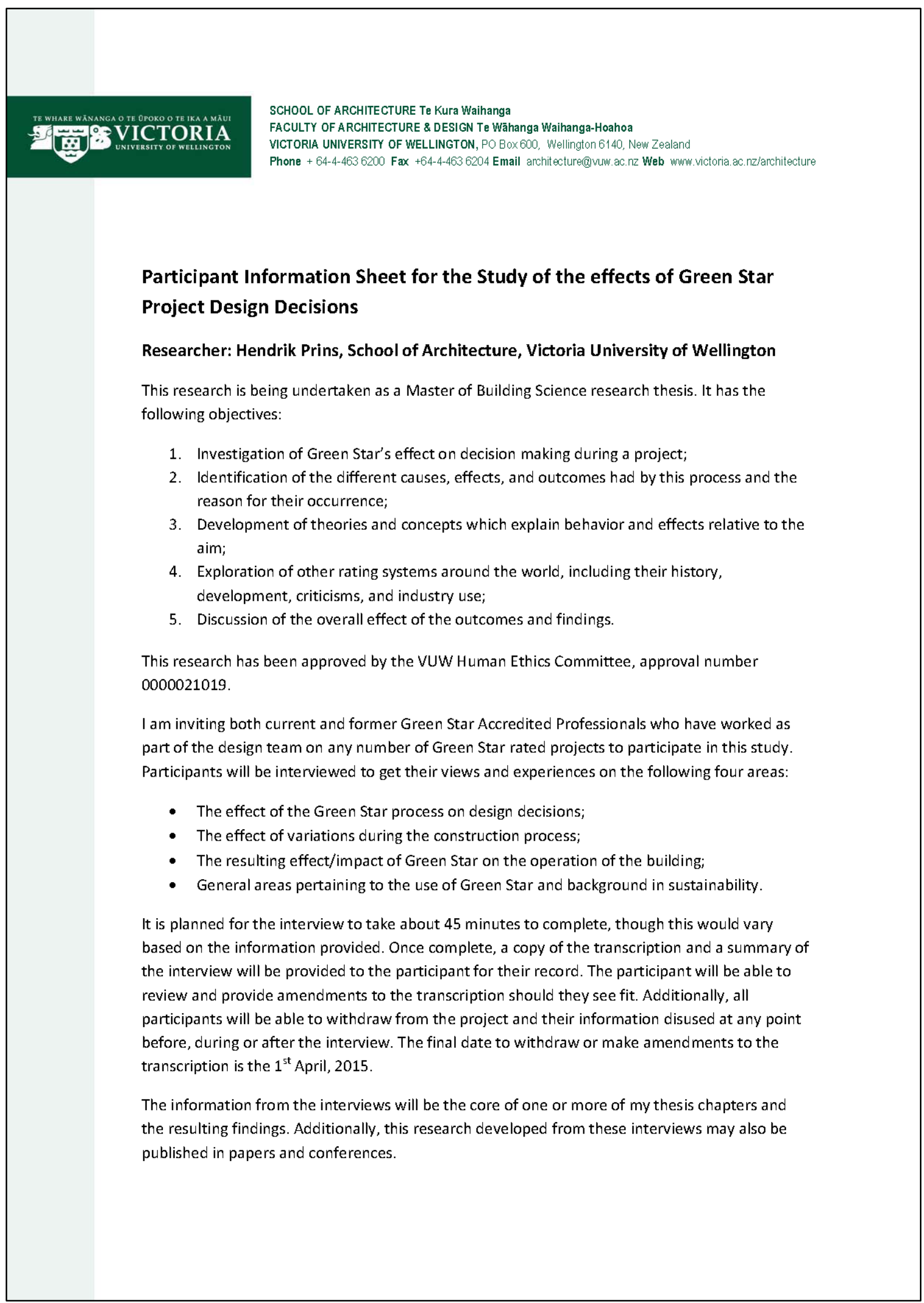


All information provided will be treated as confidential and will mostly be aggregated with that provided by other participants. The information will be analysed by investigating trends and themes across the different sets of aggregated data where the names of people, participants and buildings will not be identifiable. Direct quotes may be included, though confidentiality will be maintained through the use of pseudonyms and the exclusion of any potentially identifiable material.

Once my thesis is completed it will be accessible from the Victoria University library. I will provide a link to participants for them to access it should they wish.

If you have any questions or would like to receive further information about the project then please contact me on 0273864963 or email me at prinshend@myvuw.ac.nz. You can also contact my supervisor, Professor George Baird, at george.baird@vuw.ac.nz.

If you have any ethical concerns about the research then you should contact Dr Allison Kirkman, Chair of the Human Ethics Committee, Victoria university of Wellington, on 044635676 or email at Allison.Kirkman@vuw.ac.nz.

Hendrik Prins 


\section{Appendix C - Participant Consent Form}

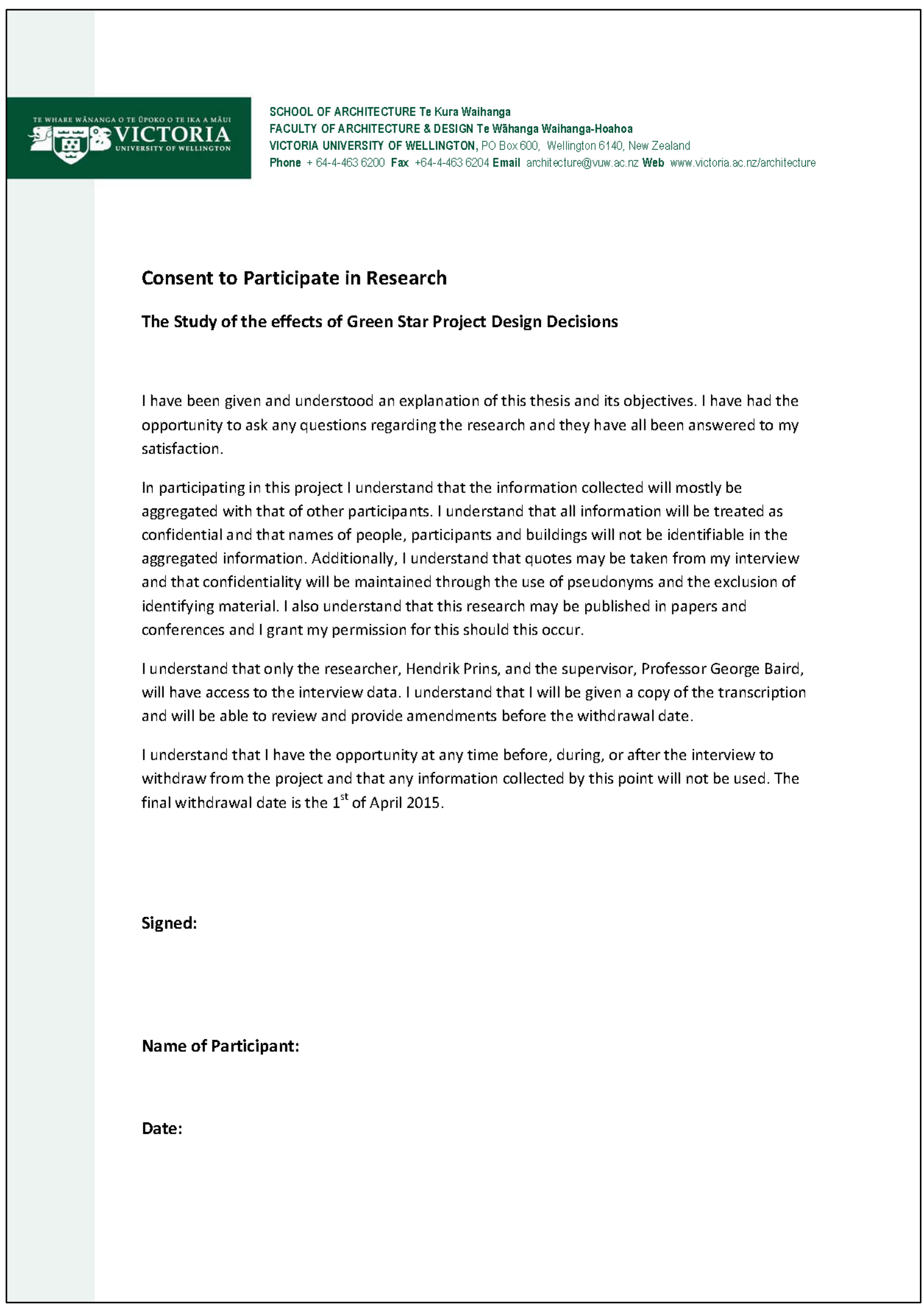




\section{Appendix D - Standardised Letter}

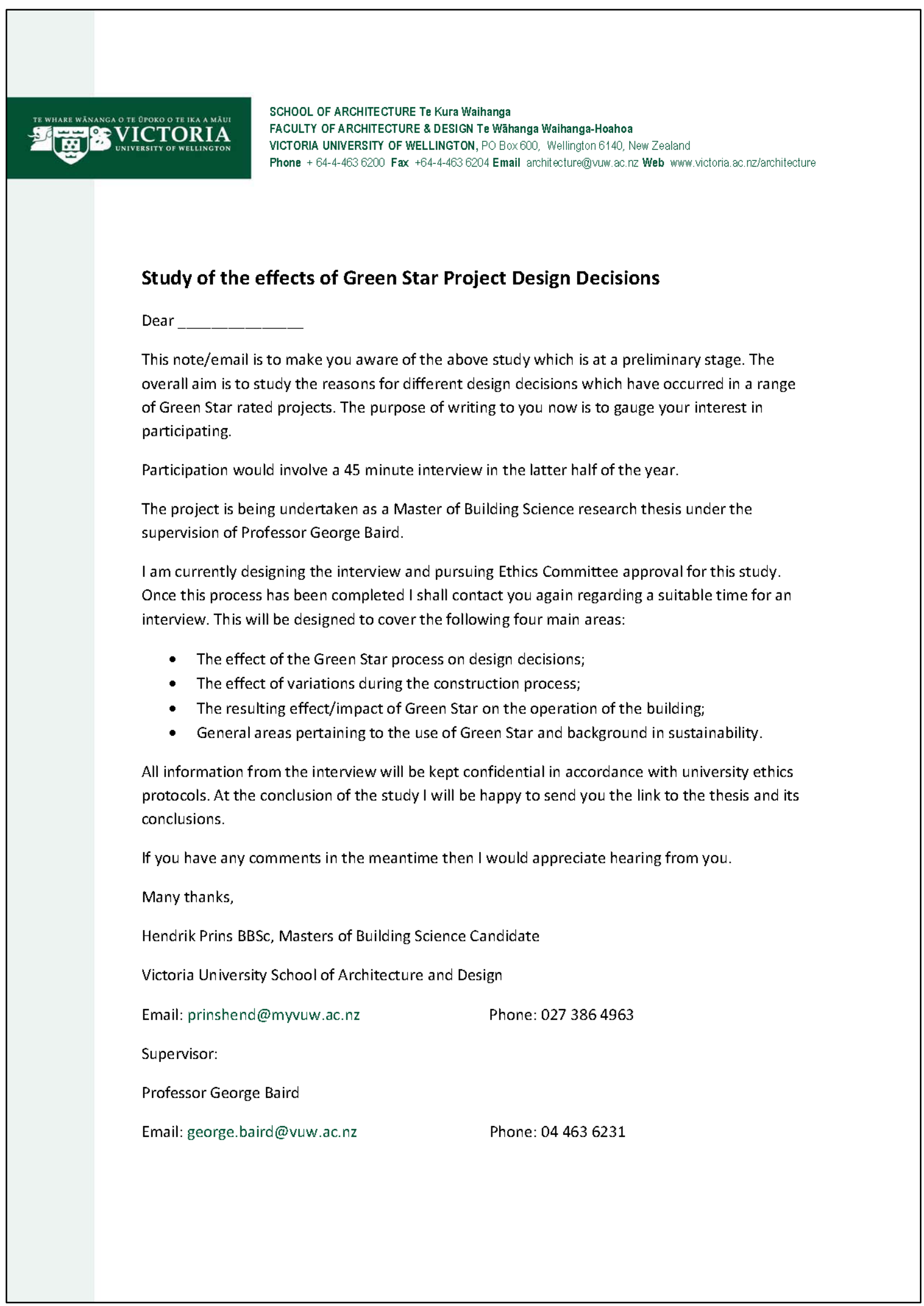




\section{Appendix E - Initial Interview Guide}

\section{(1) Background questions}

Could you describe to me your history with sustainable design? / How did you get involved in sustainable design?

$>$ If they came from other countries, ask if they did work there on sustainable construction and if they have any experience with the associated rating tool and how it might compare to Green Star.

$>$ If Green Star is their first sustainable project but they have worked on several other projects in the past, then ask what it was like working on the Green Star project(s) compared to the others

$>$ If they have worked on other non-Green Star buildings but would consider them sustainable, then inquire about the differences they felt between the two types of projects - the non-rated and the rated.

\section{(2) General Green Star questions}

What is your experience with Green Star? / Your portfolio shows that you have done X number of Green Star rated projects. How would you describe your experience with Green Star over these projects?

$>$ If they mention how Green Star affected the organisation of the different teams involved and their input, then I could inquire more about that to see what their thoughts are on the integration process involved, otherwise this will be something I may follow-up on in a later part of the interview. 
What are your thoughts of Green Star's effect on the design process?

$>$ Did you set a target rating when you started? / Do you normally set a target rating at the beginning of projects?

-> If they go into it in a lot of detail, or even in minor detail, then I could follow up the question with something along the lines of "what credits do you normally include in your projects? Are there any particular reasons that you include them across your projects?" / "are there any credits that you generally avoid? Are there any reasons for excluding them?" (If multiple projects done). Would change to adapt to those who have only done one, and possibly 2, by asking along the lines of "did you find that there were any credits that you thought you should include?"

$>$ Depending on how they are answering the overall questions I could inquire as to the overall influence of Green Star on the decisions and choices that they made.

$>$ If they respond to this inquiry along the lines of mentioning feeling restrained or such then I could ask (or confirm) if they felt limited by Green Star. Follow this up with asking about whether or not they felt that Green Star limited them in the different choices / design decisions that they could have made.

> Likewise, if they respond by feeling that Green Star didn't restrain them / was very flexible for what it was that they were trying to do, then I could ask (or confirm) if they felt it was flexible and un-restraining where they didn't feel that it limited or restricted the different decisions that they could have made.

$>$ Ask, follow-up on and/or expand on if there were any exclusions / inclusions that had to be made because of Green Star. 


\section{(4) Construction stage}

How did you feel about the construction process of these buildings?

> Did you feel that the Green Star process involved led to any unique situations?

$>$ Were there any alterations that you had to make during the construction?

$>$ If there were any alterations made then try and inquire more about them such as what their impacts were and if they were related to Green Star in any way.

$>$ Depending on how they answer the question(s) for the construction stage then I could ask about any effects of the integration of the different teams/disciplines and how this might compare to other projects and if it led to any advantages or issues.

> Also depending on how they answer the different questions and whether any of their buildings have a built rating in addition to a design rating, then I could inquire about any changes which may have happened during construction and their effect on the built rating.

\section{(5) Operation and Maintenance}

What are your thoughts on Green Star's effects on the operation and maintenance of the building?

$>$ Inquire about / expand on anything which may have happened over the course of the 12 month tuning period as part of the relevant management credit.

$>$ As with above, inquire about / expand on if there were any unforeseen benefits or issues which have arisen (and may not necessarily have been part of the 12 month tuning period). 


\section{Appendix F - Final Interview Guide}

\section{(1) Background questions}

Could you describe to me your history with sustainable design? / How did you get involved in sustainable design?

$>$ If they came from other countries, ask if they did work there on sustainable construction and if they have any experience with the associated rating tool and how it might compare to Green Star.

$>$ If Green Star is their first sustainable project but they have worked on several other projects in the past, then ask what it was like working on the Green Star project(s) compared to the others

$>$ If they have worked on other non-Green Star buildings but would consider them sustainable, then inquire about the differences they felt between the two types of projects - the non-rated and the rated.

\section{(2) General Green Star questions}

What is your experience with Green Star? / Your portfolio shows that you have done $\mathrm{X}$ number of Green Star rated projects. How would you describe your experience with Green Star over these projects?

$>$ If they mention how Green Star affected the organisation of the different teams involved and their input, then I could inquire more about that to see what their thoughts are on the integration process involved, otherwise this will be something I may follow-up on in a later part of the interview. - Do you feel that the process was engaged with by all of the different parties involved? 
What do you think of the industry's involvement with Green Star? / What's your opinion on Green Star's uptake by the industry?

$>$ How much do you think that different parts of the industry (architects, engineers, clients, builders, etc.) understand Green Star and its requirements?

$>$ Do you think that there are any gaps of knowledge in the industry?

$>$ Do different levels of understanding and knowledge affect the project or the decisions being made in any way?

What is your opinion of the structure of Green Star? / What do you think of the structure of Green Star?

$>$ How do you find the documentation requirements? / Do you think that the documentation requirements restrict what is done in a project?

> Does the structure of Green Star help projects meet their requirements / goals?

(3) Design Stage

What are your thoughts on Green Star's effect on the design process? / What are your experiences with Green Star's integration with the design process?

How involved do you think Green Star gets in the design? / How much do you think that Green Star gets incorporated into the design?

$>$ Did you set a target rating when you started? / Do you normally set a target rating at the beginning of projects?

$>$ If they go into it in a lot of detail, or even in minor detail, then I could follow up the question with something along the lines of "what credits do you normally include in your projects? Are there any particular reasons that you include them across your projects?" / "are there any credits that you generally avoid? Are there any reasons for excluding them?" (If multiple 
projects done). Would change to adapt to those who have only done one, and possibly 2, by asking along the lines of "did you find that there were any credits that you thought you should include?"

$>$ Follow up on how they decide when a credit is no longer worth achieving on a project, or what do they look for when deciding what credits are achievable or worth achieving.

$>$ Depending on how they are answering the overall questions I could inquire as to the overall influence of Green Star on the decisions and choices that they made, or how they made decisions to balance the different Green Star requirements of the project. Inquire about any restrictions they might experience from the requirements

$>$ If they respond to this inquiry along the lines of mentioning feeling restrained or such then I could ask (or confirm) if they felt limited by Green Star. Follow this up with asking about whether or not they felt that Green Star limited them in the different choices / design decisions that they could have made.

$>$ Do you find the process constrains what you can do on a project? / How do you manage the different constraints during a project?

$>$ Do you think that the Constraints affect what you choose to do on a project? / How do the different requirements and constraints affect the different outcomes and deliverables of a project?

$>$ Likewise, if they respond by feeling that Green Star didn't restrain them / was very flexible for what it was that they were trying to do, then I could ask (or confirm) if they felt it was flexible and un-restraining where they didn't feel that it limited or restricted the different decisions that they could have made. 
> Ask, follow-up on and/or expand on if there were any exclusions / inclusions that had to be made because of Green Star.

$>$ Did they do anything they wouldn't normally do on a non-Green Star project? Did any decisions lead to unusual outcomes?

Do you see any specifications included in projects that you might not recommend if you approached the ESD without using Green Star? / What would you do differently if you approached Green Star using a more holistic approach?

\section{(4) Construction stage}

How did you feel about the construction process of these buildings?

$>$ Did you feel that the Green Star process involved led to any unique situations?

$>$ How were these unique situations managed? Depending on the outcome I can ask something regarding how impactful they think it is.

$>$ Were there any alterations that you had to make during the construction?

$>$ If there were any alterations made then try and inquire more about them such as what their impacts were and if they were related to Green Star in any way.

$>$ Depending on how they answer the question(s) for the construction stage then I could ask about any effects of the integration of the different teams/disciplines and how this might compare to other projects and if it led to any advantages or issues.

> Also depending on how they answer the different questions and whether any of their buildings have a built rating in addition to a design rating, then I could inquire about any changes which may have happened during construction and their effect on the built rating. 
What are your thoughts on Green Star's effects on the operation and maintenance of the building?

$>$ Inquire about / expand on anything which may have happened over the course of the 12 month tuning period as part of the relevant management credit.

$>$ As with above, inquire about / expand on if there were any unforeseen benefits or issues which have arisen (and may not necessarily have been part of the 12 month tuning period).

$>$ Have you found the buildings operate as intended? Did any alterations affect the performance / usage?

(6) Closing

Are there any other things you can think of which you would like to add? / Do you have anything else which you would like to add? 


\section{Appendix G - Transcription Template}

Date:

Location:

Interviewer:

Participant Number:

Length:

Interview Start

[00:00:00]

(1) Interviewer:

(1) Participant:

(2) Interviewer:

(2) Participant:

(3) I:

(3) P:

(4) I:

(4) P:

Interview Ends

[00:00:00] 
